UNIVERSIDAD POLITÉCNICA DE MADRID

ESCUELA TÉCNICA SUPERIOR DE INGENIERÍA AGRONÓMICA, ALIMENTARIA Y DE BIOSISTEMAS

\title{
HOW TO INCREASE THE VALUE OF RURAL TOURISM IN SPAIN, BASED ON CUSTOMER EXPERIENCES
}

\author{
$\mathrm{PhD}$ THESIS
}

Wookhyun An

Master of Business Administration 

Departamento de Economía Agraria, Estadística y Gestión de Empresas

Escuela Técnica Superior de Ingeniería Agronómica, Alimentaria y de Biosistemas Universidad Politécnica de Madrid

\section{HOW TO INCREASE THE VALUE OF RURAL TOURISM IN SPAIN, BASED ON CUSTOMER EXPERIENCES}

PhD THESIS

Wookhyun An

Master of Business Administration

Director

Silverio Alarcón

Dr. Ingeniero Agrónomo

Madrid, 2021 



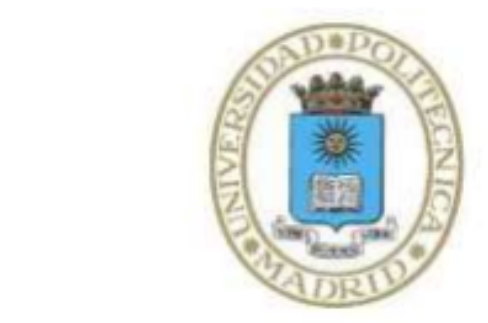

\section{UNIVERSIDAD POLITÉCNICA DE}

MADRID

Tribunal nombrado por el Mgfco. y Excmo. Sr. Rector de la Universidad Politécnica de Madrid, el día. de. de $\ldots . . .$.

Presidente:

Vocal:

Vocal:

Vocal:

Secretario:

Suplente:

Suplente:

Realizado el acto de defensa y lectura de la Tesis el día... de de...., en la E.T.S.I. Agronómica, Alimentaria y de Biosistemas. 

For my family

나의 가족에게 



\section{ACKNOWLEDGEMENTS}

First and foremost, I am grateful to the gracious Lord for guiding, helping, and loving me and my family. I confess that achieving a $\mathrm{PhD}$ is one of the many graces the Lord has given me.

I would also like to express my gratitude to the Korean government for giving me the opportunity to pursue my $\mathrm{PhD}$ in Spain. With the support of the Korean government, I came to Universidad Politécnica de Madrid in September 2017 and I have been able to realize what is important and precious in my life while attending this university. Since beginning my studies here, I have devoted all my time and effort to writing this thesis; in total, about 3 years and 6 months. In the process, I was also able to realize the power of earnestness.

I would never have earned a PhD without my respected professor Silverio Alarcón. Thank you for your interest, love, and guidance. I want to live with the heart of repaying the grace that this professor has given me for the rest of my life. I believe that it was not by chance that I met professor Silverio Alarcón, but rather, it was God's warm and perfect plan.

I would also like to thank all of you who have contributed so much to the completion of this thesis. In particular, I would like to express my gratitude to Sabrina Bowen, who has greatly helped me with her English revisions during the process of writing high quality articles.

Half of all the successes I have achieved in my life is due to the love and dedication of my beloved parents. My father, who died seven years ago, will surely smile when he sees me receive my $\mathrm{PhD}$. I am dedicated, without giving up under any circumstances and I believe this is the valuable heritage that my father taught me through his example. Without my mother, who has always loved me and prayed for me, I would not have obtained any of my achievements. I would like to say that I love and appreciate my mother. In addition, I want to express my gratitude to my younger sister, Hyunjung, who has always been encouraging to me. I would not have attained this achievement without her help in Korea.

The other half of the successes that I have achieved in my life are due to my beloved wife Ji Yeon. I met her for the first time in the winter of 2005, and until now, she has stayed silently by my side, praying and cheering for me so that I do not lose my self-esteem. I will love her and devote myself to her all my life. I would also like to share this honor with my beloved daughter Seungju, who is always proud of her dad and celebrates her dad's achievements more than her own. I really want to tell my daughter that her dad loves her so much.

I will never forget the gratitude I feel now and with a feeling of repayment, I will do my best to change this world into a more livable place with the little power I have.

Thank you.

Wookhyun An 



\section{ABSTRACT}

The purpose of this research is to offer a basis upon which to establish a strategic direction that can strengthen the competitive capacity to rural tourism providers and local government legislators, through deep analysis of the essence of the customer experience in order to enhance customer value in rural tourism.

To achieve this goal, different three studies were conducted. Study 1 aimed to use a non-immersive approach to understand the reality of rural tourism in Spain, assess the quality of the information that users freely post in different forums on the internet and process those opinions so that it would serve as a basis for the design of questionnaires used in future research. Next, Study 2 focused on exploring rural tourists' views in order to identify different market segmentation in relation to rural tourism experiences. Finally, Study 3 concentrated on reviewing articles associated with sustainable rural tourism found on the Web of Science database over a 10-year span from 2009 to 2019.

The different studies incorporated into this thesis applied the optimal methods in order to reach each goal. For Study 1, the netnography methodology, which is an online participatory observation technique based on usergenerated content that enables market researchers to observe natural consumer behaviors, was conducted on 1002 tourists' opinions in three online communities. Qualitative information derived from netnography combined with quantitative tools, multiple correspondence analysis and cluster analysis, allows for the segmentation of the rural tourism market. For Study 2, visual Q, a personal subjectivity research methodology, was applied to present both visual and linguistic aspects so that tourists can more intuitively recognize and answer questions regarding their experiences. Thus, it enables researchers to explore rural tourism experiences from tourists' subjective perceptions. For Study 3, systematic review was conducted on the 73 articles that were selected due to their inclusion of the concept of sustainable rural tourism and listed in a comprehensive table; thereby revealing the research purpose, topics, detailed topics, research methods, and data source of the articles.

According to the present study areas, three key conclusions were extracted. In Study 1, the information from online users was confirmed to be valuable, and this allows for the characterization of rural tourists and their segmentation. In Study 2, the results showed that there are three primary segments of tourist experiences in rural tourism: occasion driven visitor, active leisure seeker and rural immersion pursuer and across all visitors, a common pursuit of a pleasant break. In Study 3, the findings indicate that many papers on sustainable rural tourism were written from a holistic sustainability perspective without being biased towards any one of the environmental, economic or social aspects. In the field of rural tourism, it is essential to pay attention to interactions with all aspects of the environment, economy, and society, and to analyze them overall. In addition, this study confirmed that efforts to understand sustainable rural tourism from the customer perspective have increased, since customer loyalty is considered important for sustainability.

The present thesis is significant in that it began with the qualitative collection of a user-generated or personal subjective content and finished with the quantitative segmentation of the market. In addition, it is significant in that since it evaluated the knowledge status for the first time through systematic review and applied content analysis to academic literature related to sustainability in the sector of rural tourism, it can expand and deepen knowledge and the understanding of related topics and raise awareness of a new research direction. 



\section{RESUMEN}

El propósito de esta investigación es ofrecer una base para establecer la dirección estratégica, que pueda fortalecer la capacidad competitiva, a los proveedores de turismo rural y legisladores de los gobiernos locales, a través de un análisis profundo de cuál sería la esencia en la experiencia de los consumidores para mejorar el valor del cliente en turismo rural.

Para lograr este objetivo, se realizaron tres estudios diferentes. El primer estudio tuvo como objetivos obtener una primera aproximación no inmersiva a la realidad del turismo rural en España, valorar la calidad de la información que los usuarios vierten libremente en distintos foros en internet y procesar estas oponiones para que sirviera de base para el diseño de cuestionarios en futuras investigaciones. A continuación, el segundo estudio se centró en explorar las opiniones de los turistas rurales para identificar diferentes segmentaciones del mercado en relación con las experiencias de turismo rural. Finalmente, el tercer estudio se concentró en revisar artículos asociados con el turismo rural sostenible que se encuentran en la base de datos de Web of Science durante un período de 10 años desde 2009 a 2019.

Los diferentes estudios de esta tesis aplicaron los métodos óptimos para alcanzar cada objetivo. Para el primer estudio, la metodología de netnografía, que es una técnica de observación participativa online basada en contenido generado por el usuario que permite a los investigadores de mercado observar comportamientos naturales de los consumidores, se llevó a cabo sobre 1002 opiniones de turistas en tres comunidades en línea. La información cualitativa derivada de la netnografía combinada con herramientas cuantitativas, análisis de correspondencia múltiple y análisis de conglomerados, permite la segmentación del mercado del turismo rural. Para el segundo estudio, se aplicó visual Q, una metodología de investigación de la subjetividad personal, en la que se presentaron estímulos tanto visuales como lingüísticos para que los turistas puedan reconocer y responder de manera más intuitiva a las preguntas sobre sus experiencias. Por lo tanto, permite a los investigadores explorar experiencias de turismo rural a partir de las percepciones subjetivas de los turistas. Para el tercer estudio, se realizó la revisión sistemática de los 73 artículos que fueron seleccionados por su inclusión del concepto de turismo rural sostenible y enumerados en una tabla integral; revelando así el propósito de la investigación, los temas, los temas detallados, los métodos de investigación y la fuente de datos de los artículos.

De acuerdo con estas tres estudios, se extrajeron tres conclusiones clave. En el primer estudio, Se ha confirmado que efectivamente la información de los usuarios en internet es valiosa, permite caracterizar a los turistas rurales e incluso segmentarlos. En el segundo estudio, el resultado mostró que hay tres segmentos principales de experiencias turísticas en el turismo rural: visitante impulsado por la ocasión, buscador de ocio activo y perseguidor de inmersión rural y, entre todos los visitantes, una búsqueda común de un descanso agradable. En el tercer estudio, los resultados indican que muchos artículos sobre turismo rural sostenible se escribieron desde una perspectiva de sostenibilidad holística sin estar sesgados hacia ninguno de los aspectos ambientales, económicos y sociales. En el ámbito del turismo rural, es fundamental prestar atención a las interacciones en todos los aspectos del medio ambiente, la economía y la sociedad, y analizarlas de forma global. Además, este estudio 
confirmó que se han incrementado los esfuerzos para entender el turismo rural sostenible desde la perspectiva del cliente, ya que la fidelización del cliente se considera importante para la sostenibilidad.

La presente tesis ofrece aportaciones significativas en cuanto que comenzó con la recopilación cualitativa de un contenido generado por el usuario o subjetivo personal y terminó con la segmentación cuantitativa del mercado. Además, evalua por primera vez el estado del conocimiento, a través de la revisión sistemática y el análisis de contenido, de la literatura académica relacionada con la sostenibilidad en el sector del turismo rural, que permite ampliar y profundizar el conocimiento y la comprensión de temas relacionados. y dar a conocer una nueva dirección de investigación. 



\section{TABLE OF CONTENTS}

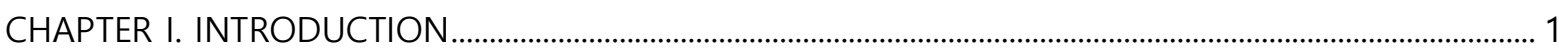

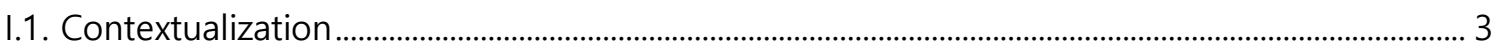

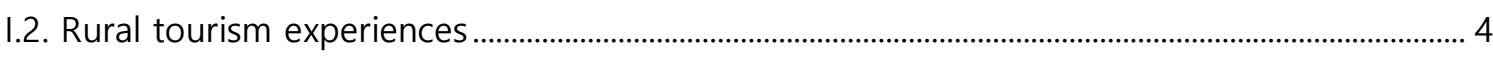

I.3. Segmentation in rural tourism research............................................................................................

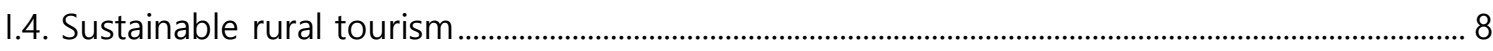

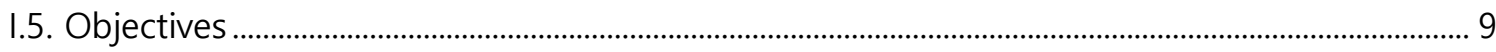

I.5.1. Specific objective of Study 1 ............................................................................................. 9

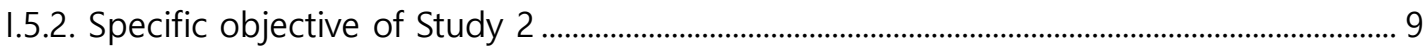

1.5.3. Specific objective of Study 3 .......................................................................................... 10

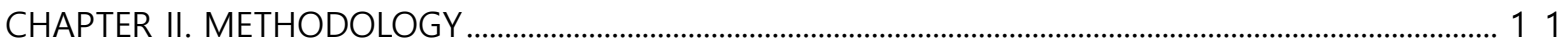

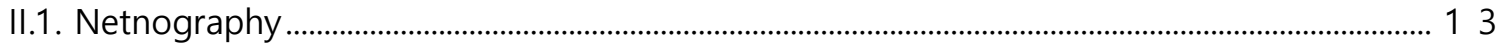

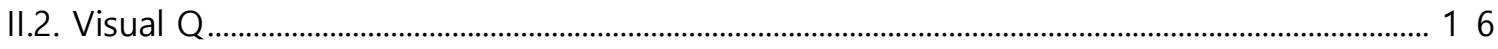

II.3. Systematic review for sustainable rural tourism ............................................................................. 19

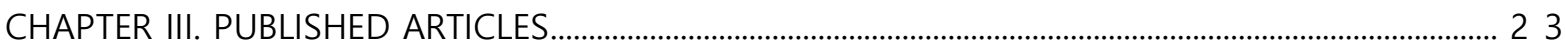

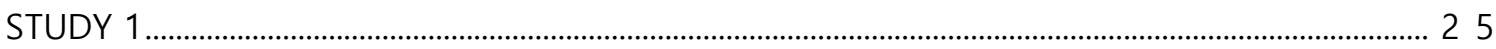

STUDY 2

STUDY 3

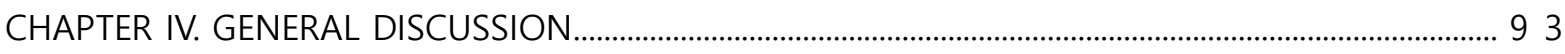

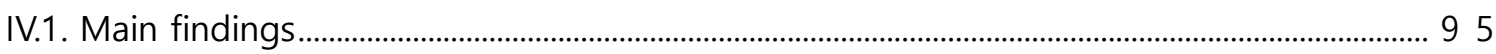

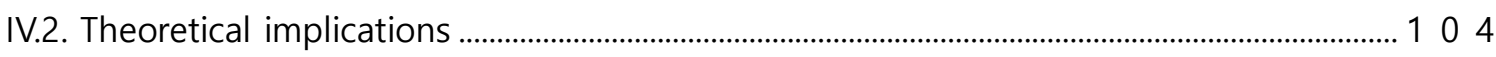

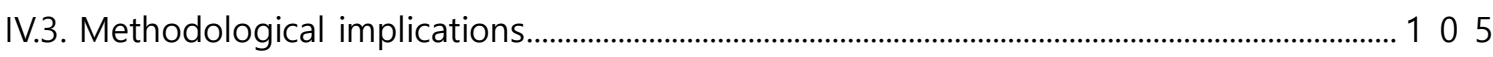




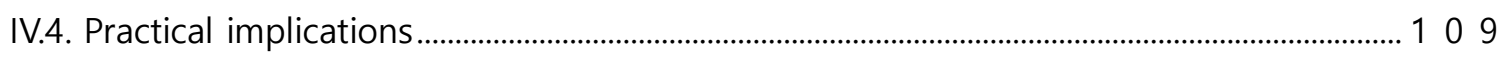

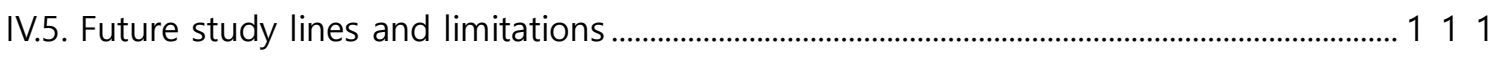

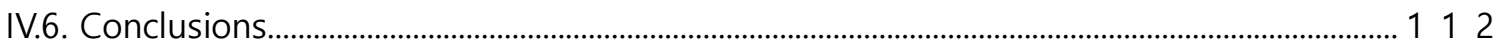

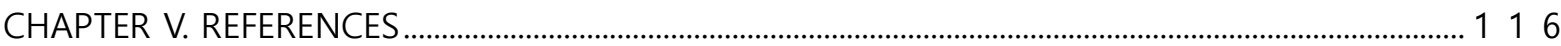



CHAPTER I. INTRODUCTION 


\section{I.1. Contextualization}

Rural tourism in Spain was developed for the purpose of overcoming the tendency of Spanish tourism to be focused on sun and beach, a focus which had reached maturity (García, 1996; Besteiro, 2006). Additionally, rural tourism can assist agriculture, where holdings are at risk from economic pressures (Blanco, 1996). Rural areas have made an effort to provide special experiences through making an investment in the cultural and natural heritage in response to the increasing demand for the possibility to escape from the city and experience the tranquility of the countryside (García, 1996; Yagüe, 2002; Besteiro, 2006). This has helped rural tourism grow rapidly. Between 2013 and 2017, after a long period of ups and downs, the total annual number of tourists in rural tourism in Spain increased by more than one and a half million and exceeded four million (INE, 2017). But despite the growth in scale, the occupancy rates and the average stay length in rural tourism have decreased, leading to a decline in competitiveness (Campón-Cerro et al., 2017). According to INE (2018), its prices have risen at a much lower rate than the rest of the sector. This is due to the fact that in rural tourism, there is greater sensitivity to price among tourists (Correia Loureiro \& Miranda González, 2006). The answer to the question "What do rural tourism clients look for when they travel?" is merely "to do nothing" (Grande \& Maynar, 2010). This is evidence that the value which rural tourism proposes to tourists is limited by a lack of diversity. Therefore, it is necessary to take measures to overcome the limit of price sensitivity through various customer value propositions. A variety of customer value propositions in rural tourism can be made from providing clients with diverse experiences.

Customer experiences in rural tourism have been considered an essential factor that can drive the success and innovation of the industry (Ellis \& Rossman, 2008; Stamboulis \& Skayannis, 2003; Zehrer, 2009). Tourists generally seek distinctive and engaging experiences and their decisions are affected by images of the destination (Ellis \& Rossman, 2008; Mossberg, 2007; Prebensen \& Foss, 2011). For the sustainability of tourism, three changes are needed: the optimized utilization of local resources, the harmonization of diversified stakeholders' needs, and the improvement of tourists' satisfaction through offering meaningful experiences (Kastenholz et al., 2012). Considering that tourists pursue experiences of diversity and high quality on short-term holidays, rural areas must make an effort to provide distinguished, attractive and diverse customer experiences (Lane \& Kastenholz, 2015). Accordingly, understanding individual perceptions associated with customer experiences in rural tourism is important (Ritchie \& Hudson, 2009). In order to be successful, it is necessary for rural tourism to seek ways of satisfying customers' needs, which is first done by viewing the diversified customer experiences through tourism research (Uriely, 2005). Tourists pursue unique, attractive and unforgettable experiences in particular circumstances influenced not only by specific behaviors and ways of responding to environments and situational occurrences, but also by previous travel experiences, images of destinations and personal motivation levels (Ellis \& Rossman, 2008; Mossberg, 2007; Prebensen \& Foss, 2011). It is very important to improve tourist experiences in rural areas to win against the stiff competition (Lane, 2009; Lane \& Kastenholz, 2015). A principal challenge for developing rural tourism is to meet the needs of the diversified tourist segments pursuing varied experiences. Thus, it is essential to understand the subjective meanings and perceptions related to the individual experiences in rural tourism (Uriely, 2005).

Among the many ways to explore customer experiences, segmentation is useful for creating a better market 
positioning strategy since it can offer desirable information about customers and insights on meeting their needs (Matzler, Pechlaner, \& Hattenberger, 2004). According to Buhalis (2000), segmentation is important because each tourism destination is only able to fulfill specific types of demands. Therefore, each tourism destination has to understand the needs of its potential customers and endeavor to attract the proper customer group. It is also crucial to be aware of existing segments for effective and efficient rural tourism management and marketing. The information on clear segments allows for the development of promotion and communication programs (Park \& Yoon, 2009). Various research articles over the years have addressed market segmentation in rural tourism, but the majority of them have segmented the data based on motivation (Chen, Lin, \& Kuo, 2013; Park \& Yoon, 2009; Polo Peña et al., 2016; Rid, Ezeuduji, \& Pröbstl-Haider, 2014), benefits (Frochot, 2005; Martins-Almeida, Correia, \& Pimpão, 2014; Park, Lee, \& Yoon, 2014), and activity (Eusébio et al., 2017; Pesonen \& Tuohino, 2015). There is a distinct lack of market segmentation research based on tourist experiences in rural tourism. In addition, most of the segmentation research on rural tourism has focused on quantitative research like customer interview surveys. The existing quantitative research based on researchers' viewpoints has a limitation, which is that it is difficult to reflect the potential needs and deep insights drawn from consumer opinions due to the use of uniform survey questionnaires and limited choice options during the response process. Thus, many scholars have argued that an in-depth understanding of customer experiences through complementary methods is needed (Neuhofer, 2016).

Online environments such as an online community, blogs, or social networking services (SNS) have been rapidly developed due to the spread and diffusion of the internet. Opportunities to clearly understand consumer desires and experiences through user-generated content are increasing. In this atmosphere, netnography has recently attracted attention (Stockinger, 2015). Netnography is a combination of the terms "Inter (net)" and "Ethnography" and is an online participatory observation technique that extends traditional and cultural research methods into technological development. Netnography has been defined as a form of genealogy drawing from researching communities and their cultures, which are accessible through online communications (Kozinets, 2015). Netnography can complement the existing limitations of other quantitative or qualitative research because it can grasp customers' vivid experiences and honest opinions through online data created by the customers themselves (Mkono, 2012). As user-generated content like tourist reviews contains numerous texts, photos, and videos related to tourism experiences, it can be an appropriate resource for analyzing the experiences and complaints of various tourists in tourism research (W. Lu \& Stepchenkova, 2015).

\section{I.2. Rural tourism experiences}

Rural tourism refers to multifaceted and niche activities consisting of various combinations of activities such as cultural tourism, nature tourism, ecotourism, wine, food, sports and adventure (Lane, 2009). As opposed to urban areas, rural areas are generally regarded as open spaces with small residences and small settlements, filled with rural flora and fauna. Rural tourism is based on rural areas characterized by natural resources, traditions, open space, small scale, and local control (Lane, 1994).

Tourist experiences are perceived as the essence of tourism, which attracts tourists and focuses on 
maximizing their satisfaction (Mossberg, 2007). One of the main challenges for developing rural tourism is to meet the needs of tourists seeking various experiences. Tourists are active in determining their experience in ways such as seeking information and imagining diverse experiences before starting travel and also taking advantage of experiences offered by the rural tourism destination (Gnoth, 2003).

Rural tourism experiences must be perceived as an overall experience through a variety of environments, attractions, resources, people and services provided by rural destinations (Kastenholz et al., 2018). There are many purposes and reasons for the increasing pursuit of rural tourism experiences. Varied studies on rural tourism have shown that the key motivations for tourists to decide on rural tourism are access to nature, rest, spending meaningful time with family in places different from the city, meeting with friends, recreation, sports activities, and experiencing traditional lifestyle in rural areas (Figueiredo \& Raschi, 2012; Kastenholz et al., 2018; Kline et al., 2014).

Studies have shown that nature and landscape are important elements of the tourism experiences that tourists pursue (Figueiredo \& Raschi, 2012; Frochot, 2005; Kastenholz et al., 2012). Access to nature for urban residents is achieved through different landscapes that can be experienced visually (Woods, 2003). Occasionally, rural tourists seek nature to escape from the stress of urban life (Kastenholz, João Carneiro, et al., 2018). Tourists pursue rural tourism experiences thinking about the opposite of negative emotions such as the stress of urban life. In other words, positive emotions are promoted through rural tourism, a medium that can escape urban life (Kastenholz, João Carneiro, et al., 2018). This is related to the search for authenticity of urban people who want to leave their current imperfect life full of stress and reach an ideal past (Sims, 2009). Lastly, the rural way of life, that is, traditional and authentic, is another important factor in rural tourism (Sims, 2009).

Some rural tourists choose rural tourism for human interaction with the local people living in rural areas (Frochot, 2005). Local people are not only those who create rural assets and add value to them, but they themselves become a part of the experiences that rural tourism offers (Garrod, Wornell, \& Youell, 2006). A personal experience stemming from specific interactions between hosts and tourists is regarded as a valued factor in rural tourism (Choo \& Petrick, 2014). It can have influence on bonding with the tourist on various levels such as the physical, rational, emotional, sensorial, and spiritual level (Gentile, Spiller, \& Noci, 2007; Pelegrín, GonzálezMenorca, \& Meraz, 2019). The meeting of tourists and locals in the rural village environment can also play an important role in improving the quality of rural tourism experiences (Kastenholz et al., 2012).

According to Schmitt (1999), a company's ability to provide quality customer experiences is a prerequisite to maintaining its competitiveness. Customer experiences can be defined as the customers' subjective responses naturally formed by them in the indirect contact process through a series of communication activities such as advertisement, PR, events and promotions, as well as the direct contact process between a company and its customers through products and services (Meyer \& Schwager, 2007). Mascarenhas, Kesavan, and Bernacchi (2006) insisted that customer experiences were made up of affective experience, which means the feeling customers have while using products and services, sensory experiences that stimulate the five senses, as well as cognitive experiences that provide functional benefits to customers. Shaw (2005) also viewed customer experiences as a fusion of cognition, affect, and senses and argued that companies that provide affective and 
sensory experiences together with cognitive experiences could have the best competitive edge. The structure of the tourist experiences includes cognitive factors related to beliefs or knowledge about tourist attractions as well as emotional factors related to feelings about tourist attractions (Baloglu \& McCleary, 1999). This study presupposes customer experience as a combination of cognitive, affective and sensory experiences based on previous literature.

Cognitive experience are understood to be the thoughts and beliefs customers have due to the functional benefits formed in the process of purchasing and using products and services (Fiore \& Kim, 2007). As a result of the individual's perception of the facilities of the tourist destination itself, cognitive experience about the tourist destination is formed (Stepchenkova \& Mills, 2010). In terms of cognitive experiences in rural tourism, functional attributes such as rural-based activities, the infrastructure of rural tourism and tourism attractions around rural areas create a variety of tourist experiences (Knutson \& Beck, 2008). Rural tourism mainly consists of activities created with various combinations of sports and adventure, cultural tourism, natural tourism, ecotourism, wine tourism, and food tourism of rural background (Lane, 2009). Bigné Alcañiz et al. (2009) viewed cognitive experience as tangible or measurable functional components such as accommodation and price levels.

According to Cohen, Pham, and Andrade (2008), affective experience can be defined as emotions that customers feel when they use products or services or those that they could imagine feeling, even if they don't actually use them. According to Son and Pearce (2005), an emotional experience in the field of tourism refers to the tourists' individual feelings about destinations, which can be expressed as preference, neutral, or non-favorite. Diversified tourism and hospitality studies have founded their attention on the influence of the customers' affective experiences on overall customer satisfaction, their word of mouth, and their purchase intention (Bigné, Mattila, \& Andreu, 2008; Ladhari, 2009; Martin, O’Neill, Hubbard, \& Palmer, 2008). In terms of affective experiences in rural tourism, to escape from the negative emotions accumulated in urban life is the main reason why tourists pursue the rural tourism experience (Figueiredo \& Raschi, 2012). Rural tourism relieves urban tourists from the stress of urban life by inspiring them with positive emotions (Kastenholz et al., 2018). In addition, the tranquility and relaxation associated with emotional fullness are the important experiences that tourists seek in rural tourism (Richard Sharpley \& Jepson, 2011). Finally, the interactions between tourists and rural tourism hosts can be another emotional level of rural tourism experience (Choo \& Petrick, 2014).

To have a sensory experience is to feel aesthetic pleasure, excitement and satisfaction through the stimulation of the five senses: sight, hearing, smell, touch and taste (Schmitt, 1999). Diversified tourism studies have empathized that properly stimulating five senses of tourists plays an important role in creating value, relative to a customer's interests and leading to his/her positive reactions (Agapito, Mendes, \& Valle, 2013; Mossberg, 2007; Walls et al., 2011). Some hospitality and tourism studies have addressed noise at the destination, the overall atmosphere, and the surrounding environment as attributes that create positive sensory experiences (Callan \& Bowman, 2000; Devi Juwaheer, 2004). In terms of sensory experiences in rural tourism, rural tourism studies reveal landscape as well as nature can be considered essential rural tourism experiences (Kastenholz et al., 2012). They not only provide a strong motivation for tourists to choose rural tourism, but also influence their evaluation of the perceived quality after his/her rural tourism experience (Marujo \& Santos, 2012). The visual experience 
that nature and scenery offer to tourists can play a role in purifying the minds of tourists (Frochot, 2005).

\section{I.3. Segmentation in rural tourism research}

Market segmentation is widely recognized as an effective method for exploring consumer behavior. Segmentation of tourism markets should be completed in order to create marketing strategies for differentiating the target audiences. Segmentation indicates that a market is made up of subgroups which have distinctive perceptions and needs (Mok \& Iverson, 2000), and generally, can be defined as the procedure for splitting a whole market into segments in order to offer practical marketing implications (Middleton et al., 2009). Market segmentation is applied to clarify targeted tourist groups, develop and offer better tourism packages, maximize the tourist benefits at tourism destinations, and establish an efficient tourism policy and positioning strategy (Nickerson, Jorgenson, \& Boley, 2016; Xia et al., 2010). The variables used to segment the tourism market can be motivation, benefits sought by customers, attributes for vacation, lifestyle, personality, image, and experience, in addition to traditional factors such as demographic, economic, and geographical characteristics (Middleton et al., 2009).

In a large number of rural tourism studies, factor-cluster segmentation has been used. First of all, diversified studies have segmented the rural tourism market based on motivation. Chen, Lin, and Kuo (2013) indicated four segments based on motivation for the rural tourism market in their study: relaxation and novelty pursuers, physical utility pursuers, socialization and accessibility pursuers, and trend pursuers. Rid, Ezeuduji, and Pröbstl-Haider (2014) identified four Gambian rural tourist segments based on motivation: sun and beach pursuers, beach and multi-experience pursuers, nature and heritage pursuers, and multi-experience pursuers. Polo Peña et al. (2014) segmented the rural tourism market by motivation: undertaking activities in the rural area, enjoying a rural destination's services and facilities, and visiting a rural destination. Applying factor-cluster segmentation, Park and Yoon (2009) defined four different segments for the Korean rural tourism market: learning and excitement, want-it-all, passive tourists, and family togetherness. Next, market segmentation by the benefits sought by customers is effective in establishing a marketing strategy that differentiates the target market because it divides the market in terms of the value pursued by tourists (Botschen, Thelen, \& Pieters, 1999). Park, Lee, and Yoon (2014) conducted segmentation according to the benefits sought by customers. The result of this study is that five rural tourism market segments: the pursuit of spending time with family, the pursuit of escape from the daily routine, the pursuit of learning and socialization, the pursuit of rural experience, and the pursuit of education were found to exist in Korea. Frochot (2005) conducted market segmentation on the basis of benefits pursued by rural tourists in Scotland, using factor-cluster segmentation. As a result, the market was divided into active type, rural type, resting type, and contemplating type. Almeida, Correia, and Pimpão (2014) segmented the rural tourism market by benefits: want-it-all, family oriented, relaxers, and ruralist. Meanwhile, some studies have broken down the rural tourism market on the basis of activity. Eusébio et al. (2017) indicated four Portuguese rural tourism segments based on activity: summer family vacationers, inactive, passive nature observers, and active visitors. 
Pesonen and Tuohino (2015) segmented the rural tourism market by activity, using factor-cluster segmentation. As a result, the market was divided into spa goers, well-being enthusiasts, and sporties.

Segmentation by multiple correspondence analysis (MCA) is considered a useful method for segmentation in case the application of traditional factor-cluster segmentation is not possible since respondents must only answer yes, no, or not sure instead of using Likert-type scales. Through MCA, the associations between respondents who are close to each other and other variables can be quantified (Carroll, Green, \& Schaffer, 1987). There are also some other existing segmentation studies of the rural tourism market that apply MCA. Agapito, Valle, and Mendes (2014) comprehended tourist's perceptions by segmenting the Portuguese rural tourism market based on sensory experiences by applying MCA. The four themes for the segments, balanced experience, rural experience, nature-based experience, and generic beach related experience were suggested. Albaladejo-Pina and Díaz-Delfa (2005) examined the rural tourism market demand by accommodation type, applying MCA.

The aforementioned studies are characterized by MCA with the data collected through a quantitative consumer survey. However, there is no other existing tourism research that segments by MCA with user-generated online data. The application of MCA in this investigation differs from the existing studies because it analyzes user-generated online data instead of the data through a quantitative consumer survey.

\section{I.4. Sustainable rural tourism}

Sustainable tourism has become recognized as a desirable goal in tourism development due to the addition of the concept of sustainability to tourism in order to reduce the negative impacts experienced during the tourism development process (R. Sharpley, 2003). Sustainability-based tourism development models can evolve when they are able to meet the demands of locals as well as respond to the needs of tourists (WTO, 1993). Through tourist participation in activities in developed tourism, positive or negative factors are created, which affect the sustainability of environmental, social and economic dimensions (Yoon, Gursoy, \& Chen, 1999). First of all, on the positive side, the development of tourist activities in rural areas can create verified positive effects; improvement of the quality of life for locals, creation of employment, preservation of cultural heritage, development of business networks, and enhancement of public image of the region (Andereck \& Nyaupane, 2011). In addition, through the development of rural tourism, there may be other positive effects such as the opportunity to enhance the natural environment value, improvements related to public transport networks or public facilities, and the activation of cultural interactions (Almeida-García et al., 2016). Whereas there may be also negative effects such as overcrowding of public places and facilities, disruption of local people's lives, skyrocketing price of property ownership, safety concerns, environmental damage, increased waste, and overuse of resources (Almeida-García et al., 2016). These have negative impacts on the sustainability of rural tourism from social, economic, and environmental points of view. Sustainable rural tourism aims to raise the sustainability with regard to the long term improvement of living standards by maintaining the balance between environmental protection, promoting economic benefits, establishing social justice, and maintaining cultural integrity (Liu et al., 2013).

As interest in the sustainability of rural tourism has increased, various types of research on sustainable 
rural tourism have been conducted, and research achievements related to this sector have been accumulated (De Luca et al., 2017). However, a comprehensive overview of how studies related to sustainable rural tourism have been conducted and what results have been presented has not yet been created, although there have been some systematic review studies on the sustainability of general tourism (Guo, Jiang, \& Li, 2019; Kristjánsdóttir, Ólafsdóttir, \& Ragnarsdóttir, 2018; Niñerola, Sánchez-Rebull, \& Hernández-Lara, 2019; Yoopetch \& Nimsai, 2019; Zolfani et al., 2015). Thus, the need for a systematic review of sustainable rural tourism has emerged. The accumulation of comprehensive and systematic understanding can be said to be a very important task in terms of expanding and deepening the knowledge of related topics and raising awareness of a new research direction (Hulland \& Houston, 2020). A systematic review of sustainable rural tourism can contribute to future research in many ways. This study enables researchers designing new research into sustainable rural tourism to understand a cutting edge subject and quickly get used to it (Barczak, 2017). In addition, this systematic review study helps researchers establish a new perspective on the phenomenon by synthesizing new insights from various existing studies (Houston, 2019). Next, it leads them to identify research topics and questions that have not yet been investigated by analyzing the overall trend of the research conducted so far (Hulland \& Houston, 2020). Finally, it can provide guidance for future investigators who will conduct research on the topic of sustainable rural tourism to determine research structure and method (Palmatier, Houston, \& Hulland, 2018).

\section{I.5. Objectives}

The purpose of this research is to offer a basis upon which to establish a strategic direction that can strengthen the competitive capacity to rural tourism providers and local government legislators, through deep analysis of the essence of the customer experience in order to enhance customer value in rural tourism.

\section{I.5.1. Specific objective of Study 1}

The objective of Study 1 is to offer a basis for developing appropriate response strategies by understanding customers' natural perceptions related to their rural tourism experiences as well as the characteristics of the rural tourism market segments through applying the non-artificial survey method, netnography, and providing it to rural tourism providers.

\section{I.5.2. Specific objective of Study 2}

The objective of Study 2 was to explore rural tourists' perceptions in order to identify different market 
segmentation in relation to rural tourism experiences for rural tourism providers, as well as policymakers in local governments, amongst others.

\section{I.5.3. Specific objective of Study 3}

The objective of Study 3 is to enable researchers designing new research into sustainable rural tourism to understand a cutting-edge subject and quickly get used to it. In addition, this systematic review study helps researchers establish a new perspective on the phenomenon by synthesizing new insights from various existing studies. Next, it leads them to identify research topics and questions that have not yet been investigated by analyzing the overall trend of the research conducted so far. Finally, it can provide guidance for future investigators who will conduct research on the topic of sustainable rural tourism to determine research structure and method. 
CHAPTER II. METHODOLOGY 


\section{II.1. Netnography}

The changes produced by the invention of the internet have compelled the discovery of new research methods that could allow the who, what, when, where, and how amongst various online environments and diverse virtual communities to be determined (Turpo Gebera, 2008). Netnography is separate from ethnography in the time required to collect information and the degree of researcher engagement in the research field (ClementeRicolfe \& Escribá-Pérez, 2014).

Netnography is characterized by the freedom that people feel in expressing their perceptions as compared to the inconvenience of completing a structured questionnaire that forces them to respond to questions about their direct experiences (M. del F. García, 2011). Due to this, netnography enables market researchers to observe natural consumer behaviors, such as consumer opinions about products or information searches (Kozinets, 2015). Netnography allows researchers to confidentially observe consumer behavior in various cultures and internet communities (Ji, Li, \& Hsu, 2016). Fox and Roberts (1999) explained that netnography is the use of sociology in virtual social spaces and online interactive communities. Netnography is a research technique using publically accessible information in order to comprehend and identify the consumer needs that influence decisions made online (Kozinets, 2015).

In comparison to other commercial research techniques, netnography has advantages such as low cost, rapid collection of diverse opinions, accessibility to research participants, higher reflective quality of online opinions, and the acquisition of useful and interesting results with a relatively small number of messages, provided that they have extensive descriptions. On the other hand, it also has disadvantages, such as suspicions about the honesty of the user when taking advantage of the use of a pen name and the need to complement it with other techniques to ensure a more accurate analysis (Kozinets, 2015; Xun \& Reynolds, 2010).

The application of netnography has been growing rapidly since systematic netnography research guidelines were presented by Kozinets (2002). In terms of developing sectoral weightings, marketing research is still primarily used, but this netnographic research is spreading rapidly within various academic fields such as tourism and sociology due to the proliferation of social media (Bengry-Howell et al., 2011). Netnography can be a very useful way to analyze tourist experiences since tourists' reviews are usually completed at the post-tour stage, which means that netnography can then be used to obtain the broader vision of tourist experiences (Y. Zhang \& Hitchcock, 2017). Netnography utilizes the varied virtual environment of tourism and the situation that people from the same cultural and social level participate increasingly in virtual communities (Munar, Gyimóthy, \& Cai, 2013). As online communities generated by users, which enable potential tourists to look for tour information easily, continue growing, researchers have a great opportunity to grasp tourist experiences at ease (Mkono \& Markwell, 2014).

Pearce and $\mathrm{Wu}$ (2018) applied the netnography research method to tourists' reviews from Tripadvisor.com to analyze the structure of entertainment tourists' experiences. The result shows that international tourists generally perceived the traditional and unique style of tourism as a positive experience. Rageh, Melewar, and Woodside (2013) attempted to clarify the detailed tourist experiences using the netnography methodology. For this purpose, the reviews from Tripadvisor.com and holidaywatchdog.com left by tourists who visited branded 
Egyptian resorts were analyzed. Through this analysis, customer experiences were categorized into eight dimensions: comfort, education, pleasure, novelty, perception, relationship, safety, and beauty. Dillette, Douglas, and Andrzejewski (2016) conducted a netnographical research by extracting the reviews from wellness tourists on Tripadvisor.com in order to explore the tourists' experience structure. As a result of the analysis, the tourists' experience structure was defined in four dimensions: body, mind, spirit, and environment.

There is no prior research applying netnography to rural tourism. This study is the first to apply netnography in the field of rural tourism.

In this investigation, netnography was applied because customers are increasingly accessing online communities for more objective information (Kozinets, 2015). The field work was begun by looking for online communities whose subject matter was linked to the dissemination of opinions between customers about rural tourism. Thus, three target online communities (Toprural, Clubrural, and Escapadarural) were chosen based on the number of visitors in order to extract customer experiences by analyzing the consumer opinions. Each rural tourism online community has extensive information about more than 30,000 rural accommodations throughout Spain and allows for the reading of various user opinions about a particular rural accommodation. A netnography study was conducted on 1,002 tourist opinions, including 400 users at Toprural, 347 users at Clubrural, and 255 users at Escapadarural. Only tourist opinions from within the last four years from 2016 to 2019 were analyzed.

The netnography methodology was used to analyze the tourists' reviews that were shown to have a great influence on other tourists' decisions (Kozinets, 2015). For the validity and reliability of the investigation, four criteria were considered. First, opinions that are suspected to be on owners' self-promotion were excluded. Second, opinions assigned by 'visit region', which means the seventeen regions in Spain visited by tourists, reflected. Third, negative opinions, as well as positive ones, were selected. Fourth, opinions not only on the popular places but also on the unpopular ones were applied.

This study was not based on data mining using specific software for data collection, but rather, by a feature that researchers have deeply observed and have selected to interpret the overall experiences of each individual tourist expressed in the customer review section. Considering not only the verbal expressions in the customer reviews, but also the visual expressions through photographs related to tourist experiences, the tourists' experiences and feelings in rural tourism were interpreted (Kozinets, 2015). The experiences in rural tourism that are important to each tourist were derived by analyzing the opinions about the rural tourism experiences that the tourists have had. After key sentences expressing tourist experiences were extracted from the tourists' reviews for qualitative analysis, the meanings of each sentence were summarized into words of experiences, which would be later used as variables, for quantitative analysis. Even though the expressions used were different, words with similar meanings were bound to one type of experience, and even if there were no experience words in a sentence, the sentence was classified into a specific experience after its synthetic meaning was interpreted. For example, if a tourist opinion was written as "The owner was very attentive to us, explaining everything we could do, where to visit, where to eat. He made us feel like home.", the researchers collected data by interpreting it as an experience word 'customer care'. Depending on the tourists, just one experience or several experiences may have been 
derived from each opinion. Immediately after data collection, it was checked whether the same tourist's opinion for a particular rural tourism accommodation was posted on multiple sites or not. Through analyzing the 1,002 opinions, the important experiences in rural tourism pursued by customers were derived from the data. After the opinions were collected, the same comments were individually reviewed by two researchers. In the case of any difference of interpretation between two researchers, the messages were reviewed by a third researcher.

Due to the nature of the netnography study, which was based on user-generated content online, there was a limitation of items that could be used as variables. For example, as 'gender', 'trip type', which consists of family, friend group and couple, and 'price level' which means prices that each customer paid for a specific rural tourism accommodation for one night per person with '10-19 euros' as a low price, '20-39 euros' as a medium price, and '40-66 euros' as a high price, were able to be obtained, they could be used as variables. But since it was impossible to grasp the attributes such as 'travel frequency', 'education level', 'income level', 'age', and 'profession', they couldn't be used as variables in this study.

Multiple correspondence analysis (MCA) was applied in order to observe the relative position of more diversified tourist experiences. MCA is an exploratory data analysis technique which investigates the relationship among three variables or more through visualizing them in multiple contingency tables with plotted points in twodimensional space (Hoffmann \& Franke, 1986). For this study, we defined customer groups according to tourist experiences in rural tourism as variables for MCA. The variables were placed into columns, and individuals into rows. Meaningful themes based on tourist experiences in rural tourism were extracted by analyzing the associations among tourist experiences. MCA, an exploratory and interdependent research technique, allows for the quantitative exploration of multiple variables with qualitative characteristics and a graphical description through the use of a perceptual map (Anderson et al., 2009; Nenadic \& Greenacre, 2007). Since the described points which are near or far from each other explain association or dissociation on the perceptual map, MCA can examine relationships not only between variables but between the categories of each variable and can further group customers who pursue the same experiences (Carroll, Green, \& Schaffer, 1986). In order to effectively interpret the perceptual map of MCA, a cross-tabulation table was applied (Do Valle, Mendes, \& Guerreiro, 2012; Pan \& Ryan, 2009). Thus, it was possible to obtain meaningful alternatives to segmenting customers through MCA (Carroll \& Schaffer, 1987).

K-mean clustering was applied as a supplementary analysis to MCA (Ribeiro, Valle, \& Silva, 2013). The market segmentation based on the tourists' perception of his/her experiences in rural tourism that resulted from MCA was extracted. Since the proximity of diversified variables in MCA shows the existence of tourists with similar profiles resulting from distinctive characteristics that reflect dissimilar groups of tourists, it is possible to combine MCA with the k-mean clustering (Arimond \& Elfessi, 2001; Greenacre, 2016). K-mean clustering can be used for certifying the results of MCA and is regarded as a useful methodology for segmenting markets (Albaladejo-Pina \& Díaz-Delfa, 2005). The variable obtained in segments, which originates from the dimensional scores in MCA and points out the clusters where each customer is classified, is contained as an additional variable on the MCA map. The customers' profiles and characteristics were analyzed by crossing the variable obtained as 
segments with the previous variables like 'tourist experiences', 'trip type', 'price level', 'gender', and 'region'. This process permits validation of the segments and the presence of distinctive customers' profiles (Do Valle, Mendes, \& Guerreiro, 2012).

The most common approach to using dimension reduction and cluster analysis has been to conduct them in a time-ordered sequence (H. Hwang, Dillon, \& Takane, 2006). This approach may not generate an optimal cluster assignment since dimension reduction and cluster analysis have different criteria for optimization. The aim of the former is normally to maintain the maximum variance in the minimum number of dimensions. On the other hand, the aim of the latter is to assign the observations to clusters after finding those that are similar and dissimilar in the dataset (Vichi \& Kiers, 2001). To solve this problem, the combinations of dimension reduction with cluster analysis has been needed. A new method 'joint dimension reduction and clustering', which implements dimension reduction and clustering together at the same time, has been proposed (Markos et al., 2018). It overcomes the inconvenience of doing 'dimension reductions' and 'clustering' separately. In this study, the R package 'clustrd', that applies the method 'joint dimension reduction and clustering', was used, thus, the result of clustering was simultaneously displayed on the positioning map for MCA.

\section{II.2. Visual Q}

Q methodology is called semi-qualitative because the analysis is very quantitative but the interpretation is broadly qualitative (Ramlo \& Newman, 2011). Q methodology seeks an understanding and interpretation of subjective preferences and perspectives (Swaffield \& Fairweather, 1996). It is a modified factor analysis technique, which is different from the widely used $\mathrm{R}$ methodology. The difference between them is that the former has the purpose of measuring the correlations between subjects in a sample, while the latter measures the correlations between variables (Naspetti et al., 2014). Q methodology has different characteristics from the existing research methodologies in terms of a set of factors which express individuals' perceptions and enable their opinions to naturally emerge without being prompted by a researcher (Bacher et al., 2014).

Several studies have shown us that images are more useful than words in mental processing (Azizian et al., 2006; Schlochtermeier et al., 2013). Using photographs in Q methodology has been thought to provide a lot of advantages for visitor experience assessments in tourism (Swaffield \& Fairweather, 1996). It is easy to sort photographs because it is not an abstract process (Daniel, 2001). Images are considered to lead to a clearer emotional response than words. We can find that differences exist in the way of experiencing emblematic stimulants, such as images, that lead us to a more realistic interpretation (Kiefer \& Pulvermüller, 2012). Since photographs, as well as statements, are supposed to offer an experience that is related to reality, their evaluation by subjects corresponds to their visual reaction to the actual landscape (Amedeo et al., 1989). Through 
photographs, participants can also recall emotions, feelings and remembrances that cannot be expressed in statements. Visual Q enables us to systematically select a set of photographs, which we call the Q-set (Amedeo et al., 1989). The velocity of image processing is faster than words as images are the easiest way to approach true meaning and an interpretation is not required (Schlochtermeier et al., 2013).

The application of visual Q, which is the use of images within the Q methodology, has been appreciated as an easy method to understand the task and also does not require a complex process (Daniel, 2001). Visual Q is expected to offer the respondents a realistic experience of the actual places visited due to the use of images instead of words or statements, which enables them to think of memories and recall feelings (Zube \& Pitt, 1981). Since visual $\mathrm{Q}$, which is the $\mathrm{Q}$ methodology in conjunction with photographs, was initially adopted as a technique for evaluating landscape values (Zube et al., 1975), it has had a wide range of applications in various studies. Naspetti et al. (2016) applied visual images and the Q methodology to describe tourists' perceptions of photovoltaic systems, connected to their effect on the landscape. The factors extracted were innovative design advocates, mimics lovers, and farm managers. In order to offer useful proposals and in-depth analysis, Fairweather and Swaffield (2001) investigated tourist perceptions and attitudes on Kaikoura tourism in New Zealand applying the visual Q methodology. The result of this investigation is that five primary factors: family coastal holiday, picturesque landscape, coastal community, maritime recreation, and eco-tourists were identified in Kaikoura. Additionally, Hardy and Pearson (2018) used the Q methodology with images to analyze the attitudes of stakeholders toward sustainable tourism development. This study found that the opinions of individual stakeholders and those of stakeholder groups on sustainable tourism development do not always coincide.

Visual Q methodology was applied in accordance with McKeown and Thomas's (2013) five steps: 'Concourse' definition, 'Q-set' development, 'P-set' definition, 'Q-sort' collection and factor analysis.

The concourse of these steps provides the process to collect the population's thoughts, opinions, recognitions and perceptions related to the topic of the study (Van Exel \& De Graaf, 2005; Previte et al., 2007). In this study, we also used netnography methodology, which enables us to determine consumer awareness and conduct perception research by depicting consumer behavior in the online environment (Kozinets, 2002) in order to arrive at the 'Concourse' definition. We extracted experiences by analyzing consumers' opinions about rural tourism on online communities. Based on the number of visitors, we selected three target online communities: toprural.com, escapadarural.com, and clubrural.com and we analyzed tourist experiences in rural tourism in the following way: analyzed the opinions posted within the last 3 years; analyzed opinions assigned by regions, price level and trip type; reflected not only positive opinions, but negative ones as well; applied the opinions from the unpopular places as well as from the popular ones; opinions were individually reviewed by both researchers. We analyzed 1,000 opinions and derived 50 experiences that tourists pursue in rural tourism. According to the frequency, customer experiences in order are Customer care, Cleanliness, Maintenance of the facilities, Tranquility of the establishment, Landscape, Interior design, Gastronomy, Comfort, Pool, Coziness, Accessibility, Recreation area, Exterior design, Disconnection from the world, Lots of cultural tourism, Value for money, Barbecue, Rest, Spa, Nature, Space for children, Excursion, Chimney, Beach, Climbing.Hiking, Garden, Luxuriousness, Space for dogs, River-Lake, Mountain·Forest, Privacy, Bicycle, Winery, Rustic environment, 
Stargazing, Farm, Classic style, Horse riding, Observation of fauna and flora, Sunbathing, Modern style, Low price, Boat $\cdot$ Kayak, Tennis, Promotion, Fishing, Ski, Golf and Cable car.

The Q-set is the step of confirming attributes such as words, sentences and images to be used in the Q survey. The Q-set consists of the thematic attributes extracted from the concourse, which will be applied in the Q analysis. The selection of the Q-set is very important but is largely determined by the discretion of the researcher through structured or unstructured methods (McKeown, 1998). Regardless of which structure is selected, researchers should choose opinions that are different from each other to endow the Q-set with representativeness (Van Exel \& De Graaf, 2005). All possible expressions related to the subject extracted from all possible viewpoints are utilized in the Q-set (Zabala, 2014). Usually a Q-set collection is made up of scales of between 40 and 80 attributes (Watts \& Stenner, 2012). In this study, we decided to use all of the 50 possible experiences in rural tourism as the Q-set discovered through the use of the netnography methodology (Kozinets, 2015). We selected photographs that described the 50 experiences well and created cards that could display images and sentences at the same time.

The P-set means a group of interviewees that participate in Q-sort collection. The P-set plays a role in the representation of the collected opinions. Since the purpose of the research completed the Q methodology is not to generalize, but rather to analyze individual subjectivity, the number of samples, which enables us to generate and compare factors, is sufficient. Usually, the number of the P-set is not higher than the Q-set. The P-set is selected by following a structured sampling with experience and knowledge on the subject irrespective of the random sampling (Van Exel \& De Graaf, 2005). Those who participate in the research should be chosen if they have the possibility of expressing central or interesting viewpoints (Watts \& Stenner, 2012). The current P-set was created by recruiting participants in two major groups: tourists with travel experience related to rural tourism during the past three years and experts like professors, officers and members of rural tourism organizations. Our P-set consisted of 50 participants: 25 customers and 25 experts.

According to Coogan and Herrington (2011), the Q-sort sequences the opinions that make up the Q-set and shows the participants' subjectivities. Participants were expected to sort the attributes of the Q-set in accordance with their subjective preferences. At the beginning, participants classified the photographs into three groups; what they feel is most important, what they feel is most unimportant and what they feel neutral about. Then they sorted 50 photographs to the Q-grid map distributed by a force similar to normal distribution which was divided into 11 groups from 'most unimportant' (-5) to 'most important' (+5). They positioned things that they thought were the most important on the right side and the things they thought were the most unimportant to the left side. Finally, they were asked to account for the reason for their selections by qualitative interview. Such interviews contribute to improving the quality of research as well as assist in making plenty of data available with the result from the statistical analysis (Fairweather \& Swaffield, 2001). These additional qualitative studies allow us to delve deeper into the nature of influential factors and to understand the meaning of the critical attributes categorized by respondents (Fairweather \& Swaffield, 2001).

The final step of visual Q is factor analysis. It is possible to create distinguishable groups of participants with Q-grids, which are meaningfully similar and meaningfully distinct (Davis \& Michelle, 2011). This is a large 
point of difference from the R methodology, which is a correlation analysis among variables according to Previte et al. (2007). The factor loading means the degree of a Q-sort's relationship with a factor, is counted for every Qsort (Van Exel \& De Graaf, 2005). All participants with a similar viewpoint can be analyzed on the same factor since the pattern of their opinions that express their subjectivity is similar (Coogan \& Herrington, 2011). A participant's high factor loading means that the association of this participant with the factor is high as well (Pereira et al., 2016).

The Q method package that was developed for R programming, has been applied to the present study (Zabala, 2014). This package executes the principal component analysis (PCA) instead of the factor analysis from the Q methodology. PCA is already available for R methodology, and the results from both methodologies are similar (McKeown \& Thomas, 2013). Varimax, which is the most commonly used, was applied for the rotation of components.

\section{II.3. Systematic review for sustainable rural tourism}

Sustainable development was originally recognized for its importance as a consideration for tourism research in regards to the environment and the natural resource limits of the Earth (Du Pisani, 2006). Sustainable development can be prescribed as development which meets the current generation's needs while maintaining the ability to satisfy the future generation's needs (Burton, 1987). Hall (2008) embodied the concept of sustainable development by establishing five basic principles: a holistic strategy and plan that encompasses environmental, social and economic aspects, preserves essential natural ecology, development that maintains productivity in the future, balanced protection of biodiversity and human heritage, and seeks balance between countries in terms of opportunity and fairness. Sustainable development was conducted in the early stages by emphasizing the environmental dimension, but it is recognized that social and economic dimensions are also important in achieving true sustainability (Echebarria et al., 2018). This conclusion led to the widespread acceptance of the notion of sustainability being comprised of three basic elements: environmental, economic and social (Elkington, 1997). The importance of comprehensively looking at the three dimensions; environmental, economic, and social, has also been emphasized for the establishment of a sustainable development strategy (Echebarria et al., 2018). In the end, sustainable development should not be restricted to just one aspect, but rather it is a comprehensive system that encompasses the whole, such as environmental systems that preserve life resources, social systems that aim for equity, and economic systems for efficiency in resource use (Glavič \& Lukman, 2007).

Among the sectors of tourism research, sustainable tourism development has grown very rapidly (Niñerola et al., 2019). Sustainable tourism has emerged in response to issues such as environmental damage and the deterioration of traditional culture from tourism development (Bramwell \& Lane, 1993). The negative aspects of tourism development could be converted into positive aspects through the application of the concept of sustainable tourism (Zolfani et al., 2015). Sustainable tourism development maximizes future opportunities while 
simultaneously meeting the needs of existing tourists and hosts (WTO, 1993). It manages resources in terms of aesthetics and social and economic factors, while protecting biological diversity and maintaining traditional culture (Zolfani et al., 2015). According to Liu et al. (2013), sustainable tourism can be defined as any type of tourism that directly contributes to sustainable development or is suitable for sustainable development. Sustainable tourism includes not only enhancing the sustainability of the environment and its resources, encouraging sustainable growth in terms of socio-economic, but also conducting sustainable management based on a deep understanding of demand (Zolfani et al., 2015).

Rural tourism consists of several activities that harmonize with nature, the culture of the rural area, and the lifestyle of the local people (Lane, 2009). Rural tourism has developed rapidly as more and more people are looking for a new space to escape from the city's busy everyday life (Schmidt et al., 2016). Sustainable rural tourism can do an essential part in responding to the various challenges facing rural areas (Campón-Cerro et al., 2017). Sustainable rural tourism leads to the revitalization of rural areas such as through the protection of residents' quality of life, the maintenance of traditional culture, and the preservation of the ecological environment, and the creation of new jobs and increased income (Kallmuenzer et al., 2018). There are important considerations for the development of sustainable rural tourism: wellness of hosts and tourists, waste management, local development, pressure from tourists during peak season, irreversible deterioration of the environment, social impact, and economic returns (Sanagustín Fons, Fierro, \& Patiño, 2011). The key issues in sustainable rural tourism are environmental protection, economic assets and efficiency, and cultural awareness (Saarinen, 2006). Rural tourism can be an important part of creating employment opportunities and increasing household income for locals in terms of the economy, as well as maintaining the environment with regard to environmental protection, strengthening communities and preserving traditional cultural heritage in terms of social factors (Mcareavey \& Mcdonagh, 2011). Managing destinations for sustainable rural tourism is a complex task that requires controlling several variables (Blancas et al., 2011). Rural tourism can be a key driver in protecting and promoting destinations, but it can also serve to destroy them, because the benefits of rural tourism do not always outweigh the costs ( Yoon, Gursoy, \& Chen, 1999). For example, rural tourism can create jobs, but it can have a negative impact on rural welfare. In addition, rural tourism may increase the non-agricultural income of farmers, but it may be difficult to prevent environmental damage from an ecological viewpoint (Mcareavey \& Mcdonagh, 2011). Thus, it is necessary to promote sustainable rural tourism keeping in mind that economic, social and environmental goals may not only strengthen each other, but also interfere with each other (Caffyn, 2000).

The study reviewed SSCI and SCIE-class papers on sustainable rural tourism, which were searched on the Web of Science. The study's search was conducted only for the 10-year period from 2009 to 2019, in order to provide the latest and most relevant information (Wijesinghe, Mura, \& Bouchon, 2017). Several sets of keywords were applied to collect research related to sustainable rural tourism. These keywords were "sustainable rural tourism" or "sustainability of rural tourism". In the Web of Science, 564 articles related to the above-mentioned keywords were found.

Authors decided to target only peer-reviewed journal articles. The proceeding paper, book, and editorial materials were excluded because authors judged that they did not contribute significantly to knowledge 
development (Law, Leung, \& Cheung, 2012). Articles published in languages other than English were also excluded. Data extraction forms were then designed to identify included articles and provide an overview of approaches to sustainable rural tourism research. Considering the quality of the study, each article was evaluated in a structured data extraction format. The data extracted included author, year, title, journal, abstract, keywords, research purpose, topics, detailed topics, research methods, and data source. In the next step, for the screening of articles, the context of the keywords presented in each article and abstracts were analyzed. Through this process, articles could be divided into those that are fundamentally related to sustainable rural tourism and articles that are not related to sustainable rural tourism (for example, if the research area is not rural tourism or if the subject of the study is not associated with sustainability). The results show that 168 articles are fundamentally related to sustainable rural tourism. Finally, by analyzing the contents of the selected 168 articles, they were classified into those where sustainable rural tourism was addressed as the main issue of the study and those where it was treated as a supporting issue of the study. Finally, 73 articles covering the topic of sustainable rural tourism as the main issue were selected as the targeted material for the systematic review. This screening process was conducted independently by the authors, and in the case of data discrepancies, consensus was reached through discussions between the authors of this review.

This study grouped the selected articles by several criteria. First, the number of publications per year and per region that pertained to related studies was analyzed. Next, the publishing trends of journals related to sustainable rural tourism were analyzed. Finally, the research methods and research perspectives that were applied to the related studies were explored. This study draws a bibliographic map, which defined the co-occurrence of keywords that reveal what the main scientific knowledge of each study was (Mulet-Forteza et al., 2019). To obtain the bibliographic map based on research keywords co-occurrence, the VOSviewer software associated with the technique of multidimensional scaling was utilized in this study (van Eck \& Waltman, 2010). The software applied mapping techniques to determine the location of keywords on the map and the clustering technique to create clusters through the allocation of frequently co-occurring keywords (Borg \& Groenen, 2005). The research topics from the selected articles related to sustainable rural tourism were analyzed. First, the research topics were categorized in order to grasp the overall tendency of research in relation to sustainable rural tourism. In addition, the proportion of categorized topics was analyzed to confirm which topics were more significant in sustainable rural tourism research. Finally, the detailed topics covered in each category were analyzed to identify the specific research trends related to sustainable rural tourism. 
22 
CHAPTER III. PUBLISHED ARTICLES 
24 


\section{From netnography to segmentation for the description of the rural tourism market based on tourist experiences in Spain}

Wookhyun An, Silverio Alarcón,

From netnography to segmentation for the description of the rural tourism market based on tourist experiences in Spain, Journal of Destination Marketing \& Management, Volume 19, 2021, https://doi.org/10.1016/j.jdmm.2020.100549

Journal Citation Reports Ranking 2019: Journal of Destination Marketing \& Management was ranked 9 out of 56 in the area of 'Hospitality, Leisure, Sport \& Tourism', and 47 out of 226 in the area of 'Management'. 


\title{
From netnography to segmentation for the description of the rural tourism market based on tourist experiences in Spain
}

\begin{abstract}
This study aims to offer a basis for developing appropriate response strategies through understanding tourists' natural perceptions related to their rural tourism experiences and the characteristics of the rural tourism market segments. To achieve this purpose, the netnography methodology, which is an online participatory observation technique based on user-generated content that enables market researchers to observe natural consumer behaviors, was conducted on 1002 tourists' opinions in three online communities. Qualitative information derived from netnography combined with quantitative tools, multiple correspondence analysis and cluster analysis, allows for the segmentation of the rural tourism market. It has been confirmed that three market segments exist in rural tourism in Spain and three corresponding themes have also been derived from the results; comfort-driven visitor, rural ambiance spender, and active leisure seeker. This study is significant in that it began with the qualitative collection of user-generated online content from netnography and finished with the quantitative segmentation of the market based on tourist experiences.
\end{abstract}

Keywords: tourist experiences; netnography; multiple correspondence analysis (MCA); cluster analysis; segmentation 


\section{Introduction}

Customer experiences in rural tourism have been considered an essential factor that can drive the success and innovation of the industry (Ellis \& Rossman, 2008; Stamboulis \& Skayannis, 2003; Zehrer, 2009). Tourists generally seek distinctive and engaging experiences and their decisions are affected by images of the destination (Ellis \& Rossman, 2008; Mossberg, 2007; Prebensen \& Foss, 2011). For the sustainability of tourism, three changes are needed: the optimized utilization of local resources, the harmonization of diversified stakeholders' needs, and the improvement of tourists' satisfaction through offering meaningful experiences (Kastenholz et al., 2012). Considering that tourists pursue experiences of diversity and high quality on short-term holidays, rural areas must make an effort to provide distinguished, attractive and diverse customer experiences (Lane \& Kastenholz, 2015). Accordingly, understanding individual perceptions associated with customer experiences in rural tourism is important (Ritchie \& Hudson, 2009). In order to be successful, it is necessary for rural tourism to seek ways of satisfying customers' needs, which is first done by viewing the diversified customer experiences through tourism research (Uriely, 2005).

Among the many ways to explore customer experiences, segmentation is useful for creating a better market positioning strategy since it can offer desirable information about customers and insights on meeting their needs (Matzler et al., 2004). According to Buhalis (2000), segmentation is important because each tourism destination is only able to fulfill specific types of demands. Therefore, each tourism destination has to understand the needs of its potential customers and endeavor to attract the proper customer group. It is also crucial to be aware of existing segments for effective and efficient rural tourism management and marketing. The information on clear segments allows for the development of promotion and communication programs (Park \& Yoon, 2009). Various research articles over the years have addressed market segmentation in rural tourism, but the majority of them have segmented the data based on motivation (Chen, Lin, \& Kuo, 2013; Park \& Yoon, 2009; Polo Peña et al., 2016; Rid, Ezeuduji, \& Pröbstl-Haider, 2014), benefits (Frochot, 2005; Martins-Almeida, Correia, \& Pimpão, 2014; Park, Lee, \& Yoon, 2014), and activity (Eusébio et al., 2017; Pesonen \& Tuohino, 2015). There is a distinct lack of market segmentation research based on tourist experiences in rural tourism. In addition, most of the segmentation research on rural tourism has focused on quantitative research like customer interview surveys. The existing quantitative research based on researchers' viewpoints has a limitation, which is that it is difficult to reflect the potential needs and deep insights drawn from consumer opinions due to the use of uniform survey questionnaires and limited choice options during the response process. Thus, many scholars have argued that an in-depth understanding of customer experiences through complementary methods is needed (Neuhofer, 2016).

In this atmosphere, netnography has recently attracted attention (Stockinger, 2015). Since online environments such as online communities, blogs, or social networking services (SNS) have been rapidly developed due to the spread and diffusion of the internet and because opportunities to clearly understand consumer desires and experiences through user-generated content have been increasing, the application of netnography has been spreading. Netnography has been defined as a form of genealogy drawing from researching communities and their cultures, which are accessible through online communications (Kozinets, 2015). Netnography can 
complement the existing limitations of other quantitative or qualitative research because it can grasp customers' vivid experiences and honest opinions through online data created by the customers themselves (Mkono, 2012). As user-generated content like tourist reviews contains numerous texts, photos, and videos related to tourism experiences, it can be an appropriate resource for analyzing the experiences and complaints of various tourists in tourism research (W. Lu \& Stepchenkova, 2015). In consideration of these points, this study has attempted to derive more meaningful findings that combine qualitative and quantitative analysis by applying netnography to rural tourism.

Much investment has been made into rural tourism in Spain in order to break the monotony of Spanish tourism, which is dominated by beaches and the sun, and also to help farmers gain additional economic income through ways other than agricultural production (Besteiro, 2006). Rural tourism in Spain has been able to grow rapidly along with urban dwellers' desire to take a short, calm, and meaningful break in a completely different environment from that of the city (Julio Grande \& Maynar, 2010). However, in spite of this external growth, Spanish rural tourism has a weakness: low profitability, which is supported by the fact that Spanish rural tourism has a shorter average stay and lower economic impact than other types of leisure tourism (INE, 2018). This means that tourists have a resistance to high prices in rural tourism (Correia \& Oliveira, 2016). This situation requires a clear direction for small Spanish rural tourism owners, whose survival is threatened and seek to provide rural tourism products and services that will capture tourists' hearts. To this end, it is important to understand the needs of rural tourism tourists in Spain. In particular, a detailed exploration of the rural tourism experiences pursued by tourists is a priority for understanding and satisfying their needs.

The purpose of this study is to offer a basis for developing appropriate response strategies by understanding customers' natural perceptions related to their rural tourism experiences as well as the characteristics of the rural tourism market segments through applying the non-artificial survey method, netnography, and providing it to rural tourism providers.

In comprehensive consideration of the literature review, this study attempted to segment and characterize the Spanish rural tourism market based on tourist experiences by understanding tourists' natural perceptions through applying the non-artificial survey method, netnography. In order to analyze the characteristics of the Spanish rural tourism market based on tourist experiences, the following research questions were established (Figure 1). The first research question points out to the use of netnography to explore the rural tourism experiences that customers pursue. The second question is used to discover significant experiential themes for rural tourism from the tourist experiences derived through netnography. The third deals with the segmentation of the rural tourism market in Spain based on the tourist experiences derived through netnography. The next three questions inquire about the connections between the tourist experiences pursued and the various trip types (fourth), price levels paid (fifth) and demographic variables (sixth). 


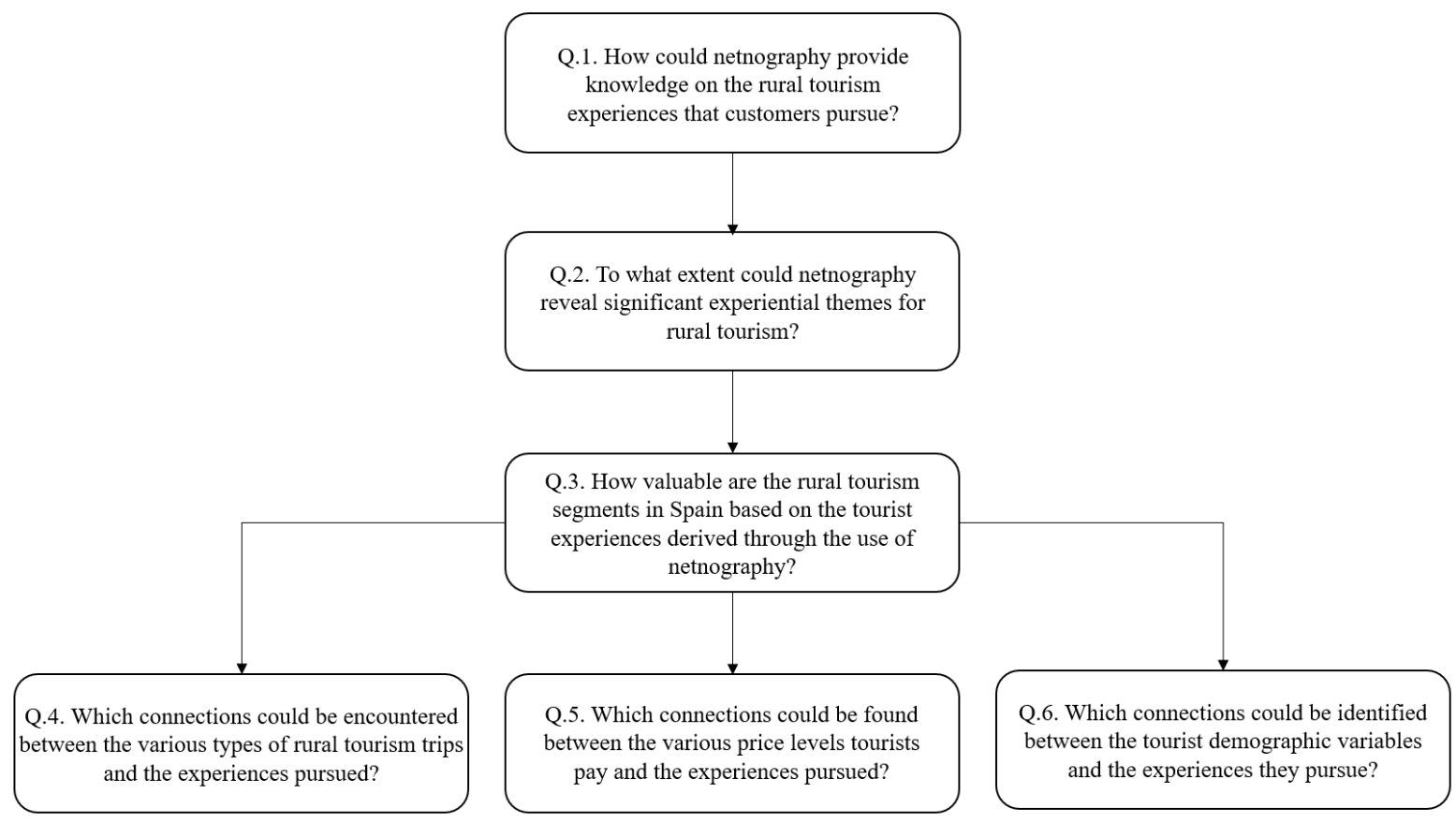

Figure. 1. Research questions

\section{Methods}

\subsection{Selection of observation target}

In this investigation, netnography was applied because customers are increasingly accessing online communities for more objective information (Kozinets, 2015). The representative online communities of Clubrural, Escapadarural, and Toprural were chosen and targeted based on the number of visitors in order to extract tourist experiences by analyzing visitor opinions. Each rural tourism online community has extensive information about more than 30,000 rural accommodations throughout Spain and allows for the reading of various user opinions about a particular rural accommodation. A netnography study was conducted on 1002 tourist opinions, including 400 users at Toprural, 347 users at Clubrural, and 255 users at Escapadarural (Table 1). Only tourist opinions from within the four years of 2016 to 2019 were analyzed, considering the relatively recent economic recovery of Spain after several years of negative growth since the economic crisis occurred in 2008 . 
Table 1. Target online communities.

\begin{tabular}{lll}
\hline Name & Website & Answers \\
\hline Toprural & www.toprural.com & $400(39.9 \%)$ \\
Clubrural & www.clubrural.com & $347(34.6 \%)$ \\
Escapadarural & www.escapadarural.com & $255(25.5 \%)$ \\
\hline
\end{tabular}

\subsection{Data collection}

In order to respond to research question 1, in this study, the netnography methodology was used to analyze the tourists' reviews that were shown to have a great influence on other tourists' decisions (Kozinets, 2015).

For the validity and reliability of the investigation, four criteria were considered. First, opinions that are suspected to be on owners' self-promotion were excluded. Second, opinions assigned by 'visit region', which means the seventeen regions in Spain visited by tourists, reflected. Third, in order to gather diversified opinions from different perspectives, negative opinions, as well as positive ones, were selected. The data were processed using the experiences mentioned and the rating ( 1 to 5$)$ as evaluated by the tourists regarding the respective variables. Fourth, additionally, for the collection of opinions on various aspects, opinions not only on the popular places but also on the unpopular ones were applied.

This study was not based on data mining using specific software for data collection, but rather on the researchers' observations and interpretations of the overall experiences of each individual tourist expressed in the customer review section. In order to avoid bias, the tourists' reviews were not selected based on their contents, but rather through a random sampling of dates within each online community and year. A random procedure, which is a mechanism to make random decisions, was used. After key sentences expressing tourist experiences were extracted from the tourists' reviews for qualitative analysis, the meanings of each sentence were summarized into words of experiences, which would be later used as variables, for quantitative analysis. Even though the expressions used were different, words with similar meanings were bound to one type of experience, and even if there were no experience words in a sentence, the sentence was classified into a specific experience after its synthetic meaning was interpreted. For example, if a tourist opinion was written as "The owner was very attentive to us, explaining everything we could do, where to visit, where to eat. He made us feel like home.", the researchers collected data by interpreting it as an experience word 'customer care'. Depending on the tourists, just one experience or several experiences may have been derived from each opinion. Immediately after data collection, whether the same tourist's opinion for a particular rural tourism accommodation was posted on multiple sites or not was checked, in order to prevent duplicate responses from being reflected in survey data.

Through analyzing the 1002 opinions, the important experiences in rural tourism pursued by customers were derived from the data. After the opinions were collected, the same comments were individually reviewed by 
two researchers. In the case of any difference of interpretation between two researchers, the messages were reviewed by a third researcher.

Due to the nature of the netnography study, which was based on user-generated content online, there was a limitation of items that could be used as variables. For example, as 'gender', 'trip type', which consists of family, friend group and couple, and 'price level' which means prices that each customer paid for a specific rural tourism accommodation for one night per person with '10-19 euros' as a low price, '20-39 euros' as a medium price, and '40-66 euros' as a high price, were able to be obtained, they could be used as variables. But since it was impossible to grasp the attributes such as 'travel frequency', 'education level', 'income level', 'age', and 'profession', they couldn't be used as variables in this study.

\subsection{Data analysis}

With the purpose of responding to research question 2, multiple correspondence analysis (MCA) was applied in order to observe the relative position of more diversified tourist experiences. For this study, customer groups, according to the rural tourism experiences tourists seek, were defined as variables for MCA. They were placed into columns, and individuals into rows. Meaningful themes based on tourist experiences in rural tourism were extracted by analyzing the associations among tourist experiences. MCA, an exploratory and interdependent research technique, allows for the quantitative exploration of multiple variables with qualitative characteristics and a graphical description through the use of a perceptual map (Anderson et al., 2009; Nenadic \& Greenacre, 2007). Since the described points which are near or far from each other explain association or dissociation on the perceptual map, MCA can examine relationships not only between variables but between the categories of each variable and can further group customers who pursue the same experiences (Carroll et al., 1986). In order to effectively interpret the perceptual map of MCA, a cross-tabulation table was applied (Do Valle et al., 2012; Pan \& Ryan, 2009). Thus, it was possible to obtain meaningful alternatives to segmenting customers through MCA (Carroll, Green, \& Schaffer, 1987).

In order to answer research questions 3, 4, 5, 6, k-mean clustering was applied as a supplementary analysis to MCA (Ribeiro et al., 2013). The market segmentation based on the tourists' perception of his/her experiences in rural tourism that resulted from MCA was extracted. Since the proximity of diversified variables in MCA shows the existence of tourists with similar profiles resulting from distinctive characteristics that reflect dissimilar groups of tourists, it is possible to combine MCA with the k-mean clustering (Arimond \& Elfessi, 2001; Greenacre, 2016). The variable obtained in segments, which originates from the dimensional scores in MCA and points out the clusters where each customer is classified, is contained as an additional variable on the MCA map. The customers' profiles and characteristics were analyzed by crossing the variable obtained as segments with the previous variables like 'tourist experiences', 'trip type', 'price level', 'gender', and 'region' (Do Valle, Mendes, \& Guerreiro, 2012). 
The most common approach to using dimension reduction and cluster analysis has been to conduct them in a time-ordered sequence (H. Hwang et al., 2006). This approach may not generate an optimal cluster assignment since dimension reduction and cluster analysis have different criteria for optimization. The aim of the former is normally to maintain the maximum variance in the minimum number of dimensions. On the other hand, the aim of the latter is to assign the observations to clusters after finding those that are similar and dissimilar in the dataset (Vichi \& Kiers, 2001). To solve this problem, the combinations of dimension reduction with cluster analysis has been needed. A new method 'joint dimension reduction and clustering', which implements dimension reduction and clustering together at the same time, has been proposed (Markos et al., 2018). It overcomes the inconvenience of doing 'dimension reductions' and 'clustering' separately. In this study, the R package 'clustrd', that applies the method 'joint dimension reduction and clustering', was used, thus, the result of clustering was simultaneously displayed on the positioning map for MCA.

\section{Results}

\subsection{Sample profile and extracted customer experiences}

The demographic characteristics of the research samples are shown in Table 2. It shows that there were slightly more female customers (56.4\%) than male. 'Trip type' consisted of 'family (45.1\%)', 'friend group (28.4\%)', and 'couple (26.4\%)'. 'Price level', which refers to the prices that each customer paid for a specific rural tourism accommodation for one night per person, was composed of '10-19 euros (14.6\%)' as a low level, '2039 euros (65.2\%) as a medium level, and '40-66 euros (20.3\%)' as a high level. The online communities where the customers submitted opinions on his/her experiences in rural tourism are Toprural (39.9\%)', 'Clubrural (34.6\%)', 'Escapadarural (25.4\%)'. The term 'visit region' evenly includes the seventeen regions of Spain visited by tourists for rural tourism.

Table 2. Demography of the research samples.

\begin{tabular}{ll}
\hline $\begin{array}{l}\text { Demographic } \\
\text { factors }\end{array}$ & Answers \\
\hline Gender & Male: $437(43.6 \%)$, Female: $565(56.4 \%)$ \\
Trip type & Family: $452(45.1 \%)$, Friend group: $285(28.4 \%)$, Couple: $265(26.4 \%)$ \\
Price level & 10-19 euros: $146(14.6 \%), 20-39$ euros: $653(65.2 \%), 40-66$ euros: $203(20.3 \%)$ \\
Visit region & Andalusia: $72(7.2 \%)$, Aragón: 70 (7.0\%), Asturias: $75(7.5 \%)$, Cantabria: $80(8.0 \%)$, \\
& Castilla y León: $81(8.1 \%)$, Castilla-La Mancha: $62(6.2 \%)$, Catalonia: $82(8.2 \%)$, \\
\hline
\end{tabular}


There were 1002 personal opinions gathered, which could be broken down into 2921 comments. This large number of comments was possible because each tourist could either make several comments related to the rural tourism experiences, or only one. These experiences were derived from three dimensions: cognitive (978 comments), affective (1163), and sensory (780). The percentages in Table 3 are expressed with respect to the 1002 tourist opinions. With research question 1 (How could netnography provide knowledge on the rural tourism experiences that customers pursue?) in mind, the cognitive experiences extracted are 'well-equipped' (31.8\%), 'cleanliness' (26.7\%), 'maintenance of facilities' (26.1\%), 'activities' (6.8\%), and 'value for money' (6.1\%). The affective experiences extracted are 'customer care' (65.5\%), 'coziness' (25.7\%), 'convenience' (12.2\%), 'relaxation' (9.8\%), and 'privacy' (2.9\%). The sensory experiences extracted are 'overall atmosphere' $(26.6 \%)$, 'rustic landscape' (20.3\%), 'gastronomy' (15.4\%), 'natural environment' (9.3\%), and 'lots of cultural tourism' (6.3\%). This study showed that rural tourism experiences in Spain consisted of a combination of cognitive, affective and sensory experiences (Mascarenhas, Kesavan, \& Bernacchi, 2006).

Table 3. Experiences in rural tourism.

[N=1002 tourist opinions, plural response]

\begin{tabular}{llll}
\hline Categories & Frequency & Categories & Frequency \\
\hline Cognitive & 978 & Sensory & 780 \\
Well-equipped & $319(31.8 \%)$ & Overall atmosphere & $267(26.6 \%)$ \\
Cleanliness & $268(26.7 \%)$ & Rustic landscape & $203(20.3 \%)$ \\
Maintenance of facilities & $262(26.1 \%)$ & Gastronomy & $154(15.4 \%)$ \\
Activities & $68(6.8 \%)$ & Natural environment & $93(9.3 \%)$ \\
Value for money & $61(6.1 \%)$ & Lots of cultural tourism & $63(6.3 \%)$ \\
& & & \\
Affective & 1163 & & \\
Customer care & $656(65.5 \%)$ & & \\
Coziness & $258(25.7 \%)$ & & \\
Convenience & $122(12.2 \%)$ & & \\
Relaxation & $98(9.8 \%)$ & & \\
Privacy & $29(2.9 \%)$ & & \\
\hline
\end{tabular}




\subsection{MCA and cluster analysis}

In order to synthetically investigate the association between the fifteen customer experiences, MCA was applied. According to Gifi (1990), if the first two dimensions dominate with regard to the variance explained and the third doesn't have more significance, just two dimensions are sufficient to analyze the data for MCA. In the present study, the contribution to the inertia, that is the percentage of variance, of dimension 1 and dimension 2 is $18.6 \%$ (Table 4). The low variance demonstrated seems to be caused by many variables or a similar pattern in an individual's online opinion expression. Even though the percentages of variances of the two dimensions are low, it doesn't imply a lack of explanatory power in MCA (Agapito, Valle, \& Mendes, 2014).

Table 4. Eigenvalues.

\begin{tabular}{lrr}
\hline & Dim. 1 & Dim. 2 \\
\hline Eigenvalue & 0.102 & 0.084 \\
Percentage of variance & $10.2 \%$ & $8.4 \%$ \\
Cumulative percentage of variance & $10.2 \%$ & $18.6 \%$ \\
& $(54.8 \%$ of var. of dim. $1 \& 2)$ & $(100.0 \%)$ \\
\hline
\end{tabular}

If the discrimination measure rating of a variable is high, it means that the variable is discriminated in the dimension (Nenadic \& Greenacre, 2007). In order to distinguish the high ratings from the low ratings, the discrimination measure ratings, which are higher than the means were highlighted in bold (Table 5). Variables such as 'natural environment' (0.278), 'activities' $(0.202)$, 'coziness' $(0.200)$, 'relaxation' ( 0.180$)$, 'lots of cultural tourism' (0.173), 'well-equipped' (0.122), 'privacy' $(0.094)$, 'overall atmosphere' $(0.086)$, and 'convenience' $(0.080)$ are discriminated in dimension 1. Variables such as 'maintenance of facilities' $(0.415)$, 'gastronomy' (0.260), 'value for money' (0.156), 'customer care' (0.119), 'cleanliness' $(0.064)$, and 'rustic landscape' $(0.034)$ are discriminated in dimension 2.

Table 5. Discrimination measures.

\begin{tabular}{lcclllll}
\hline Variables & Dim.1 & Dim.2 & Mean & Variables & Dim.1 & Dim.2 & Mean \\
\hline Cognitive & & & & Sensory & & & \\
Well-equipped & $\mathbf{0 . 1 2 2}$ & 0.094 & 0.108 & Overall atmosphere & $\mathbf{0 . 0 8 6}$ & 0.000 & 0.043 \\
Cleanliness & 0.004 & $\mathbf{0 . 0 6 4}$ & 0.034 & Rustic landscape & 0.001 & $\mathbf{0 . 0 3 4}$ & 0.018 \\
Maintenance of facilities & 0.000 & $\mathbf{0 . 4 1 5}$ & 0.208 & Gastronomy & 0.015 & $\mathbf{0 . 2 6 0}$ & 0.138 \\
Activities & $\mathbf{0 . 2 0 2}$ & 0.073 & 0.138 & Natural environment & $\mathbf{0 . 2 7 8}$ & 0.015 & 0.146 \\
Value for money & 0.089 & $\mathbf{0 . 1 5 6}$ & 0.123 & Lots of cultural tourism & $\mathbf{0 . 1 7 3}$ & 0.009 & 0.091
\end{tabular}




\begin{tabular}{|c|c|c|c|c|c|}
\hline Affective & & & Active total & 1.533 & 1.263 \\
\hline Customer care & 0.009 & 0.119 & 0.064 & & \\
\hline Coziness & 0.200 & 0.005 & 0.103 & & \\
\hline Convenience & 0.080 & 0.017 & 0.048 & & \\
\hline Relaxation & 0.180 & 0.000 & 0.090 & & \\
\hline Privacy & 0.094 & 0.002 & 0.048 & & \\
\hline
\end{tabular}

Numbers in bold correspond to ratings higher than the means

Taking synthetics into consideration for all information related to the fifteen variables gathered from customer experiences in rural tourism for dimension 1 and dimension 2, the positioning map for MCA was drawn (Figure2). It was presented on the map, focusing on the associations among tourist experiences in rural tourism. This study implemented dimension reduction and clustering at the same time, thus, the result of clustering was able to be derived on the positioning map for MCA (Markos et al., 2018). The respondents' coordinate values of MCA are performed to activate the k-mean clustering. Three clusters were determined by looking for maximizing the segment centers with minimizing the number of clusters and making a comparison of the results of lots of tests (Cairns, Sallu, \& Goodman, 2014). Figure 2 shows that there exist three key experience-based themes generated by representing rural tourism experiences located close to each other on the map. On the map, 'Coziness.y' indicates the response of a customer who mentioned coziness in his/her opinion, while 'Coziness.n' means the response of a customer who did not mention coziness in his/her opinion. The first group of rural tourism experiences is located above the horizontal axis. First of all, the theme of the first group was termed 'comfortdriven visitor', since it included affective experiences related to coziness, as well as cognitive experiences associated with rural tourist accommodations such as maintenance of facilities, cleanliness, and well-equipped. This theme is similar in comparison to the Spanish rural tourism segment 'enjoying a rural destination's services and facilities' found by Polo Peña et al. (2014), who pursue comfort from rural tourism destinations. It also can be seen that the segment 'seeking facilities-based comfort' exists in the Spanish rural tourism market, from the findings of Albaladejo-Pina and Díaz-Delfa (2009) that Spanish tourists value house size and the type of building when choosing rural tourism. For the first group, it seems to be important to mainly stay in rural accommodations of high quality. In sequence, the theme located in the right downward direction was named 'rural ambiance spender'. Given that the experiences contained in this group were rustic landscape, overall atmosphere, and gastronomy in sensory terms, as well as convenience and customer care in affective terms and value for money in cognitive terms, it is considered to be a group looking for enjoyment and quiet rest near rural tourism accommodations. Molera and Albaladejo-Pina (2007) defined the characteristics of Spanish tourists seeking an uncrowded, quality environment, quiet atmosphere and independence as a rural life tourist. In addition, since for Spanish tourists it is important whether or not rural tourism is located in the country-mountain area, they are willing to pay more for the location (Albaladejo-Pina \& Díaz-Delfa, 2009). Finally, the theme portrayed in the 
left downward direction was entitled 'active leisure seeker', since it seems to be a group that pursues enjoying active leisure in natural areas based on experiences such as activities, relaxation, privacy, natural environment, and lots of cultural tourism. In Spain, since the decade of the 1990s, it has already been very common that in many rural destinations, sophisticated tourist products are offered that include cultural or environmental routes, as well as sports, adventure or gastronomic activities (Cánoves et al., 2004). Among these products, perhaps the one that has grown the most in Spain is wine tourism (Molina et al., 2015) and adventure tourism linked to activities in nature (Martín \& del Campo, 2019). At a great distance, but with some growth in recent years is olive tourism, mainly in the olive producing areas of central and southern Spain (Millán-Vazquez de la Torre, Arjona-Fuentes, \& Amador-Hidalgo, 2017). Taken together, three rural tourism markets such as comfort-driven visitors, rural ambiance spenders, and active leisure seekers have been identified in Spain. With research question 2 (To what extent could netnography reveal significant experiential themes for rural tourism?) in mind, three key experiencebased themes and the corresponding rural tourism experiences were suggested (Table 6).

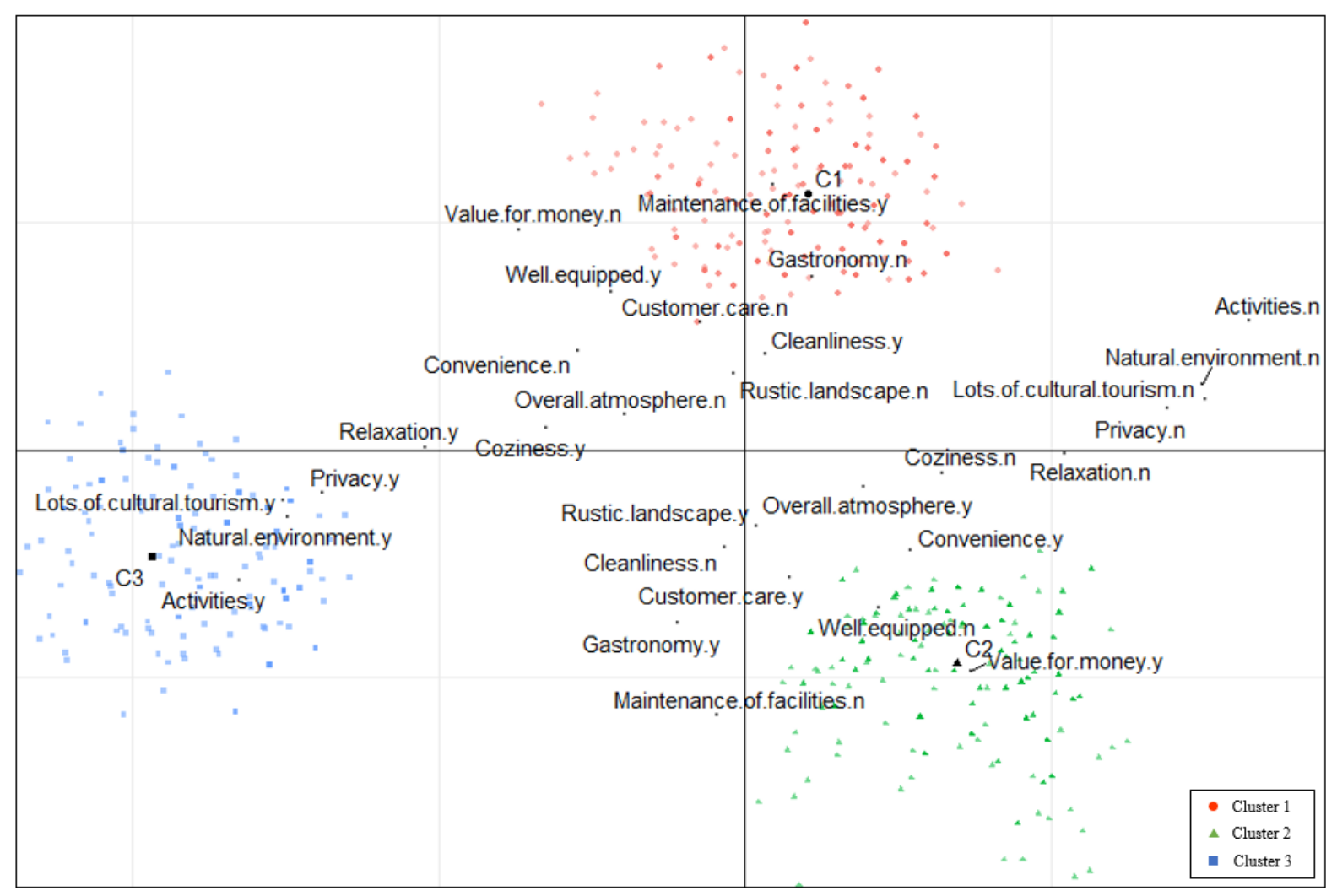

Figure 2. Positioning map for clustering of MCA. 
Table 6. Themes and detailed experiences.

\begin{tabular}{llll}
\hline & Comfort-driven visitor & Rural ambiance spender & Active leisure seeker \\
\hline Cognitive & Well-equipped & Value for money & Activities \\
& Cleanliness & & \\
& Maintenance of facilities & & \\
Affective & Coziness & Convenience & Relaxation \\
& & Customer care & Privacy \\
Sensory & & Overall atmosphere & Natural environment \\
& & Rustic landscape & Lots of cultural tourism \\
\hline
\end{tabular}

In this study, since it is based on the opinions written by tourists, the rural tourism experience variables were derived and market segmentation then proceeded, and references from tourists related to the experiences that make up each theme can be examined.

First of all, references related to the experiences such as well-equipped, cleanliness, maintenance of facilities, and coziness that make up the first theme 'comfort-driven visitor' are as follows:

"The house is fully equipped with everything you might need, from the bathrooms to the kitchen. We had the possibility to enjoy a spa and sauna, to make barbecues in the patio with garden, as well as to use the children's playroom and the football table itself."

$(\mathrm{Mo} * * * * *, 03 / 2017)$

"The house is clean and mostly tidy. It has everything you need, clean sheets and towels. Ideal for a weekend..."

$(\mathrm{Is} * * * *, 08 / 2016)$

"The facilities cannot be of better quality. The sports spaces are also very well maintained. It is the general comment of all who attend. I will visit again absolutely."

$(\mathrm{Ma} * * * * *, 09 / 2016)$

"The house was in perfect condition with equipment that we felt at home. It was very comfortable with everything we needed."

$\left(\mathrm{Ju}^{* * * * *}, 02 / 2019\right)$ 
Next, references related to the experiences such as value for money, convenience, customer care, overall atmosphere, rustic landscape, and gastronomy that influence on the second theme 'rural ambiance spender' are as follows:

"The house has a very large kitchen, a comfortable and cozy living room, two bathrooms and the water come out hot and with pressure. It has the more quality and value for the price. The house seemed excellent.”

$\left(\mathrm{Fr}^{* * * * * *}, 11 / 2017\right)$

"Regarding the stay, the house has enough rooms, many bathrooms, kitchen amenities, and above all, a fenced exterior where there is everything."

$\left(\mathrm{Mi}^{* * * * *}, 12 / 2017\right)$

"The owner is a woman of the most endearing who has gone out of her way to give us all the necessary explanations to make sure that we take full advantage of our vacation in her beautiful land. She opened the doors of her home in a detailed, generous and affectionate way."

$\left(\mathrm{Ma}^{* * * *}, 09 / 2017\right)$

"The house is super maintained, decorated in the last detail, and with a rustic but comfortable touch. It's nice to wake up with the crowing of the rooster .... what a big difference to the noise of the cars. The environment is a huge gift."

$\left(\mathrm{Ju}^{* * * * *}, 06 / 2019\right)$

"The house was clean and comfortable, with a terrace overlooking olive groves and hillsides. The landscape that surrounds the farmhouse is wonderful. There is an impossible greener valley in which absolute tranquility is breathed."

(Us*******, 09/2016)

"The breakfast very rich and super good quality. In the area, where to eat and what places to visit that were worth it."

(Da****, 07/2017) 
Finally, references related to the experiences such as activities, relaxation, privacy, natural environment, and lots of cultural tourism that make up the third theme 'active leisure seeker' are as follows:

"Perfectly equipped house and the tennis, soccer, and ping-pong court has been fun for seniors and children. We have enjoyed hiking and horse riding, too."

$\left(\mathrm{Ra}^{* * * * *}, 10 / 2018\right)$

"A very quiet place to fully enjoy your free time and disconnect from noise. Whether you go with friends or with children, you have everything at hand, zero worries. A beautiful cabin with all possible comforts."

$\left(\mathrm{Lu}^{* * * * *}, 05 / 2017\right)$

"An ideal place for a family getaway to enjoy nature. We chose here because we found it a beautiful and well- located natural enclave not only to make excursions in the countryside with the children but also to know the nearby villages."

$(\mathrm{En} * * * * *, 04 / 2017)$

"The even better environment has the Jewish quarter. It is full of natural charms and Roman, Arab and medieval heritage, you will find routes and excursions of all kinds."

(Ro****, 08/2018)

In order to capture the key themes and to identify the segmentation based on tourist experiences, k-mean clustering was performed, applying the respondents' coordinate values of MCA as input variables. Three segments were derived and, accordingly, three key themes were proposed. Segment centers and the quantity of individuals corresponding to each segment are shown in Table 7. Segment 1 is the largest, containing $41.1 \%$ of all individuals. In second place is segment 2 with $40.1 \%$ of participants. Finally, segment 3 is defined with $18.8 \%$ of individuals.

Table 7. Segment centers and quantity of individuals.

\begin{tabular}{llll}
\hline & $\begin{array}{l}\text { Comfort-driven visitor } \\
(\text { Segment 1) }\end{array}$ & $\begin{array}{l}\text { Rural ambiance spender } \\
\text { (Segment 2) }\end{array}$ & $\begin{array}{l}\text { Active leisure seeker } \\
\text { (Segment 3) }\end{array}$ \\
\hline Dim.1 & 0.006 & 0.015 & -0.047 \\
Dim.2 & 0.027 & -0.023 & -0.008 \\
Individuals & $412(41.1 \%)$ & $402(40.1 \%)$ & $188(18.8 \%)$ \\
\hline
\end{tabular}




\subsection{The profile of the three segments}

Fifteen rural tourism experiences were crossed with the three segments (Table 8). The chi-square test was performed because the cells with expected values of less than 5 did not exceed $20 \%$ of the total (11.1\%). Chisquare test (chi-square $=1252.9, \mathrm{p}$-value $=0.000)$ shows that there is a significant dependence relationship between the three segments and tourist experiences in rural tourism. Thereby, these results verify that in terms of experiences in rural tourism, the three segments are differentiated research question 3 (How valuable are the rural tourism segments in Spain based on the tourist experiences derived through the use of netnography?).

Table 8. Frequency distribution of experiences in rural tourism by segments.

\begin{tabular}{|c|c|c|c|c|c|c|c|c|}
\hline \multirow[t]{2}{*}{$\begin{array}{l}\text { Experiences } \\
\text { in rural tourism }\end{array}$} & \multicolumn{2}{|c|}{$\begin{array}{l}\text { Comfort-driven visitor } \\
\text { (Segment } 1 \text { ) }\end{array}$} & \multicolumn{2}{|c|}{$\begin{array}{l}\text { Rural ambiance spender } \\
\text { (Segment 2) }\end{array}$} & \multicolumn{2}{|c|}{$\begin{array}{l}\text { Active leisure seeker } \\
\text { (Segment 3) }\end{array}$} & \multicolumn{2}{|l|}{ Total } \\
\hline & Num. & $\%$ & Num. & $\%$ & Num. & $\%$ & Num. & $\%$ \\
\hline \multicolumn{9}{|l|}{ Cognitive } \\
\hline Well equipped & 204 & 63.9 & 35 & 11.0 & 80 & 25.1 & 319 & 100.0 \\
\hline Cleanliness & 155 & 57.8 & 74 & 27.6 & 39 & 14.6 & 268 & 100.0 \\
\hline Maintenance of facilities & 226 & 86.3 & 15 & 5.7 & 21 & 8.0 & 262 & 100.0 \\
\hline Activities & 0 & 0.0 & 7 & 10.3 & 61 & 89.7 & 68 & 100.0 \\
\hline Value for money & 2 & 3.3 & 58 & 95.1 & 1 & 1.6 & 61 & 100.0 \\
\hline \multicolumn{9}{|l|}{ Affective } \\
\hline Customer care & 209 & 31.9 & 325 & 49.5 & 122 & 18.6 & 656 & 100.0 \\
\hline Coziness & 102 & 39.5 & 62 & 24.0 & 94 & 36.4 & 258 & 100.0 \\
\hline Convenience & 32 & 26.2 & 85 & 69.7 & 5 & 4.1 & 122 & 100.0 \\
\hline Relaxation & 31 & 31.6 & 12 & 12.2 & 55 & 56.1 & 98 & 100.0 \\
\hline Privacy & 5 & 17.2 & 2 & 6.9 & 22 & 75.9 & 29 & 100.0 \\
\hline \multicolumn{9}{|l|}{ Sensory } \\
\hline Overall atmosphere & 99 & 37.1 & 142 & 53.2 & 26 & 9.7 & 267 & 100.0 \\
\hline Rustic landscape & 57 & 28.1 & 106 & 52.2 & 40 & 19.7 & 203 & 100.0 \\
\hline Gastronomy & 13 & 8.4 & 93 & 60.4 & 48 & 31.2 & 154 & 100.0 \\
\hline Natural environment & 12 & 12.9 & 9 & 9.7 & 72 & 77.4 & 93 & 100.0 \\
\hline Lots of cultural tourism & 10 & 15.9 & 2 & 3.2 & 51 & 81.0 & 63 & 100.0 \\
\hline
\end{tabular}

Chi-square $=1252.900, \mathrm{p}$-value $=0.000(<0.05)$

Regarding research question 4 (Which connections could be encountered between the various types of rural tourism trips and the experiences pursued?), Table 9 shows that there are differences among the three 
segments in terms of trip types (chi-square $=35.261, \mathrm{p}$-value $=0.000$ ). Amongst the trip types, the proportion of 'family' and 'friend group' is relatively high in segment 1 . In segment 2, the trip type has a relatively high proportion of 'couple'. In segment 3, 'couple' and 'family' trip types are evenly distributed.

Table 9. Frequency distribution of trip type by segments.

\begin{tabular}{|c|c|c|c|c|c|c|c|c|}
\hline \multirow[t]{2}{*}{ Trip type } & \multicolumn{2}{|c|}{$\begin{array}{l}\text { Comfort-driven visitor } \\
\text { (Segment 1) }\end{array}$} & \multicolumn{2}{|c|}{$\begin{array}{l}\text { Rural ambiance spender } \\
\text { (Segment 2) }\end{array}$} & \multicolumn{2}{|c|}{$\begin{array}{l}\text { Active leisure seeker } \\
\text { (Segment 3) }\end{array}$} & \multicolumn{2}{|l|}{ Total } \\
\hline & Num. & $\%$ & Num. & $\%$ & Num. & $\%$ & Num. & $\%$ \\
\hline Couple & 79 & 19.1 & 130 & 32.3 & 56 & 29.8 & 265 & 26.5 \\
\hline Family & 189 & 45.9 & 162 & 40.3 & 101 & 53.7 & 452 & 45.1 \\
\hline Friends & 144 & 35.0 & 110 & 27.4 & 31 & 16.5 & 285 & 28.4 \\
\hline Total & 412 & 100.0 & 402 & 100.0 & 188 & 100.0 & 1002 & 100.0 \\
\hline
\end{tabular}

Chi-square $=35.261, \mathrm{p}$-value $=0.000(<0.05)$

With regards to research question 5 (Which connections could be found between the various price levels tourists pay and the experiences pursued?), Table 10 shows that each segment is different from the others in the price level dimension (chi-square $=20.020, \mathrm{p}$-value $=0.000$ ). The '20-39 euros (medium price)' and '10-19 euros (low price)' price levels are the majorities in segment 1. Segment 2 mainly uses the rural tourism accommodations at the '20-39 euros (medium price)' price level. In segment 3, the '40-66 euros (high price)' price level is mainly distributed.

Table 10. Frequency distribution of price level by segments.

\begin{tabular}{|c|c|c|c|c|c|c|c|c|}
\hline \multirow[t]{2}{*}{ Price level } & \multicolumn{2}{|c|}{$\begin{array}{l}\text { Comfort-driven visitor } \\
\text { (Segment 1) }\end{array}$} & \multicolumn{2}{|c|}{$\begin{array}{l}\text { Rural ambiance spender } \\
\text { (Segment 2) }\end{array}$} & \multicolumn{2}{|c|}{$\begin{array}{l}\text { Active leisure seeker } \\
\text { (Segment 3) }\end{array}$} & \multicolumn{2}{|l|}{ Total } \\
\hline & Num. & $\%$ & Num. & $\%$ & Num. & $\%$ & Num. & $\%$ \\
\hline 10-19 euros & 60 & 14.5 & 51 & 12.7 & 35 & 18.6 & 146 & 14.5 \\
\hline 20-39 euros & 285 & 69.2 & 270 & 67.2 & 98 & 52.1 & 653 & 65.2 \\
\hline 40-66 euros & 67 & 16.3 & 81 & 20.1 & 55 & 29.3 & 203 & 20.3 \\
\hline Total & 412 & 100.0 & 402 & 100.0 & 188 & 100.0 & 1002 & 100.0 \\
\hline
\end{tabular}

Chi-square $=20.020, \mathrm{p}$-value $=0.000(<0.05)$

The attributes in demography are shown in Table 11. In order to respond to research question 6 (Which connections could be identified between the tourist demographic variables and the experiences they pursue?), whether the three segments differ in demographic variables was analyzed. No significant association was found 
for gender (chi-square $=1.702, \mathrm{p}$-value $=0.427$ ) while there was a difference among three segments regarding region $($ chi-square $=51.533, \mathrm{p}$-value $=0.016$ ) In segment 1 , the proportion of Catalonia, Galicia, La Rioja, Madrid, Murcia, Navarra, and Valencia is relatively high. Those who have visited to Andalusia, Asturias, Cantabria, Catalonia, Galicia, Canary Islands, and Basque Country mainly belong to segment 2. In segment 3, Aragón, Cantabria, Castilla-La Mancha, Castilla y León, Extremadura, Murcia, and Basque Country are majorities.

Table 11. Frequency distribution of demographic variables by segments.

\begin{tabular}{|c|c|c|c|c|c|c|c|c|}
\hline & \multicolumn{2}{|c|}{$\begin{array}{l}\text { Comfort-driven visitor } \\
\text { (Segment } 1)\end{array}$} & \multicolumn{2}{|c|}{$\begin{array}{l}\text { Rural ambiance spender } \\
\text { (Segment 2) }\end{array}$} & \multicolumn{2}{|c|}{$\begin{array}{l}\text { Active leisure seeker } \\
\text { (Segment 3) }\end{array}$} & \multicolumn{2}{|l|}{ Total } \\
\hline & Num. & $\%$ & Num. & $\%$ & Num. & $\%$ & Num. & $\%$ \\
\hline \multicolumn{9}{|l|}{ Gender } \\
\hline Man & 184 & 44.7 & 179 & 44.5 & 74 & 39.4 & 437 & 43.6 \\
\hline Woman & 228 & 55.3 & 223 & 55.5 & 114 & 60.6 & 565 & 56.4 \\
\hline Total & 412 & 100.0 & 402 & 100.0 & 188 & 100.0 & 1002 & 100.0 \\
\hline \multicolumn{9}{|c|}{ Chi-square $=1.702, \mathrm{p}$-value $=0.427(>0.05)$} \\
\hline \multicolumn{9}{|l|}{ Region } \\
\hline Andalusia & 29 & 7.0 & 32 & 8.0 & 11 & 5.9 & 72 & 7.2 \\
\hline Aragón & 27 & 6.6 & 26 & 6.5 & 17 & 9.0 & 70 & 7.0 \\
\hline Asturias & 23 & 5.6 & 38 & 9.5 & 14 & 7.4 & 75 & 7.5 \\
\hline Cantabria & 22 & 5.3 & 41 & 10.2 & 17 & 9.0 & 80 & 8.0 \\
\hline Castilla-La Mancha & 25 & 6.1 & 25 & 6.2 & 12 & 6.4 & 62 & 6.2 \\
\hline Castilla y León & 29 & 7.0 & 31 & 7.7 & 21 & 11.2 & 81 & 8.1 \\
\hline Catalonia & 34 & 8.3 & 34 & 8.5 & 14 & 7.4 & 82 & 8.2 \\
\hline Extremadura & 25 & 6.1 & 23 & 5.7 & 14 & 7.4 & 62 & 6.2 \\
\hline Galicia & 34 & 8.3 & 34 & 8.5 & 13 & 6.9 & 81 & 8.1 \\
\hline Balearic Islands & 5 & 1.2 & 1 & 0.2 & 1 & 0.5 & 7 & 0.7 \\
\hline Canary Islands & 5 & 1.2 & 10 & 2.5 & 2 & 1.1 & 17 & 1.7 \\
\hline La Rioja & 26 & 6.3 & 16 & 4.0 & 6 & 3.2 & 48 & 4.8 \\
\hline Madrid & 33 & 8.0 & 14 & 3.5 & 8 & 4.3 & 55 & 5.5 \\
\hline Murcia & 20 & 4.9 & 4 & 1.0 & 7 & 3.7 & 31 & 3.1 \\
\hline Navarra & 36 & 8.7 & 26 & 6.5 & 10 & 5.3 & 72 & 7.2 \\
\hline Basque Country & 8 & 1.9 & 18 & 4.5 & 9 & 4.8 & 35 & 3.5 \\
\hline Valencia & 31 & 7.5 & 29 & 7.2 & 12 & 6.4 & 72 & 7.2 \\
\hline Total & 412 & 100.0 & 402 & 100.0 & 188 & 100.0 & 1002 & 100.0 \\
\hline
\end{tabular}




\section{Discussion and conclusions}

This study was conducted in order to understand the rural tourism market segments in Spain, based on customers' natural perceptions of rural tourism experiences collected through the application of netnography. This study confirmed diversified rural tourism experiences are pursued by Spanish tourists, which means that they enjoy rural tourism with a variety of motivations and in diverse ways. According to the result of this study, it was confirmed that three market segments exist in rural tourism in Spain and three corresponding themes were also derived from the results. In this study, three key themes associated with rural tourism experiences were derived from the analysis and rural tourism markets were segmented. The characteristics of each key theme are as follows: above all, the first theme was named 'comfort-driven visitor' that lays emphasis on staying mainly in rural accommodations of high quality. It included tourist experiences such as maintenance of facilities, cleanliness, well-equipped, and coziness. This segment contains a high proportion of people who enjoy rural tourism in 'family' or 'friend group' units and seek accommodations at a relatively affordable price. This is presumably because the segment 'comfort-driven visitor' utilizes rural tourism with a focus on rural tourism facilities for gatherings with family or friends.

In sequence, the second theme was entitled 'rural ambiance spender', which is characterized by the pursuit of enjoyment and quiet rest around rural tourism accommodations. They pursue experiences in rural tourism such as convenience, customer care, overall atmosphere, rustic landscape, gastronomy, and value for money. This segment has a high proportion of 'couple' units and consists of people paying relatively medium prices for rural tourism accommodations. These results are presumed to stem from the fact that the segment 'rural ambience spender' seeks to enjoy the rural atmosphere and is willing to pay more money for this.

Finally, the third theme is 'active leisure seeker', which is characterized by pursuing a variety of ways to enjoy active leisure in natural areas. The experiences included are activities, relaxation, privacy, natural environment, and lots of cultural tourism. This group enjoys rural tourism in 'couple' or 'family' units. In this segment, the high price level is the most common price range. These results may be because the segment 'active leisure seeker' pursues a variety of activities around nature and rural areas and would gladly pay more for rural tourism accommodations that provide the conditions for such activities.

This study also confirmed that different themes related to rural tourism experiences were created according to the characteristics sought by customers, which were primarily based on trip types and price levels. The first theme 'comfort-driven visitor' was mainly composed of 'family' and 'friend group' as the type of rural tourism pursued by tourists. In the second theme 'rural ambiance spender', the proportion of 'couple' was relatively high, and in the third theme 'active leisure seeker', the trip type had a relatively high proportion of 'couple' and 'family'. In terms of price level, the first theme 'comfort-driven visitor' contained a number of tourists seeking low and medium price levels. While the medium price level category was mainly distributed into the second theme 'rural ambiance spender', high price level was the majority in the third theme 'active leisure seeker'. 


\subsection{Theoretical and methodological implications}

This study contributes to the existing literature in terms of theory and methodology. First, in the theoretical terms, this study was able to derive themes based on rural tourism experiences. The first theme 'comfort-driven visitor' is similar to 'inactives' in Portugal (Eusébio et al., 2017) that show a passive attitude and present low literacy levels and with higher familiarity levels with rural areas; 'the relaxers' in Scotland (Frochot, 2005) that prefer cheaper accommodations and do not practice many activities; 'passive tourists' in South Korea (Park \& Yoon, 2009) with low motivation but educated and wealthy; and 'enjoying rural destination's services and facilities' in Spain (Polo Peña et al., 2014) with the pursuit of comfort in rural tourism. According to Hearne and Salinas (2002), being well-equipped is a very important attribute in choosing rural tourism. Also, in terms of functionality, the maintenance of facilities is an important experience pursued by tourists (Polo Peña et al., 2014).

With regard to existing research, the second theme 'rural ambiance spender' is consistent with the segment 'ruralist' derived from Almeida, Correia, and Pimpão (2014) or the term 'rural explorers' determined by Dong et al., (2013). This group shares an interest in the rural lifestyle from other empirical research such as 'traditional ruralists' in Portugal (Kastenholz, Davis, \& Paul, 1999), 'the rurals' in Scotland (Frochot, 2005) or 'rural life tourists' in South-Eastern Spain (Molera \& Albaladejo-Pina, 2007). In rural tourism choices, customer care created through the interaction between rural tourism hosts and tourists should also be seen as an important attribute (Choo $\&$ Petrick, 2014). Additionally, previous studies show that a rustic landscape is a key resource of rural tourism (Figueiredo \& Raschi, 2012; Kastenholz et al., 2012). Simultaneously, gastronomy is regarded as an important attractor in maximizing the tourist experiences on a sensory level (Everett, 2008).

The final theme 'active leisure seeker' has connections with 'nature lovers' and 'active visitors' segments in Portugal (Eusébio et al., 2017; Kastenholz, Davis, \& Paul, 1999), 'the actives' and the gazers in Scotland (Frochot, 2005), and 'heritage \& nature seekers' in Gambia (Rid, Ezeuduji, \& Pröbstl-Haider, 2014). According to Chaminuka et al. (2012), outdoor activity should be considered a key attribute when choosing the rural tourism destination. In addition, the relaxation associated with emotional fullness is the most important experience that tourists seek in rural tourism (Richard Sharpley \& Jepson, 2011). Similar to the findings from previous studies, the natural environment plays an important role in choosing the rural tourism destination (Figueiredo \& Raschi, 2012; Kastenholz et al., 2012).

This study enables researchers to promote an experiential approach by understanding the experiences pursued by rural tourists. Although there are specific experiences in which each theme has a deeper relationship, this study found that tourists seek comprehensive experiences in terms of the cognition, affection and sensory factors. In the first theme 'comfort-driven visitor', experiences in the cognitive dimension related to facilities were most highly considered in the selection process (Knutson \& Beck, 2008). In the second theme 'rural ambiance spender', sensory experiences based on landscape and gastronomy were most emphasized and affective experiences related to customer care were considered next (Choo \& Petrick, 2014; Kastenholz et al., 2012). In the third theme 'active leisure seeker', affective experiences based on relaxation and sensory experiences derived 
from nature and culture were primarily considered to be of equal important (Frochot, 2005; Richard Sharpley \& Jepson, 2011).

Next, in the methodological terms, this study contributes to the existing literature. Above all, this study is significant in that it has quantitatively analyzed the tourist experiences and segmented the market through the qualitative application of netnography based on the tourists' voluntary opinions rather than on artificial consumer surveys (M. del F. García, 2011). This study started with collecting user-generated online content from netnography. This means that the tourists' voluntarily revealed consciousness was observed online. Thus, it was able to deeply reflect the tourists' potential needs and reduce the possibility of errors and limited choice in the response process, due to the characteristics of netnography such as direct access to research participants and higher reflective quality of online opinions (Kozinets, 2015). Also, the characteristics of online-based netnography make it possible to access a wide variety of data. Therefore, it is possible to get a sufficient amount of data in a relatively short time to enable various quantitative analyses (Xun \& Reynolds, 2010). The utility of data collection in terms of cost and time will be an important consideration for the use of netnography in many fields in the future. Finally, in this study, some quantitative analyses such as MCA, and clustering were performed by collecting online data generated from the experiences of 1002 customers. MCA is considered a good alternative segmentation method when respondents must only answer yes, no, or not sure, instead of the traditional factor-cluster segmentation based on Likert-type scales (Greenacre, 2016). Since the associations between respondents who are close to each other as well as other variables can be quantified through MCA, market segmentation becomes possible. It is also important to note that through MCA and clustering, this research was able overcome the limitation of data expression by collecting voluntary customer opinions (Markos et al., 2018).

\subsection{Practical implications}

Since tourist experiences based on the theme of each segment were identified, it's possible to know specifically which experiences to offer in order to implement each theme and attract the appropriate customer base. It allows for the establishment and implementation of effective marketing strategies for the targeted tourist groups. In this study, each theme includes relevant tourist experiences in three dimensions: cognitive, affective, and sensory. Therefore, it is possible to derive information on which destination identity should be pursued on the cognitive level, which memorable experiences should be provided on the affective level, and which sense should be stimulated for tourists on the sensory level, depending on the tourist attraction.

The results of this investigation can be applied to the tourism field. Rural tourism providers should choose one or two segments that are relevant to their own resources and environment and that are considered to be marketable in terms of segment size. They have to set up the primary target and secondary target to focus on. The need to derive a target-oriented positional strategy has emerged. Above all, if the first segment, 'comfort-driven visitor', is targeted, the core value to be offered to the customer is comfort. A positioning strategy should be centered on this core value, thus for example, 'like home' could be a positioning statement. The appealing point 
is that customers can enjoy special moments with the people who accompany them in a cozy atmosphere with sincere service. In order to implement this positioning strategy, improvements to the infrastructures, accommodation services and well-equipped facilities should be made.

Next, if the second segment, 'rural ambience spender', is set up as a core target, the core value to be provided to the customer is pleasure in rural environments. A positioning strategy should be developed around this core value, thus for example, 'unusual delight' can be a positioning statement. The appealing point of this positioning strategy is that a specific rural tourism experience can offer pleasure beyond customer expectations. In order to employ this positioning strategy, it is necessary to secure and improve the surrounding or complementary facilities that can be utilized and enjoyed. In addition, it is necessary to offer an atmosphere where tourists can feel an easygoing environment and friendly, warm hosts appeal to them.

Finally, if the third segment, 'active leisure seeker', is targeted, the core value is activity. A positioning strategy should be developed around this core value, thus for example, 'revitalization' can be a positioning statement. The appealing point of this positioning strategy is that a specific rural tourism experience adds creative inspiration and vitality to the customers' lives. Based on this idea, it is necessary to be able to discover something to experience by utilizing the surrounding cultural tourism as well as various activities to be able to be enjoyed in the natural environment. Based on this positioning strategy, it is necessary to develop the appropriate experiences that can be provided for the target, and to consistently communicate the positioning statement through the customer contact points of non-mass media communications such as the web site, social network services (SNS) and word-of-mouth. When evaluating management performance, the indicators appropriate for the characteristics of a selected segment should be developed and utilized in the evaluation process.

\subsection{Future lines of research and limitations}

Netnography based on user-generated online content can have a wide range of applications in tourism research. First, segmentation by MCA after the collection of user-generated online content through netnography can be applied to diverse tourism research such as wine tourism, ecotourism, cruise tourism, and hospitality, as well as rural tourism. It would be possible to subdivide each unique tourism market into segments based on customer perspective by quantifying the associations between the respondents and variables of each market. In addition, through using the attributes derived from this netnography study, various research methodologies such as visual Q approach, choice experiments, and best-worst scaling, which are able to better define the market, can also be applied to these tourism studies.

However, the limitation of this study is that it was impossible to collect and verify the sociodemographic features (age, income, occupation, place of residence, etc.) of the customers since the study only analyzed opinions that the customers had already voluntarily left in online communities. These aforementioned aspects are especially interesting because they are considered sociodemographic variables and may have some influence on the customer's choices. Furthermore, this study is limited by a lack of information on customers' lifestyles and 
motivations for rural tourism, which can be obtained through the customers' direct responses. This shortage of information made it difficult to analyze the data more stereoscopically. For the future, supplementation through further offline quantitative research is needed. It would be necessary to combine online data from netnography with offline data such as personal interviews and focus group interviews to generalize them. 


$$
49
$$


STUDY 2

\section{Exploring rural tourism experiences through subjective perceptions: A visual $Q$ approach}

Wookhyun An, Silverio Alarcón,

Exploring rural tourism experiences through subjective perceptions: A visual Q approach, Spanish Journal of Agricultural Research, 18 (3), 2020, https://doi.org/10.5424/sjar/2020183-16572

Journal Citation Reports Ranking 2019: Spanish Journal of Agricultural Research was ranked 28 out of 58 in the area of 'Agriculture, Multidisciplinary'. 
51 


\title{
Exploring rural tourism experiences through subjective perceptions: A visual $Q$ approach
}

\begin{abstract}
Aim of study: To explore rural tourists' views in order to identify different market segmentation in relation to rural tourism experiences.

Area of study: The research was carried out in Spain.

Material and methods: Visual Q, a personal subjectivity research methodology, was applied to present both visual and linguistic aspects so that tourists can more intuitively recognize and answer questions regarding their experiences. Thus, it enables researchers to explore rural tourism experiences from tourists' subjective perceptions. Main results: There are three primary segments of tourist experiences in rural tourism: 'Occasion driven visitor', 'Active leisure seeker' and 'Rural immersion pursuer' and across all visitors, a common pursuit of 'A pleasant break'.

Research highlights: This paper suggests that rural tourism should offer a range of value propositions, thereby escaping the existing monotonous ones.
\end{abstract}

Additional key words: mixed methods research; tourists'subjectivity; segmentation

Abbreviations used: PCA (Principal Component Analysis); SE (Standard Error) 


\section{Introduction}

Rural tourism in Spain was developed for the purpose of overcoming the tendency of Spanish tourism to be focused on sun and beach, a focus which had reached maturity (García, 1996; Besteiro, 2006). Additionally, rural tourism can assist agriculture, where holdings are at risk from economic pressures (Blanco, 1996). Rural areas have made an effort to provide special experiences through making an investment in the cultural and natural heritage in response to the increasing demand for the possibility to escape from the city and experience the tranquility of the countryside (García, 1996; Yagüe, 2002; Besteiro, 2006). This has helped rural tourism grow rapidly. Between 2013 and 2017, after a long period of ups and downs, the total annual number of tourists in rural tourism in Spain increased by more than one and a half million and exceeded four million (INE, 2017).

But despite the growth in scale, the occupancy rates and the average stay length in rural tourism have decreased, leading to a decline in competitiveness (Campón-Cerro et al., 2017). According to INE (2018), its prices have risen at a much lower rate than the rest of the sector. This is due to the fact that in rural tourism, there is greater sensitivity to price among tourists (Correia Loureiro \& Miranda González, 2006). The answer to the question "What do rural tourism clients look for when they travel?" is merely "to do nothing" (Grande \& Maynar, 2010). This is evidence that the value which rural tourism proposes to tourists is limited by a lack of diversity. Therefore, it is necessary to take measures to overcome the limit of price sensitivity through various customer value propositions. A variety of customer value propositions in rural tourism can be made from providing clients with diverse experiences.

Tourist experiences are accepted as the most critical factor of innovation, competitiveness and success in the tourism field (Neuhofer, 2016; Quinlan Cutler et al., 2018). Accordingly, several studies in the field of rural tourism have been conducted to understand tourists' experiences (Figueiredo \& Raschi, 2012; Choo \& Petrick, 2014; Kastenholz et al., 2018; Pelegrín et al., 2019) and to analyze tourists' experiences-based market segmentation (Agapito et al., 2014; Kastenholz et al., 2015). It is essential to understand the subjective meanings and perceptions related to individual experiences in rural tourism (Uriely, 2005). Tourist experiences should be understood as highly variable and subjective, characterized mainly by emotional and symbolic aspects (Otto \& Ritchie, 1996). However, existing quantitative statistical methodologies make it possible for researchers' viewpoints to intervene in data collection by previously establishing a hypothesis about the experience of the tourist group and then merely verifying it, and they also tend to ignore in-depth information about individuals by relying on collective statistics and comparisons. Thus, many scholars argue that it is necessary to investigate with supplementary methods that enable a deeper understanding of tourist experiences (Neuhofer, 2016; Brown \& Osman, 2017; Quinlan Cutler et al., 2018). The Q methodology, which is a personal subjectivity research methodology, is recognized as an appropriate alternative to complement the limitations of existing research and enables researchers to explore tourist experiences in rural tourism and to describe the important experiences extracted from tourists' subjective perceptions (Swaffield \& Fairweather, 1996). It is a very powerful methodology used to reveal problems to which personal subjectivity is related (McKeown \& Thomas, 2013). At the same time, it has clear characteristics of a quantitative statistical approach and a qualitative assessment of individual concepts (Davis \& Michelle, 2011). 
In this study, the visual Q methodology was applied to present both visual and linguistic aspects so that tourists can more intuitively recognize and answer questions regarding their experiences. The purpose of this study was to explore rural tourists' perceptions in order to identify different market segmentation in relation to rural tourism experiences for rural tourism providers, as well as policymakers in local governments, amongst others.

\section{Methods}

Visual Q methodology was applied in accordance with McKeown and Thomas's (2013) five steps: 'Concourse' definition, 'Q-set' development, 'P-set' definition, 'Q-sort' collection and factor analysis.

The concourse of these steps provides the process to collect the population's thoughts, opinions, recognitions and perceptions related to the topic of the study (Van Exel \& De Graaf, 2005; Previte et al., 2007). In this study, we also used netnography methodology, which enables us to determine consumer awareness and conduct perception research by depicting consumer behavior in the online environment (Kozinets, 2002) in order to arrive at the 'Concourse' definition. We extracted experiences by analyzing consumers' opinions about rural tourism on online communities. Based on the number of visitors, we selected three target online communities: toprural.com, escapadarural.com, and clubrural.com and we analyzed tourist experiences in rural tourism in the following way: analyzed the opinions posted within the last 3 years; analyzed opinions assigned by regions, price level and trip type; reflected not only positive opinions, but negative ones as well; applied the opinions from the unpopular places as well as from the popular ones; opinions were individually reviewed by both researchers. We analyzed 1,000 opinions and derived 50 experiences that tourists pursue in rural tourism (Figure 3).

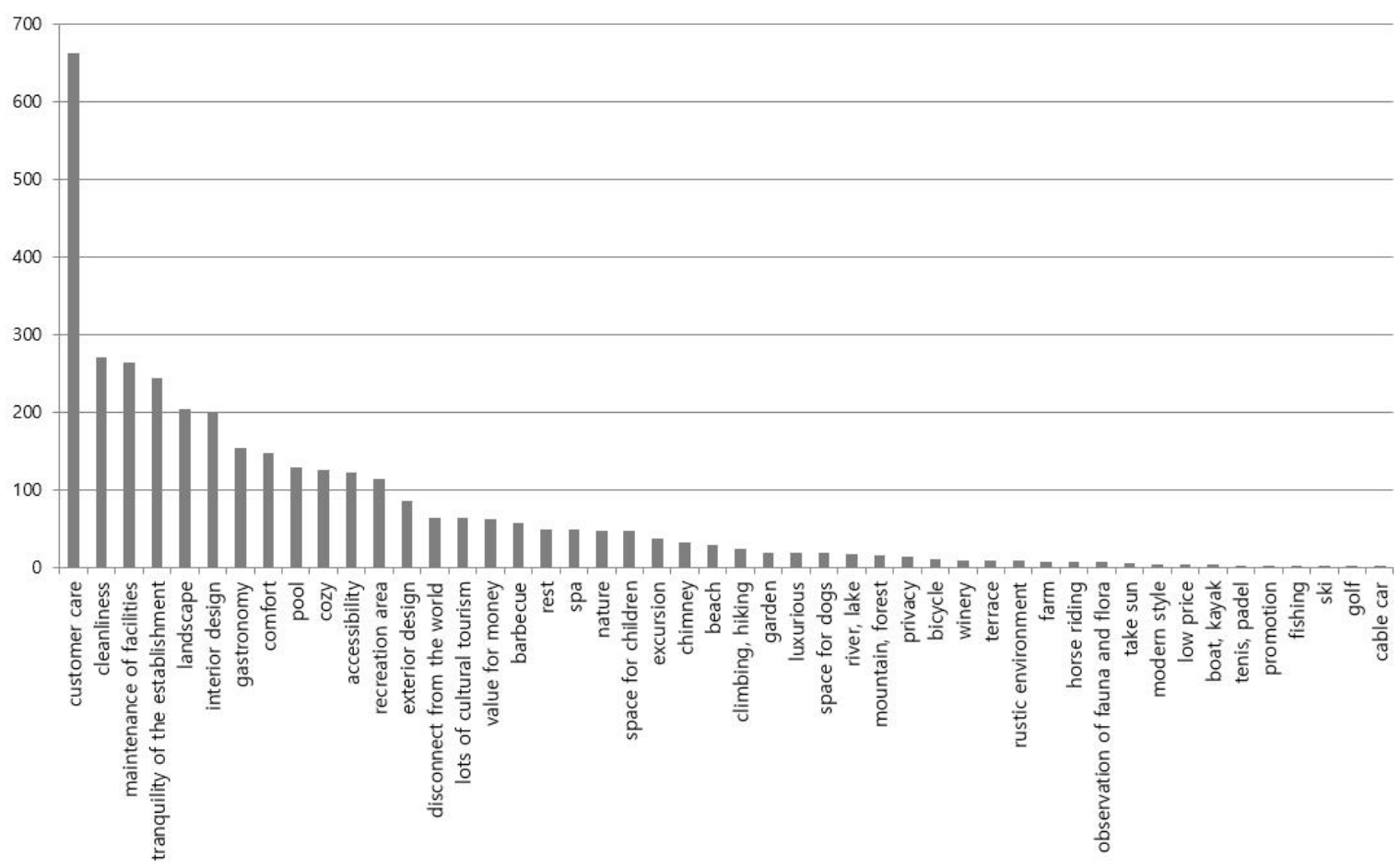

Figure 3. Experiences in rural tourism. $\mathrm{N}=1,000$, Plural response, Unit: persons 
The Q-set is the step of confirming attributes such as words, sentences and images to be used in the Q survey. The Q-set consists of the thematic attributes extracted from the concourse, which will be applied in the Q analysis. The selection of the Q-set is very important but is largely determined by the discretion of the researcher through structured or unstructured methods (McKeown, 1998). Regardless of which structure is selected, researchers should choose opinions that are different from each other to endow the Q-set with representativeness (Van Exel \& De Graaf, 2005). All possible expressions related to the subject extracted from all possible viewpoints are utilized in the Q-set (Zabala, 2014). Usually a Q-set collection is made up of scales of between 40 and 80 attributes (Watts \& Stenner, 2012). In this study, we decided to use all of the 50 possible experiences in rural tourism as the Q-set discovered through the use of the netnography methodology (Kozinets, 2015). We selected photographs that described the 50 experiences well and created cards that could display images and sentences at the same time (Figure 4).

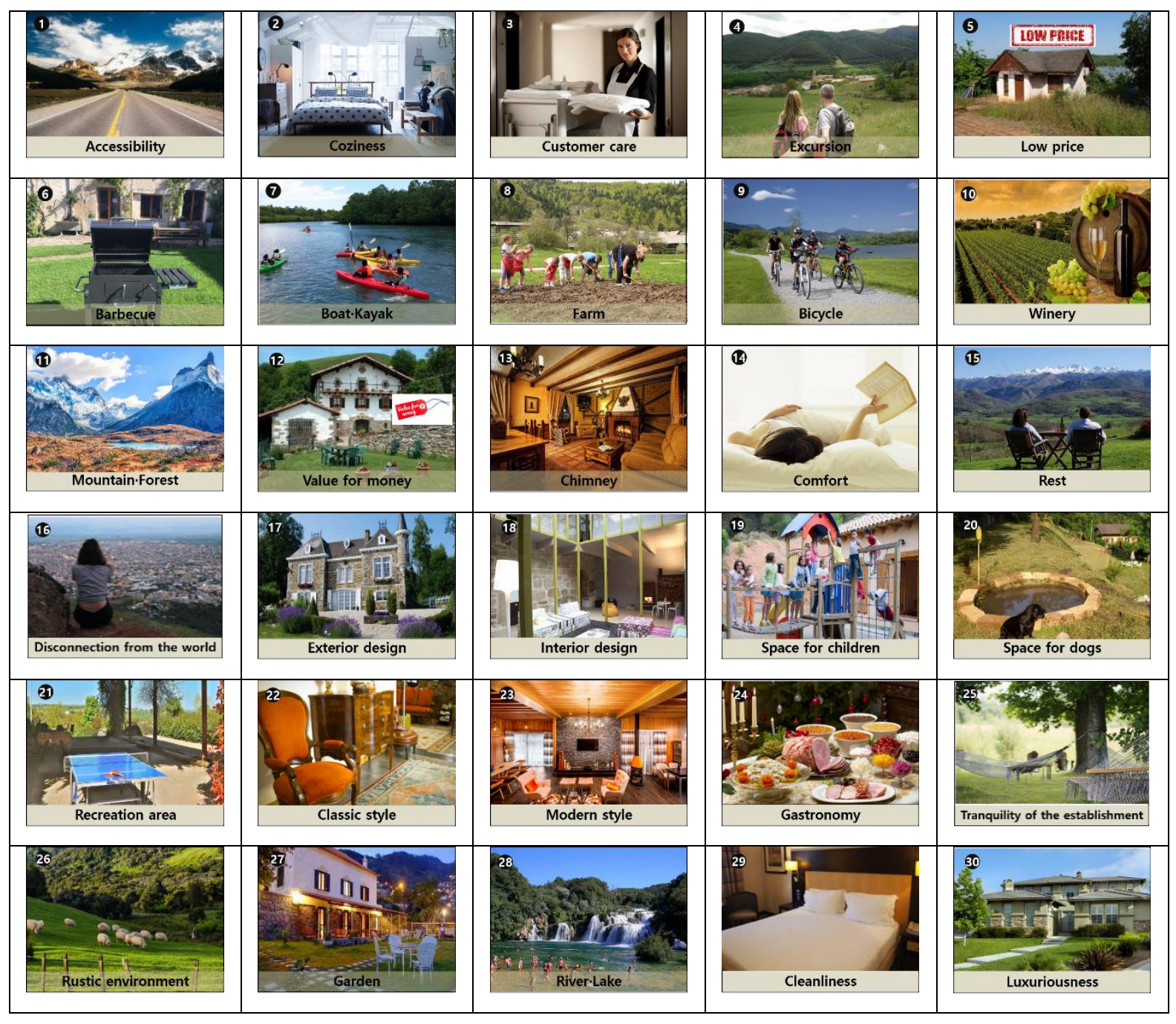




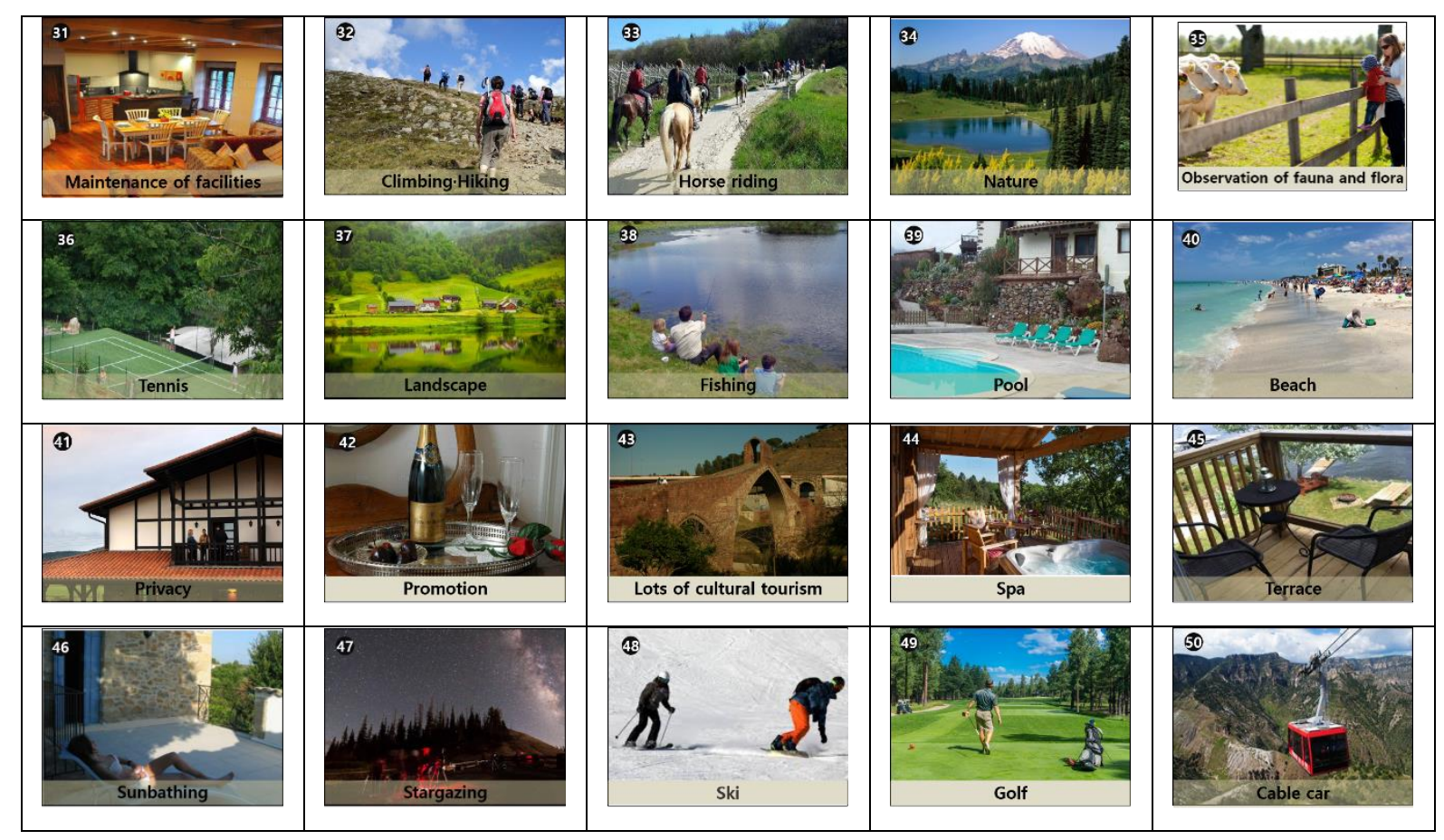

Figure 4. The factorial design of the Q-set. Source: Google images labeled for reuse

The P-set means a group of interviewees that participate in Q-sort collection. The P-set plays a role in the representation of the collected opinions. Since the purpose of the research completed the Q methodology is not to generalize, but rather to analyze individual subjectivity, the number of samples, which enables us to generate and compare factors, is sufficient. Usually, the number of the P-set is not higher than the Q-set. The P-set is selected by following a structured sampling with experience and knowledge on the subject irrespective of the random sampling (Van Exel \& De Graaf, 2005). Those who participate in the research should be chosen if they have the possibility of expressing central or interesting viewpoints (Watts \& Stenner, 2012). The current P-set was created by recruiting participants in two major groups: tourists with travel experience related to rural tourism during the past three years and experts like professors, officers and members of rural tourism organizations. Our P-set consisted of 50 participants: 25 customers and 25 experts (Table 12).

Table 12. Organization of the P-set.

\begin{tabular}{ll}
\hline \multicolumn{1}{c}{ Demographic category } & \multicolumn{1}{c}{ Answers } \\
\hline Expertise & Customer: $25(50.0 \%)$, Expert: $25(50.0 \%)$ \\
Gender & Male: $18(36.0 \%)$, Female: $32(64.0 \%)$ \\
Age & Under 30: $10(20.0 \%), 30-39: 13(26.0 \%), 40-49: 13(26.0 \%)$, \\
& $50-59: 10(20.0 \%), 60$ and older: $4(8.0 \%)$
\end{tabular}


Frequency of visits in 3 years

Trip type of rural tourism

Preferable price for one night per person
1-4 times: 40 (80.0\%), 5-9 times: 6 (12.0\%), 10 and more

times: $4(8.0 \%)$

Family: 16 (32.0\%), Friends group: 24 (48.0\%), Couple: 10

$(20.0 \%)$

$<€ 19: 2$ (4.0\%), €20 39: 30 (60.0\%), €40 59: 16 (32.0\%),

$>€ 60: 2(4.0 \%)$

According to Coogan and Herrington (2011), the Q-sort sequences the opinions that make up the Q-set and shows the participants' subjectivities (Figure 5). Participants were expected to sort the attributes of the Q-set in accordance with their subjective preferences. At the beginning, participants classified the photographs into three groups; what they feel is most important, what they feel is most unimportant and what they feel neutral about. Then they sorted 50 photographs to the Q-grid map distributed by a force similar to normal distribution which was divided into 11 groups from 'most unimportant' (-5) to 'most important' (+5). They positioned things that they thought were the most important on the right side and the things they thought were the most unimportant to the left side. Finally, they were asked to account for the reason for their selections by qualitative interview. Such interviews contribute to improving the quality of research as well as assist in making plenty of data available with the result from the statistical analysis (Fairweather \& Swaffield, 2001). These additional qualitative studies allow us to delve deeper into the nature of influential factors and to understand the meaning of the critical attributes categorized by respondents (Fairweather \& Swaffield, 2001).

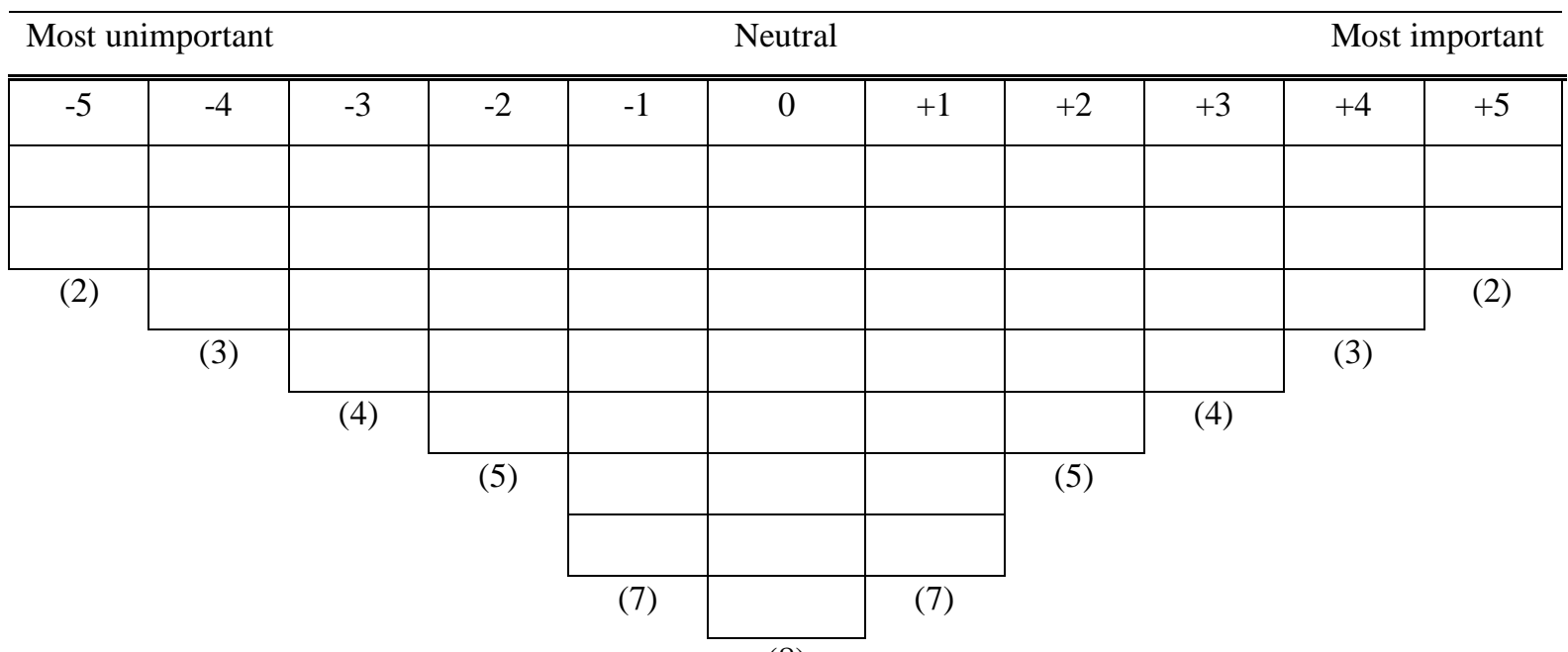

(8)

Figure 5. The Q-sort distribution. 
The final step of visual Q is factor analysis. It is possible to create distinguishable groups of participants with Q-grids, which are meaningfully similar and meaningfully distinct (Davis \& Michelle, 2011). This is a large point of difference from the R methodology, which is a correlation analysis among variables according to Previte et al. (2007). The factor loading means the degree of a Q-sort's relationship with a factor, is counted for every Qsort (Van Exel \& De Graaf, 2005). All participants with a similar viewpoint can be analyzed on the same factor since the pattern of their opinions that express their subjectivity is similar (Coogan \& Herrington, 2011). A participant's high factor loading means that the association of this participant with the factor is high as well (Pereira et al., 2016).

The Q method package that was developed for R programming, has been applied to the present study (Zabala, 2014). This package executes the principal component analysis (PCA) instead of the factor analysis from the Q methodology. PCA is already available for R methodology, and the results from both methodologies are similar (McKeown \& Thomas, 2013). Varimax, which is the most commonly used, was applied for the rotation of components.

\section{Results}

\subsection{Quantitative findings}

It is not necessary to determine a mathematically correct solution or one single goal in deciding the number of factors included in the Q methodology. More important are clarity and simplicity (Cairns et al., 2014). Factors were extracted by seeking the best way to maximize the percentage of the explained variance with the minimal number of factors and comparing the results through multiple tests (Cairns et al., 2014). Thus, in this study, we composed three factors that, in total, explained $57 \%$ of the variance. In accordance with the result of this study, the participants who classified a set of image cards similarly were chosen to belong to the same factor (Table 13). The first factor formed $23 \%$ of the explained variance and consisted of 21 participants from the Q-sorts. The second factor formed $17 \%$ of the explained variance and was made up of thirteen participants from the Q-sorts. The third factor formed $17 \%$ of the explained variance and consisted of 11 participants from the Q-sorts. Five participants were not related to any factor since their factor loadings were not prominent enough in any factor to be classified as one factor (Table 14).

Table 13. Q-sort factor loadings.

\begin{tabular}{llll}
\hline ID & F1 & F2 & F3 \\
\hline 1 & 0.401 & $\mathbf{0 . 6 2 3}$ & 0.206 \\
2 & 0.046 & 0.515 & $\mathbf{0 . 5 4 0}$ \\
3 & $\mathbf{0 . 5 0 1}$ & 0.227 & 0.101 \\
4 & 0.377 & $\mathbf{0 . 7 0 1}$ & 0.328 \\
5 & 0.395 & 58 & 0.186
\end{tabular}




\begin{tabular}{|c|c|c|c|}
\hline & -0.001 & 0.348 & 0.723 \\
\hline & 0.523 & 0.289 & 0.547 \\
\hline & 0.205 & 0.579 & 0.503 \\
\hline & 0.730 & 0.077 & 0.299 \\
\hline & 0.627 & 0.032 & 0.237 \\
\hline & 0.675 & 0.020 & 0.272 \\
\hline & 0.284 & 0.395 & 0.571 \\
\hline & 0.152 & 0.350 & 0.663 \\
\hline & 0.341 & 0.209 & 0.443 \\
\hline & 0.589 & 0.257 & 0.368 \\
\hline & -0.051 & 0.228 & 0.613 \\
\hline & 0.565 & 0.471 & 0.227 \\
\hline & 0.713 & -0.001 & 0.395 \\
\hline & 0.338 & 0.021 & 0.723 \\
\hline & 0.200 & 0.161 & 0.717 \\
\hline & 0.708 & 0.404 & 0.362 \\
\hline & 0.748 & 0.134 & 0.345 \\
\hline & 0.601 & 0.006 & 0.600 \\
\hline & 0.679 & 0.278 & -0.087 \\
\hline & 0.325 & 0.320 & 0.359 \\
\hline & 0.613 & 0.432 & 0.060 \\
\hline & 0.156 & 0.578 & 0.634 \\
\hline & 0.563 & 0.379 & 0.512 \\
\hline & 0.263 & 0.606 & 0.429 \\
\hline & 0.152 & 0.688 & 0.476 \\
\hline & 0.578 & 0.429 & 0.089 \\
\hline & 0.350 & 0.475 & 0.496 \\
\hline & 0.254 & -0.030 & 0.721 \\
\hline & 0.622 & 0.084 & 0.425 \\
\hline & 0.693 & 0.320 & 0.193 \\
\hline & 0.372 & 0.593 & 0.257 \\
\hline & -0.032 & 0.824 & 0.222 \\
\hline & 0.551 & -0.012 & 0.476 \\
\hline & 0.103 & 0.826 & 0.131 \\
\hline & 0.681 & -0.010 & 0.004 \\
\hline & 0.787 & 0.238 & 0.075 \\
\hline & 0.271 & 0.523 & 0.160 \\
\hline
\end{tabular}




$\begin{array}{llll}43 & 0.456 & 0.535 & 0.444 \\ 44 & \mathbf{0 . 5 9 6} & 0.268 & 0.369 \\ 45 & \mathbf{0 . 6 9 1} & 0.237 & 0.079 \\ 46 & 0.216 & 0.191 & \mathbf{0 . 6 7 0} \\ 47 & -0.232 & \mathbf{0 . 5 7 3} & 0.143 \\ 48 & \mathbf{0 . 5 4 2} & 0.323 & 0.423 \\ 49 & 0.390 & \mathbf{0 . 5 8 4} & -0.150 \\ 50 & 0.483 & \mathbf{0 . 5 6 6} & -0.015 \\ \% \text { Expl. Var. } & 23.00 \% & 17.00 \% & 17.00 \%\end{array}$

The bold numbers refer to the sorting of the corresponding factor. The IDs that do not contain any bold numbers indicate that the factor loadings are not distinguishing enough to correspond to any factor.

Table 14. Q-sort for each factor.

\begin{tabular}{lccccc}
\hline Category & $\begin{array}{c}\text { F1 - } \\
\text { Active leisure } \\
\text { seeker }\end{array}$ & $\begin{array}{c}\text { F2 - } \\
\text { Occasion driven } \\
\text { visitor }\end{array}$ & $\begin{array}{c}\text { F3 - } \\
\text { Pleasure spender }\end{array}$ & $\begin{array}{c}\text { Q-sort } \\
\text { excluded }\end{array}$ & Total \\
\hline Users & $2,4,8,12,16,25,30$ & $1,3,9,10,11,17,24$ & & 28 & 15 \\
Experts & $6,13,27,29$ & $5,21,26$ & $18,19,20,22,23$ & $7,14,15$ & 15 \\
Total Q-sort & 11 & 10 & 5 & 4 & 30 \\
\hline
\end{tabular}

In order to identify the characteristics of each factor and the differences between the factors, it was necessary to examine the ranking of experiences indicated by the z-score, which is a weighted average of the values that the Q-sorts intimately connected with a factor assigned to an experience and the factor score (Zabala $\&$ Pascual, 2016). The interpretation of the factors was completed with priority given to the experiences of a factor that had a z-score above $|1.00|$ and distinguished from other factors (Table 15). For example, 'Cleanliness (2.076)', 'Comfort (1.463)', and 'Customer care (1.262)' were the most important experiences in rural tourism for the first factor. For the second factor, 'Nature (2.049)', 'Landscape (1.929)', and 'Mountain·Forest (1.296)' were the most important. For the third factor, the most important experiences were 'Nature (1.734)', 'Disconnection from the world (1.383)', and 'Rustic environment (1.342)'. Finally, 'Gastronomy', 'Rest', and 'Lots of cultural tourism' were common experiences with importance for all factors.

Table 15. Z-scores and factor scores for each experience.

\begin{tabular}{llllllll}
\hline \multirow{2}{*}{ Experiences } & \multicolumn{3}{c}{ Z-scores } & & \multicolumn{3}{c}{ Factor scores } \\
\cline { 2 - 7 } & & F1 & F2 & F3 & F1 & F2 & F3 \\
\hline
\end{tabular}




\begin{tabular}{|c|c|c|c|c|c|}
\hline Accessibility & 0.849 & -0.031 & -0.277 & 2 & 0 \\
\hline Coziness & 1.168 & 0.550 & -0.213 & 3 & 1 \\
\hline Customer care & 1.262 & 0.310 & 0.198 & 3 & 1 \\
\hline Excursion & 0.310 & 0.988 & 1.196 & 1 & 3 \\
\hline Low price & -0.381 & 0.604 & -0.639 & -1 & 1 \\
\hline Barbecue & 0.576 & -1.379 & -0.142 & 1 & -4 \\
\hline Boat·Kayak & -1.262 & 0.118 & -0.363 & -3 & 0 \\
\hline Farm & -0.924 & -1.330 & 0.401 & -2 & -3 \\
\hline Bicycle & -0.504 & -0.117 & 0.690 & -1 & 0 \\
\hline Winery & 0.092 & -1.240 & 0.294 & 0 & -3 \\
\hline Mountain $\cdot$ Forest & 0.059 & 1.296 & 0.830 & 0 & 4 \\
\hline Value for money & 1.192 & 0.978 & 0.625 & 3 & 3 \\
\hline Chimney & 0.395 & -1.052 & 0.001 & 1 & -2 \\
\hline Comfort & 1.463 & 0.168 & -0.090 & 4 & 0 \\
\hline Rest & 1.353 & 1.156 & 1.592 & 4 & 3 \\
\hline Disconnection from the world & 0.616 & 0.528 & 1.383 & 1 & 1 \\
\hline Exterior design & -0.652 & -0.284 & -0.078 & -1 & -1 \\
\hline Interior design & -0.035 & -0.330 & -0.625 & 0 & -1 \\
\hline Space for children & 0.548 & -1.348 & 0.818 & 1 & -4 \\
\hline Space for dogs & -0.732 & -1.212 & -0.074 & -2 & -3 \\
\hline Recreation area & 0.063 & -0.860 & -0.543 & 0 & -2 \\
\hline Classic style & -1.000 & -1.503 & -1.496 & -3 & -4 \\
\hline Modern style & -1.091 & -0.873 & -1.559 & -3 & -2 \\
\hline Gastronomy & 1.665 & 1.983 & 1.475 & 5 & 5 \\
\hline Tranquility of the establishment & 0.972 & 0.969 & 0.975 & 2 & 3 \\
\hline Rustic environment & 0.060 & 0.812 & 1.342 & 0 & 2 \\
\hline Garden & 0.431 & -0.419 & -0.298 & 1 & -1 \\
\hline River.Lake & -0.397 & 0.938 & 0.820 & -1 & 2 \\
\hline Cleanliness & 2.076 & 0.641 & 0.329 & 5 & 1 \\
\hline Luxuriousness & -1.277 & -0.894 & -1.653 & -4 & -2 \\
\hline Maintenance of facilities & 1.063 & 0.237 & -0.342 & 3 & 0 \\
\hline Climbing $\cdot$ Hiking & -0.027 & 0.811 & 1.127 & 0 & 2 \\
\hline Horse riding & -0.937 & -0.593 & 0.754 & -2 & -1 \\
\hline Nature & 0.878 & 2.049 & 1.734 & 2 & 5 \\
\hline Observation of fauna and flora & -0.100 & 0.692 & 1.151 & -1 & 2 \\
\hline Tennis & -1.564 & -1.650 & -1.825 & -4 & -5 \\
\hline Landscape & 0.624 & 1.929 & 1.129 & 2 & 4 \\
\hline
\end{tabular}




$\begin{array}{lrrrrrr}\text { Fishing } & \mathbf{- 1 . 2 5 2} & \mathbf{- 1 . 0 5 6} & -0.073 & \mathbf{- 3} & -2 & 0 \\ \text { Pool } & -0.007 & 0.014 & -0.440 & 0 & 0 & -2 \\ \text { Beach } & -0.659 & 0.892 & \mathbf{- 1 . 7 6 8} & -2 & 2 & \mathbf{- 4} \\ \text { Privacy } & 0.776 & 0.308 & -0.413 & 2 & 1 & -1 \\ \text { Promotion } & -0.010 & -0.410 & 0.031 & 0 & -1 & 0 \\ \text { Lots of cultural tourism } & \mathbf{1 . 4 1 9} & \mathbf{1 . 2 7 1} & \mathbf{1 . 1 3 5} & \mathbf{4} & \mathbf{4} & \mathbf{3} \\ \text { Spa } & -0.749 & -0.238 & -0.338 & -2 & 0 & -1 \\ \text { Terrace } & 0.320 & -0.443 & -0.680 & 1 & -1 & -2 \\ \text { Sunbathing } & -0.348 & -0.245 & \mathbf{- 1 . 4 6 8} & -1 & -1 & \mathbf{- 3} \\ \text { Stargazing } & -0.488 & 0.372 & 0.027 & -1 & 1 & 0 \\ \text { Ski } & \mathbf{- 2 . 0 9 2} & 0.018 & \mathbf{- 1 . 4 7 2} & \mathbf{- 5} & 0 & \mathbf{- 3} \\ \text { Golf } & \mathbf{- 1 . 8 0 9} & \mathbf{- 1 . 9 4 7} & \mathbf{- 2 . 0 3 0} & \mathbf{- 4} & \mathbf{- 5} & \mathbf{- 5} \\ \text { Cable car } & \mathbf{- 1 . 9 3 4} & \mathbf{- 1 . 1 7 5} & \mathbf{- 1 . 1 5 4} & \mathbf{- 5} & \mathbf{- 3} & \mathbf{- 3}\end{array}$

The bold numbers in z-scores refer to a weighted average above $|1.00|$ among z-scores. The bold numbers in factor scores indicates a score above $|3|$ among factor scores.

In addition, we conducted the bootstrapping $\mathrm{Q}$ for a more detailed interpretation of perspectives. The bootstrapping $\mathrm{Q}$ has the characteristic of measuring variability, such as the standard error (SE) of z-score and the bootstrap estimate for bias, which is the difference between the standard z-score and the bootstrapped z-score, through drawing and analyzing resamples out of the original sample with numerous iterations (Figure 6). With the extracted variability, we can determine the reliability and stability of the participants' viewpoints and get more useful information for the interpretation (Zabala \& Pascual, 2016). According to Zabala and Pascual (2016), the short length of the SE bar of an experience means that the experience position in the corresponding factor is stable. The overlap of the SE bars is interpreted to mean that both are indistinguishable. The case of the overlap of the SE bars indicates consensus experiences among the three factors. After all, experiences with the SE bar that does not overlap with the others at the same time as with the short length of the SE bar is highly distinguishing in a specific factor. For example, 'Coziness' in the first factor, 'Mountain·Forest' in the second factor, and 'Rustic environment' in the third factor are the cases mentioned above. The characteristics of each factor were identified through an overall evaluation of factor score, standard z-score, bootstrapped z-score, and SE to the variability. 


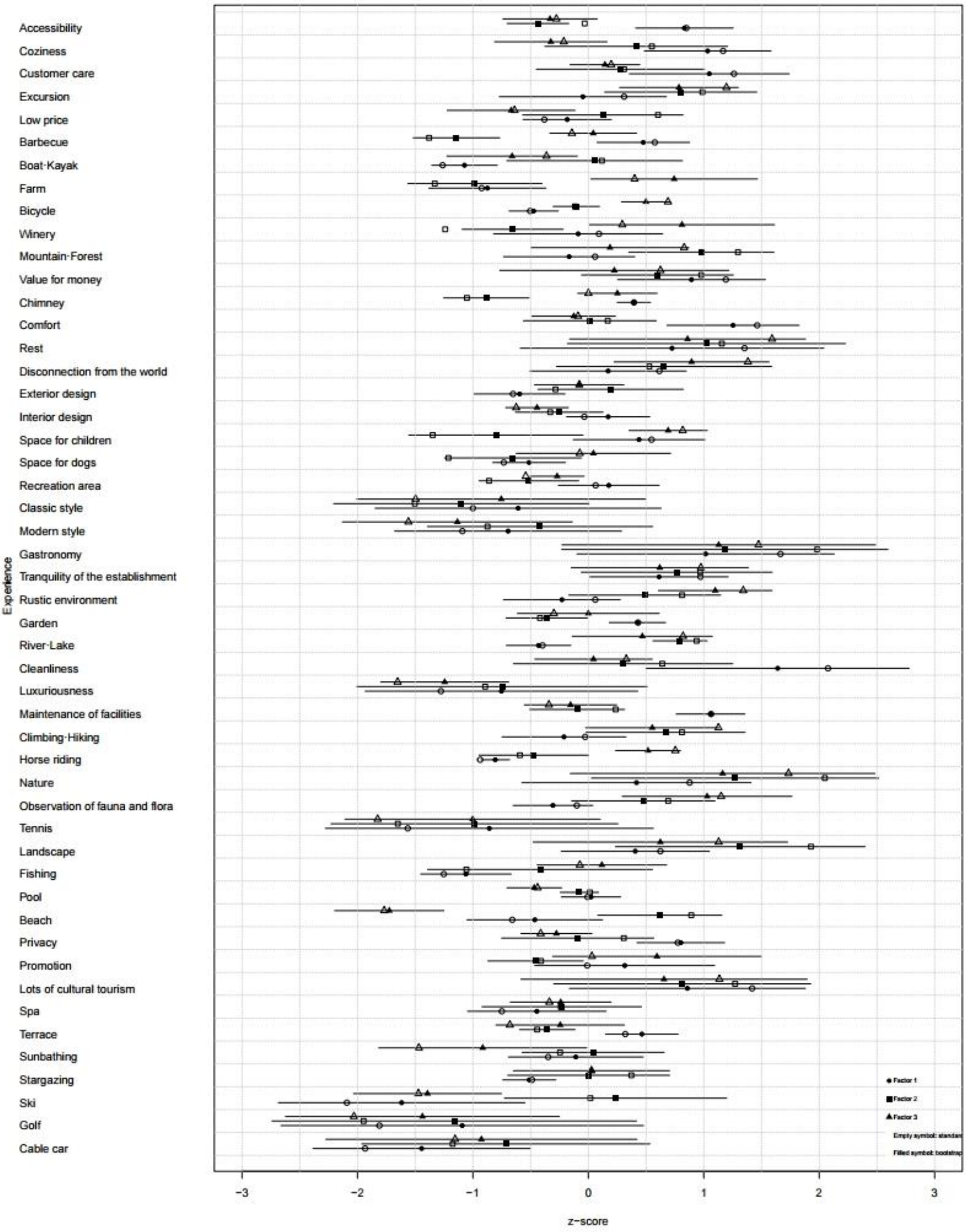

Figure 6. Standard z-score, bootstrap estimate and standard error (SE) for each experience. 


\section{Factor 1: Occasion driven visitor}

The first factor includes 21 participants: 10 customers and 11 experts in rural tourism. The experiences that participants from the first factor think are most important in rural tourism were: 'Cleanliness', 'Comfort', 'Maintenance of facilities', and 'Customer care' and the unimportant experiences in rural tourism for them were: 'Ski', 'Cable car', 'Luxuriousness', and 'Boat'Kayak' (Figure 7). We named this type 'Occasion driven visitor'. In a word, the key benefit they pursue in rural tourism was 'Ambience'. The key characteristic of this factor was that they put a high value on the feelings and images offered by rural tourism accommodation facilities and pursue special experiences there. It was a factor that they thought that the convenience of use and services in rural tourism accommodation were the most important aspects, so they used the facilities in the rural tourism area rather than something outside it. They were less interested in outdoor activities than other factors. It seems that there was a tendency to use rural tourism mainly for special experiences on special occasions.

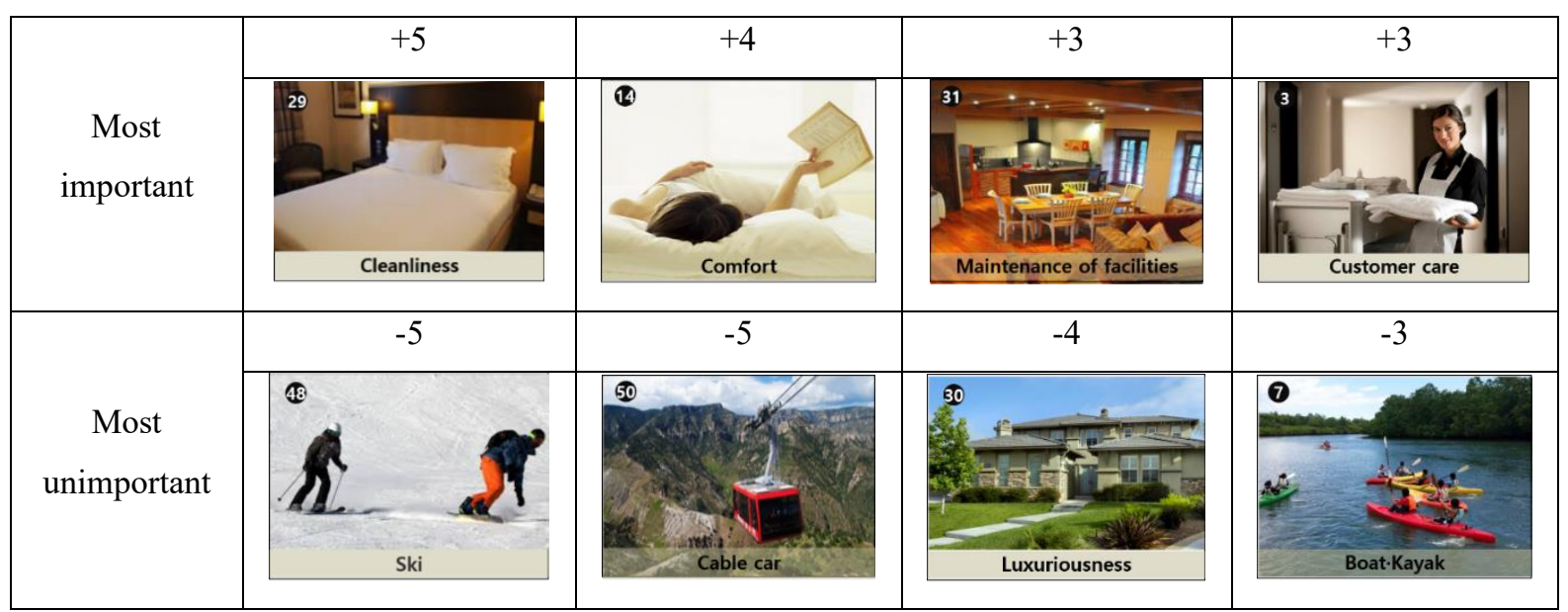

Figure 7. Distinguishing experiences in Factor 1

\section{Factor 2: Active leisure seeker}

Thirteen participants were included in the second factor: eight customers and five experts in rural tourism. The important experiences in rural tourism for the participants of the first factor were: 'Nature', 'Landscape', 'Mountain-Forest' and 'Excursion' (Figure 8). The unimportant experiences in rural tourism for them were: 'Barbecue', 'Space for children', 'Farm', and 'Winery'. We named this type 'Active leisure seeker'. In a word, the key benefit these customers pursue in rural tourism was 'Activity'. This type of factor was characterized by the preference for being active in nature. They were interested in actively enjoying nature through various activities outdoors. The distance at which the rural tourism component was located was not important for them if they could spend sufficient time participating in the leisure activities that they sought. Because they think that 
activities in nature are important, they more carefully considered the natural environment that the particular rural tourism accommodation had in its surrounding area than what the quality of the facilities was when planning their trips. This factor also demonstrates less interest in activities inside the rural tourism accommodation and in tourist attractions in the rural surroundings than other factors.

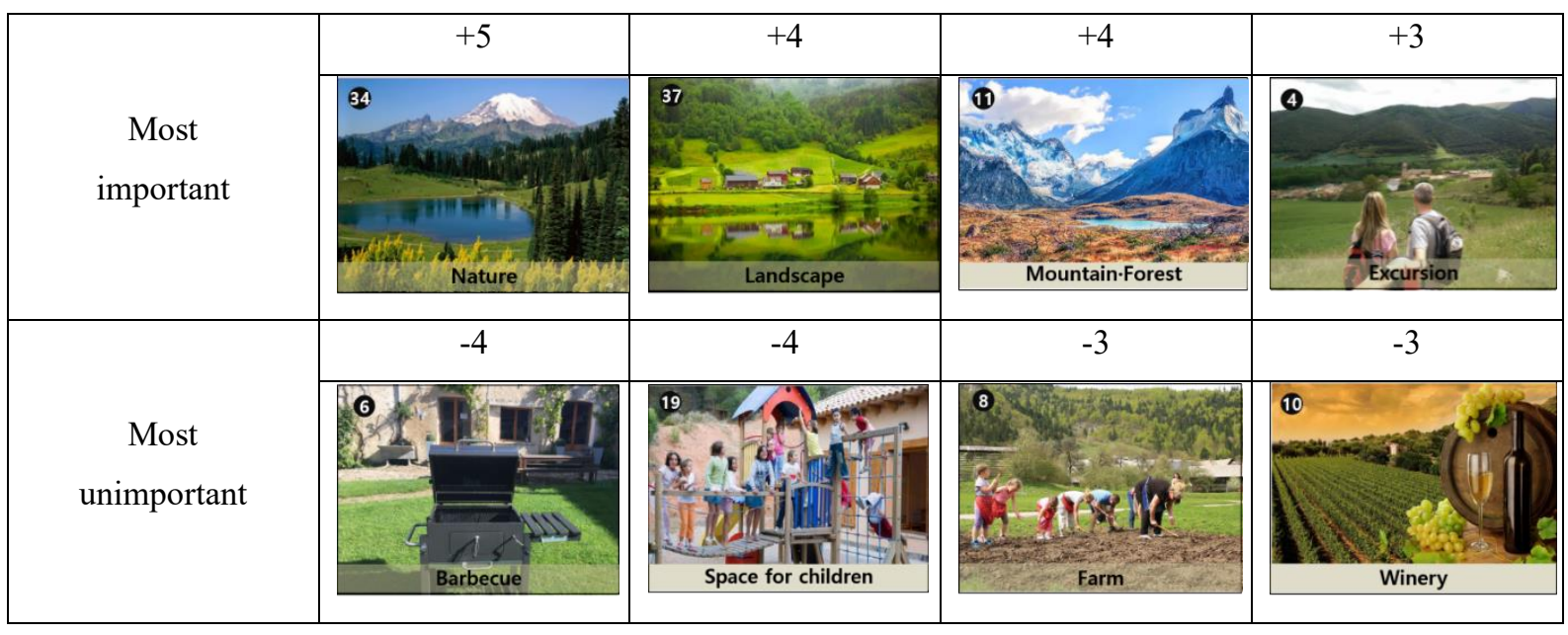

Figure 8. Distinguishing experiences in Factor 2

\section{Factor 3: Rural immersion pursuer}

Eleven participants were included in the third factor: four customers and seven experts in rural tourism. The important experiences in rural tourism for the participants of the third factor were: 'Nature', 'Disconnection from the world', 'Rustic environment', and 'Observation of fauna and flora' (Figure 9). The unimportant experiences in rural tourism for them were: 'Luxuriousness', 'Beach', 'Sunbathing', and 'Ski'. We named this type 'Rural immersion pursuer'. In a word, the key benefit they pursued in rural tourism was 'Disconnection'. This factor was characterized by its preference for being disconnected from the complicated city and completely breaking with their daily routine. They sought to escape from everyday stress and deeply heal by immersing themselves in the rural environment, which is very different from the city. This factor was less interested in participating in activities, as a means of enjoying the essence of the rural environment than the other factors.

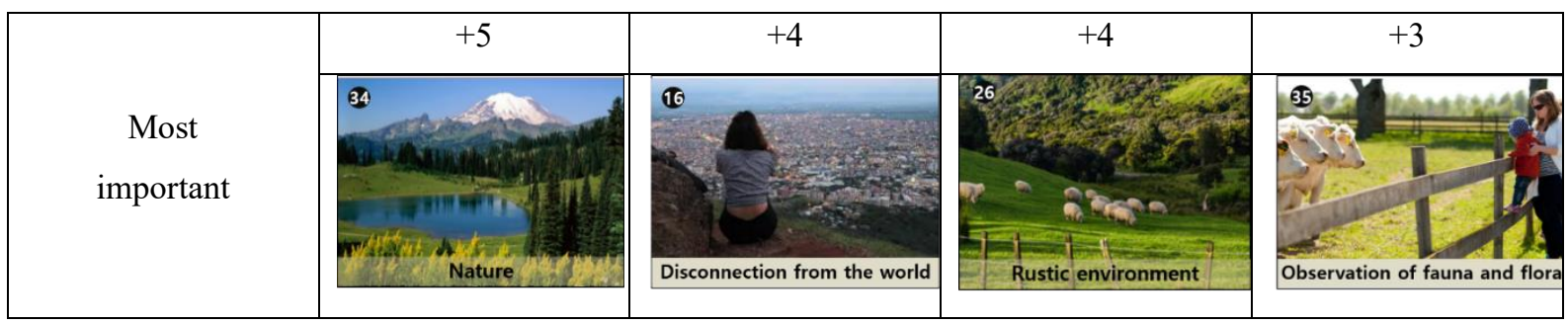




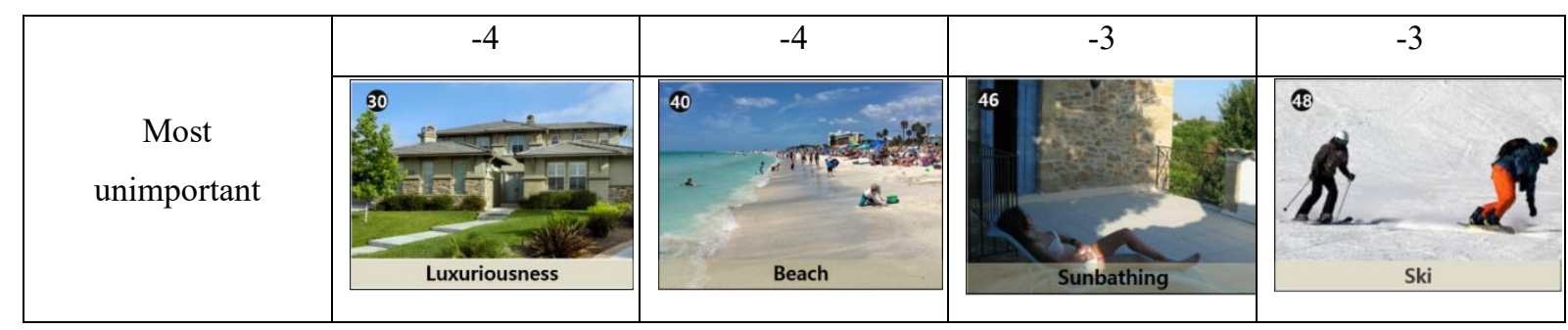

Figure 9. Distinguishing experiences in Factor 3

\section{Consensus experiences: A pleasant break}

Among the consensus attributes, the important experiences that all factors had in common were: 'Gastronomy', 'Rest', 'Lots of cultural tourism', and 'Value for money' (Figure 10). This means that the fundamental attribute that tourists expected from rural tourism was 'A pleasant break', which is characterized by the pursuit of eating something delicious at high-quality gastronomic sites, seeing a variety of things at cultural heritage sites, and feeling renewed at the rural tourism destination. It shows that a peculiar gastronomic experience and a cultural tourism experience were important parts of finding pleasure in rural tourism and value for money as a basis for choosing the rural tourism location. The unimportant experiences that these tourists agree upon were: 'Tennis', 'Golf', 'Classic style', and 'Modern style'. While rural tourism is an accommodation based service in a rural area, the classic or modern style of its facilities was not important for rural tourism tourists. Also, it shows that there was not a great desire to enjoy sports activities, that can be done near the city, in rural areas.

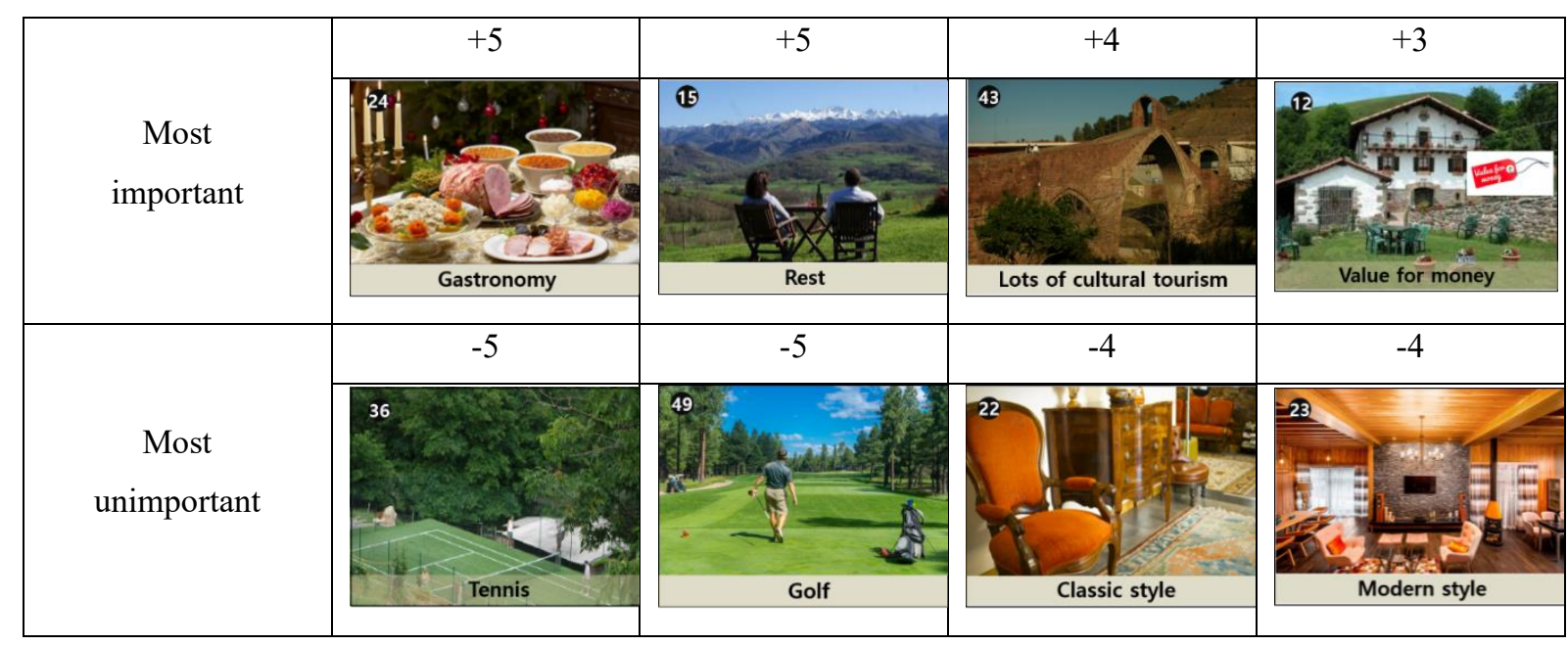

Figure 10. Consensus experiences 


\subsection{Qualitative findings}

This study explored the tourists' consciousness and behavior in each segment in depth through a qualitative approach that asked respondents the reason why they chose important attributes in conjunction with the results of the quantitative survey.

\section{Occasion driven visitor}

Occasion driven visitors' comments on the key attributes in rural tourism choices were focused on rural tourism facilities. They tended to pursue special occasions through rural tourism, such as meeting with family, partying with friends, and intimate time with partners, using rural tourism facilities.

"I do rural tourism with my family and the families of my three younger brothers. The only place for four families to gather together seems to be rural tourism. It seems to be important to have a spacious place where the four families can stay together and to have the facilities to stay without inconvenience in choosing rural tourism."

"I normally enjoy rural tourism with my boyfriend. When choosing rural tourism, the most important thing is whether the accommodation has facilities for the comfort of the two of us. Above all, I wish the place to be clean and where privacy can be maintained."

"I often use rural tourism for gatherings with friends. In a word, rural tourism gives us a good place to gather and party together. Therefore, the surrounding environment is not important when choosing rural tourism. It is important to have comfortable facilities."

\section{Active leisure seeker}

Comments from the active leisure seekers showed that the purpose of rural tourism was to be active in the natural or rural environment. They were more likely to choose rural tourism, which provides the conditions for active activities such as tracking, hiking, walking, swimming and sports.

"I like to go trekking and hiking with my family because doing outdoor activities outside of the city can give us new vitality and relieve our stress from urban life. When choosing rural tourism, I first consider whether there are natural surroundings to go walking nearby."

"I like rural tourism because it provides a good environment for me to take my dog and play with him. When deciding on a rural destination, the most important consideration is whether I can take my dog and whether there is space around it for my dog to play."

"As I have children, it is important to have an environment and facilities to do activities with my family. I carefully consider whether there are well-equipped facilities for activities such as a swimming pool and table for table tennis, and the possibility of various outdoor activities such as horse riding and fishing."

\section{Rural immersion pursuer}

The comments of rural immersion pursuers on important factors in rural tourism choices are concentrated with a rural environment that is completely different from the city. They seek perfect breaks from busy city life, 
refreshment through rural landscapes, and new experiences that only rural communities can give.

"I am a person who is too busy and has a lot to care about. Since rural tourism is a great way to get out of the environment around me very easily, I sometimes enjoy it. If I rest well without doing anything special, it will be my best experience in rural tourism."

"I like rural tourism because it seems to make me feel refreshed when I look at the landscape in a place with great natural scenery. I consider not only whether there are nature and scenery, but also whether I can fully feel the atmosphere of rural areas."

"I often do rural tourism to give my children growing up in the city the chance to experience something new. If they can directly touch the soil, plants, animals, etc., and if they can do stargazing, I think it will be the best rural tourism for my family."

\section{A pleasant break}

Comments from respondents who belong to 'A pleasant break' show that it was a pleasure for them to concentrate on rural tourism. The pursuit of enjoyment such as eating delicious food, seeing various interesting things, and staying in rural tourism accommodations at reasonable prices was an important consideration in choosing rural tourism.

"The element that I consider important in rural tourism seems to be gastronomy. Eating something delicious with my family while doing rural tourism makes me feel pretty satisfied. It's important whether rural tourism accommodation is well-equipped with barbecue and cooking facilities, and whether there are famous restaurants nearby."

"I only do rural tourism for the purpose of accommodation during my trip. This is because rural tourism accommodation is cheaper and of higher quality. For me, rural tourism is just a place for sleeping like a hotel. Therefore, the quality of a room for the price charged for it is the most important factor for me."

"Since my hometown is rural, I am already so used to the rural environment. I don't have much interest if rural tourism means just resting in a rural atmosphere. There must be something to do around the countryside and a lot of cultural heritage. I consider this a lot before going to do rural tourism."

\section{Discussion}

It is important to discover which tourist experiences in rural tourism tourists pursue in order to develop the various value propositions. In this research, we have derived three factors and consensus images on the experiences in rural tourism through the use of visual Q. We can describe tourist experiences in rural tourism in Spain with the result of the analysis (Figure 11). 


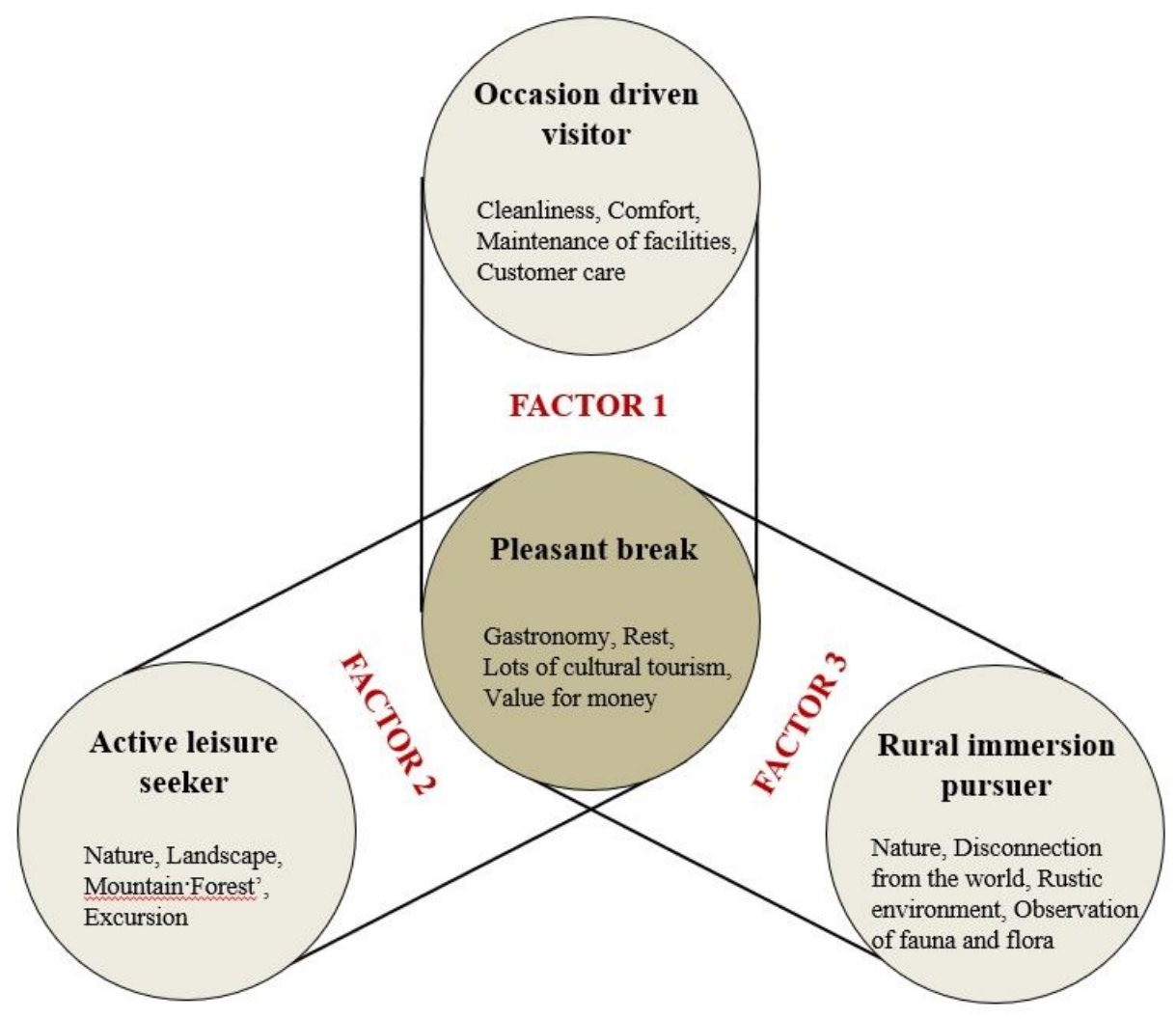

Figure 11. Description of rural tourism experiences.

This investigation has added some meaning to the existing literature from theoretical and methodological perspectives. From a theoretical point of view, this study has made some contribution. Fernandes and Cruz (2016) analyzed the factors that affect tourism experiences such as functional benefits, service providers, entertainment, learning, trust and environment. They provided criteria for identifying the kinds of experiences existing within tourism by classifying the types of tourist experiences, whereas the present study is meaningful for explaining the types of markets that exist in rural tourism by presenting tourist types based on the experiences that tourists truly pursue in rural tourism. This result helps make it possible to understand the rural tourism markets based on tourist needs. Also, related to tourist experiences in rural tourism, Sharpley and Jepson (2011) conducted focus group interviews of the tourists who had visited the Lake District and discovered four kinds of experiences in rural tourism: remoteness, the spiritualness of place, solitude/quietness and altitude/the limitless. Since the results of that study were derived based on experiences limited to a specific rural tourism area, it is difficult to apply it to other rural tourism areas with different characteristics. Nonetheless, the results of our research can be applied to the rural tourism areas in various situations because it was surveyed tourists with varied experiences as well as experts in rural tourism. It can give rural tourism an opportunity to put forward various value propositions, thus 
escaping the monotonous value propositions that we currently observe.

From a methodological point of view, this study contributes to the existing studies in evaluating the visual Q methodology as a better way to extract tourist perceptions of experiences. It has enabled tourist opinions to emerge without being enforced by a researcher who has his/her own viewpoint drawn from previous hypotheses. Since the visual stimuli of the visual Q methodology led participants to provide a rapid and clear response, an effective exploration of individual subjectivity was possible. Visual Q made it possible to qualitatively analyze tourist experiences and quantitatively segment the rural tourism market based on tourist experiences. Likewise, the analysis of individual subjectivity allowed for in-depth interpretation of the results. In addition, this study combined quantitative analysis with Q methodology and qualitative analysis with questionnaires. This kind of a mixed-methods approach made it possible not only to identify what the important attributes in the choice of rural tourism are but also to understand the reason why tourists think so. This was a good way to draw holistic pictures of tourists' perceptions and behaviors.

The results of this study have many strategic implications for both local governments and rural tourism providers. First, at a local government level, it was found that tourists were pursuing various experiences in rural tourism in Spain and there were multiple markets implicated in this research. This means that the motivations for rural tourism are diverse and many ways of reaching rural tourism consumption exist. Local governments should employ the approach of localizing the region. They should develop specific strategies to meet the needs of market subdivisions, concentrating on a specific segment with relevance to their region. Based on these strategies, they should invest in marketing their regions as a distinctive rural tourism destination by creating rural tourism products that respond to the needs of a specific segment.

Second, at the rural tourism provider level, each rural tourism provider should evaluate the derived segment and select a market on which they should concentrate. They should decide their core target audience, carefully contemplating whether they have the ability to provide the appropriate experiences for the core target audience, while considering their surrounding environment. In addition, it is necessary to establish a positioning strategy that can meet the needs of rural tourism tourists, considering the characteristics of the core target audience. These positioning strategies should be used as criteria for developing all services and communicating with tourists. With these criteria, rural tourism providers can not only offer differentiated rural tourism experiences for tourists by developing services that are relevant to their positioning strategies but also communicate with tourists to inform them of the corresponding rural tourism in a consistent manner at all touch points.

However, this investigation has limitations: with only 50 respondents collected, it is difficult to obtain representativeness in terms of sociodemographic features (age, occupation, place of residence, trip type, price level, etc.). This is due to the fact that Visual Q is a semi-qualitative methodology whose ultimate goal is a qualitative assessment of the individual through a quantitative statistical analysis. It is possible to grasp the characteristics of the rural tourism market by quantitatively examining individual perceptions, which have a qualitative aspect, but it is impossible to generalize the demographic characteristics of the individuals through such a small sample. Thus, it is difficult to identify the more detailed characteristics of each segment through the current study. 
According to Zabala (2014), the results of the Q methodology can be used as a point of departure for other quantitative methodologies and be applied conjointly with qualitative methodologies. Since this study basically served to confirm existing markets, it is still necessary to quantify the characteristics of each rural tourism market by carrying out additional quantitative research focusing on demographics. It will be possible to develop corresponding policies by determining the rural tourism market size and collecting detailed characteristics of the market. Also, based on the results of this visual Q study, we can thoroughly analyze the question of the optimal combination of tourist experiences that rural tourism can provide. In addition, Visual Q based on personal subjectivity can be widely applied to diverse tourism research in the future: hospitality, cruise tourism, ecotourism and wine tourism. 
STUDY 3

\section{How can rural tourism be sustainable?}

\section{A systematic review}

Wookhyun An, Silverio Alarcón,

How can rural tourism be sustainable? A systematic review, Sustainability, 12 (18), 2020, https://doi.org/10.3390/su12187758

Journal Citation Reports Ranking 2019: Sustainability was ranked 120 out of 265 in the area of 'Environmental Sciences', 53 out of 123 in the area of 'Environmental Studies', and 26 out of 41 in the area of 'Green \& Sustainable Science \& Technology'. 


\title{
How can rural tourism be sustainable? A systematic review
}

\begin{abstract}
This investigation reviewed articles associated with sustainable rural tourism found on the Web of Science database over a 10-year span from 2009 to 2019. The 73 articles that were selected for their inclusion of the concept of sustainable rural tourism were listed in a comprehensive table; thereby revealing the research purpose, topics, detailed topics, research methods, and data source of the articles. The findings indicate that many papers on sustainable rural tourism were written from a holistic sustainability perspective without being biased towards any one of the environmental, economic and social aspects. In the field of rural tourism, it is essential to pay attention to interactions in all aspects of the environment, economy, and society, and to analyze them overall. In addition, this study confirmed that efforts to understand sustainable rural tourism from the customer perspective have been increased, since customer loyalty is considered important for sustainability. This study is significant in that since it evaluated the knowledge status for the first time through systematic review and applied content analysis to academic literature related to sustainability in the sector of rural tourism, it can expand and deepen knowledge and the understanding of related topics and raise awareness of a new research direction.
\end{abstract}

Keywords: Sustainable rural tourism; Systematic review; Holistic sustainability; Environmental sustainability, Economic sustainability; Social sustainability; Customer sustainability 


\section{Introduction}

Sustainable tourism has become recognized as a desirable goal in tourism development due to the addition of the concept of sustainability to tourism in order to reduce the negative impacts experienced during the tourism development process (R. Sharpley, 2003). Sustainability-based tourism development models can evolve when they are able to meet the demands of locals as well as respond to the needs of tourists (WTO, 1993). Through tourist participation in activities in developed tourism, positive or negative factors are created, which affect the sustainability of environmental, social and economic dimensions (Yoon et al., 1999). First of all, on the positive side, the development of tourist activities in rural areas can create verified positive effects; improvement of the quality of life for locals, creation of employment, preservation of cultural heritage, development of business networks, and enhancement of public image of the region (Andereck \& Nyaupane, 2011). In addition, through the development of rural tourism, there may be other positive effects such as the opportunity to enhance the natural environment value, improvements related to public transport networks or public facilities, and the activation of cultural interactions (Almeida-García et al., 2016). Whereas there may be also negative effects such as overcrowding of public places and facilities, disruption of local people's lives, skyrocketing price of property ownership, safety concerns, environmental damage, increased waste, and overuse of resources (Almeida-García et al., 2016). These have negative impacts on the sustainability of rural tourism from social, economic, and environmental points of view. Sustainable rural tourism aims to raise the sustainability with regard to the long term improvement of living standards by maintaining the balance between environmental protection, promoting economic benefits, establishing social justice, and maintaining cultural integrity (Liu et al., 2013).

As interest in the sustainability of rural tourism has increased, various types of research on sustainable rural tourism have been conducted, and research achievements related to this sector have been accumulated (De Luca et al., 2017). However, a comprehensive overview of how studies related to sustainable rural tourism have been conducted and what results have been presented has not yet been created, although there have been some systematic review studies on the sustainability of general tourism (Guo, Jiang, \& Li, 2019; Kristjánsdóttir, Ólafsdóttir, \& Ragnarsdóttir, 2018; Niñerola, Sánchez-Rebull, \& Hernández-Lara, 2019; Yoopetch \& Nimsai, 2019; Zolfani et al., 2015). Thus, the need for a systematic review of sustainable rural tourism has emerged. The accumulation of comprehensive and systematic understanding can be said to be a very important task in terms of expanding and deepening the knowledge of related topics and raising awareness of a new research direction (Hulland \& Houston, 2020). A systematic review of sustainable rural tourism can contribute to future research in many ways. This study enables researchers designing new research into sustainable rural tourism to understand a cutting edge subject and quickly get used to it (Barczak, 2017). In addition, this systematic review study helps researchers establish a new perspective on the phenomenon by synthesizing new insights from various existing studies (Houston, 2019). Next, it leads them to identify research topics and questions that have not yet been investigated by analyzing the overall trend of the research conducted so far (Hulland \& Houston, 2020). Finally, it can provide guidance for future investigators who will conduct research on the topic of sustainable rural tourism to determine research structure and method (Palmatier et al., 2018). 
The authors of this article reviewed relevant studies related to sustainable rural tourism in high-level journals belonging to SSCI and SCIE, which were searched using Web of Science during the period of 2009-2019. This study was conducted to respond to the following research questions.

Research question 1: What are the general characteristics of studies related to sustainable rural tourism?

Research question 2: What are the structural characteristics in the intellectual dimension of research related to sustainable rural tourism?

Research question 3: Which research topics interest sustainable rural tourism researchers?

The remainder of this article is structured as follows: section 2 draws the literature review, the methodology is accounted for in section 3, section 4 suggests the results of this research, and the conclusions and implications are shown in section 5 .

\section{Methodology}

\subsection{Search and information sources}

The study reviewed SSCI and SCIE-class papers on sustainable rural tourism, which were searched on the Web of Science. The study's search was conducted only for the 10-year period from 2009 to 2019, in order to provide the latest and most relevant information (Wijesinghe et al., 2017). Several sets of keywords were applied to collect research related to sustainable rural tourism. These keywords were "sustainable rural tourism" or "sustainability of rural tourism". In the Web of Science, 564 articles related to the above-mentioned keywords were found.

\subsection{Data collection process and article screening}

Authors decided to target only peer-reviewed journal articles. The proceeding paper, book, and editorial materials were excluded because authors judged that they did not contribute significantly to knowledge development (Law et al., 2012). Articles published in languages other than English were also excluded.

Data extraction forms were then designed to identify included articles and provide an overview of approaches to sustainable rural tourism research. Considering the quality of the study, each article was evaluated in a structured data extraction format. The data extracted included author, year, title, journal, abstract, keywords, research purpose, topics, detailed topics, research methods, and data source. In the next step, for the screening of articles, the context of the keywords presented in each article and abstracts were analyzed. Through this process, articles could be divided into those that are fundamentally related to sustainable rural tourism and articles that are not related to 
sustainable rural tourism (for example, if the research area is not rural tourism or if the subject of the study is not associated with sustainability). The results show that 168 articles are fundamentally related to sustainable rural tourism. Finally, by analyzing the contents of the selected 168 articles, they were classified into those where sustainable rural tourism was addressed as the main issue of the study and those where it was treated as a supporting issue of the study. Finally, 73 articles covering the topic of sustainable rural tourism as the main issue were selected as the targeted material for the systematic review (Figure 12). This screening process was conducted independently by the authors, and in the case of data discrepancies, consensus was reached through discussions between the authors of this review.

\section{Step 1. Deciding source and search words}

Source: Web of Science from January 2009 to December 2019

- Search words: Sustainable rural tourism or sustainability of rural tourism

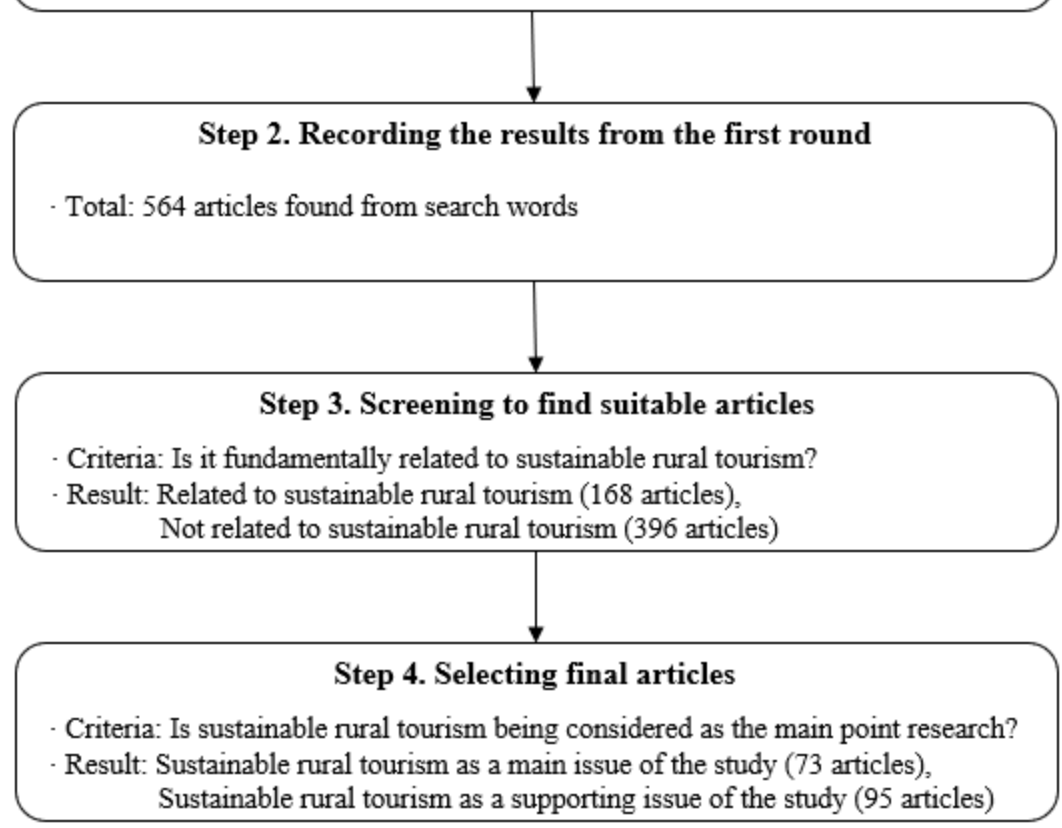

Figure 12. Flow diagram for systematic review.

\subsection{Data analysis}

With the purpose of answering research question 1 (What are the general characteristics of studies related to sustainable rural tourism?), this study grouped the selected articles by several criteria. First, the number of 
publications per year and per region that pertained to related studies was analyzed. Next, the publishing trends of journals related to sustainable rural tourism were analyzed. Finally, the research methods and research perspectives that were applied to the related studies were explored.

In response to research question 2 (What are the structural characteristics in the intellectual dimension of research related to sustainable rural tourism?), this study draws a bibliographic map, which defined the cooccurrence of keywords that reveal what the main scientific knowledge of each study was (Mulet-Forteza et al., 2019). To obtain the bibliographic map based on research keywords co-occurrence, the VOSviewer software associated with the technique of multidimensional scaling was utilized in this study (van Eck \& Waltman, 2010). The software applied mapping techniques to determine the location of keywords on the map and the clustering technique to create clusters through the allocation of frequently co-occurring keywords (Borg \& Groenen, 2005).

With regard to research question 3 (Which research topics interest sustainable rural tourism researchers?), the research topics from the selected articles related to sustainable rural tourism were analyzed. First, the research topics were categorized in order to grasp the overall tendency of research in relation to sustainable rural tourism. In addition, the proportion of categorized topics was analyzed to confirm which topics were more significant in sustainable rural tourism research. Finally, the detailed topics covered in each category were analyzed to identify the specific research trends related to sustainable rural tourism.

\section{Results}

To address research question 1, the overall characteristics of the selected studies were analyzed. Over the 10-year period from 2009 to 2019, research on sustainable rural tourism steadily increased. From 2009 to 2016, an average of 0 to 7 sustainable rural tourism articles were published annually, and from 2017 to 2019, 13 to 20 papers were published each year (Figure 13). This demonstrates that the interest in sustainable rural tourism has increased significantly over time. 


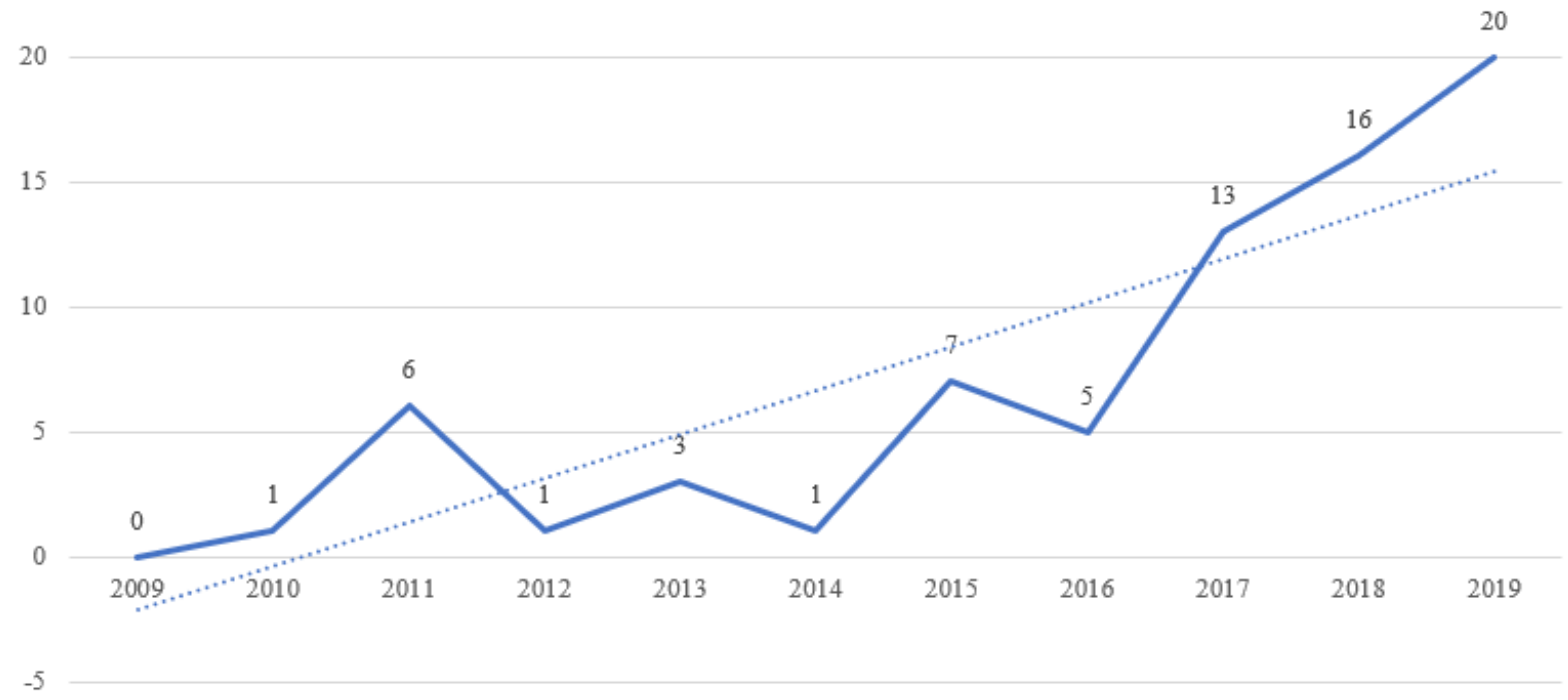

Figure 13. Article distribution from 2009 to 2019.

Regarding region, sustainable rural tourism-related research was found to be conducted in various regions (Table 16). Europe (34 papers, 46.6\%) had the highest frequency, followed by Asia (28 papers, 38.4\%). Spain (10 papers) in Europe and People's Republic of China (12) in Asia led the research on sustainable rural tourism. In addition, North America, South America, Oceania, The Middle East, and Africa have recorded 1 to 3 publications each in the last 10 years. It shows that from a regional point of view, research related to sustainable rural tourism is focused in Europe and Asia.

Table 16. Articles per region.

\begin{tabular}{llll}
\hline Regions & No. & $\%$ & Countries \\
\hline Europe & 34 & 46.6 & Austria (4), Czech Republic (1), Hungary (1), Italy (5), Montenegro (1), Poland (1), \\
& & & Portugal (2), Romania (3), Russia (1), Serbia (2), Spain (10), The United Kingdom (3)
\end{tabular}

Asia $28 \quad 38.4$

People's Republic of China (12), Japan (2), Republic of Korea (3), Laos (1),

Malaysia (2), Taiwan (4), Turkey (3), Vietnam (1)

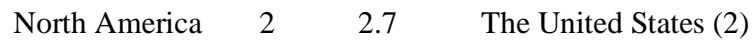




\begin{tabular}{|c|c|c|c|}
\hline South America & 3 & 4.1 & Brazil (1), Cuba (1), Nicaragua (1) \\
\hline Oceania & 3 & 4.1 & Australia (2), New Zealand (1) \\
\hline The Middle East & 1 & 1.4 & $\operatorname{Iran}(1)$ \\
\hline Africa & 2 & 2.7 & Botswana (1), Kenya (1) \\
\hline Total & 73 & 100.0 & \\
\hline
\end{tabular}

The 73 articles selected for review were published in various journals (Table 17). The journals Sustainability (21 papers) and Journal of Sustainable Tourism (10) lead in number of publications in the sector of sustainable rural tourism. Tourism management (4), Journal of Destination Marketing \& Management (4), International Journal of Tourism Research (4) and Land Use Policy (3) follow in terms of number of publications.

Table 17. Publications per journal.

\begin{tabular}{lll}
\hline Journal & No. & $\%$ \\
\hline Sustainability & 21 & 28.8 \\
Journal of Sustainable Tourism & 10 & 13.7 \\
International Journal of Tourism Research & 4 & 5.5 \\
Journal of Destination Marketing \& Management & 4 & 5.5 \\
Tourism Management & 4 & 5.5 \\
Land Use Policy & 3 & 4.1 \\
Asia Pacific Journal of Tourism Research & 2 & 2.7 \\
Current Issues in Tourism & 2 & 2.7 \\
Journal of Travel Research & 2 & 2.7 \\
Tourism Geographies & 2 & 2.7 \\
Applied Energy & 1 & 1.4 \\
Environment Development and Sustainability & 1 & 1.4 \\
Environmental Engineering and Management Journal & 1 & 1.4 \\
Fresenius Environmental Bulletin & 1 & 1.4 \\
International Journal of Contemporary Hospitality Management & & 1.4 \\
International Journal of Environment Research & 1 & 1.4 \\
International Journal of Environmental Research and Public Health & 1.4
\end{tabular}


Journal of Environmental Protection and Ecology

Journal of Hospitality Marketing \& Management

Landscape Research

Revista de Facultad de Ciencias Agrarias

Science of the Total Environment

For the selected 73 articles, three types of research methods were applied (Table 18). Quantitative analysis was used for 45 articles, qualitative analysis for 26 articles, and mixed analysis combining quantitative and qualitative analysis for 2 articles. Of the papers to which quantitative analysis was applied, 33 papers used questionnaire surveys as the primary research method, and 12 papers applied quantitative analysis on statistical data. Among the papers to which qualitative analysis was applied, studies that applied in-depth interviews (13 papers) were the majority, but there were also studies that applied Delphi (4 papers), participant observation (4 papers), qualitative analysis on textual data (4 papers), and focus group interviews (1 paper). Data sources for the 73 studies were found in the following order: residents (28 papers, $38.4 \%$ ), secondary data (15 papers, $20.5 \%$ ), tourists (13 papers, $17.8 \%$ ), stakeholders (13 papers, $17.8 \%$ ), and experts (4 papers, $5.5 \%$ ).

Table 18. Applied research methods and research perspective.

\begin{tabular}{lllc}
\hline & Classification & All articles & \% \\
\hline Research methods & Quantitative analysis & 33 & 45.2 \\
& Questionnaire survey & 12 & 16.4 \\
& Quantitative analysis on statistical data & & 5.5 \\
& Qualitative analysis & 4 & 1.4 \\
& Delphi & 1 & 17.8 \\
& Focus group interview & 13 & 5.5
\end{tabular}


Mixed analysis

Mixed methods research design 2

\subsection{Intellectual structure based on keywords}

To answer research question 2, this study examined the keywords related to sustainable rural tourism research (Figure 14). Keyword co-occurrence was analyzed using 'VOSviewer' software (van Eck \& Waltman, 2010).

The first main keyword was rural tourism and agriculture. Pursuing a win-win relationship with rural tourism and agriculture can be a primary way to increase the sustainability of rural tourism (Su, Wall, Wang, \& Jin, 2019). Providing rural tourism products by strengthening the link between rural tourism and agriculture can greatly contribute to improving the economic and ecological sustainability of rural areas (Addinsall et al., 2017). Farmers who not only participate in the busy farming season but also in the peak tourism season can enhance livelihood sustainability by maximizing the synergistic relationship between rural tourism and agriculture (Kheiri \& Nasihatkon, 2016). The keywords related to rural tourism and agriculture were "diversification" and "enterprises". From the perspective of agricultural diversification, a wide range of initiatives that pursue sustainable rural tourism can be found, varying between farm-based activities and rural tourism activities related to rural, natural and cultural resources (Hernández-Mogollón et al., 2011). Rural tourism based on agricultural diversification not only makes it possible to supplement agricultural income with tourism income, but also protects the environment and guarantees the agricultural system (Hernández-Mogollón et al., 2011). The related keyword "enterprises" creates new rural tourism experiences, increases the value of the places, beautifies the properties owned in the countryside, and preserves the local culture (Kallmuenzer et al., 2018). In order to meet the diverse needs of tourists of rural tourism, not only farmers' efforts but also entrepreneurs' efforts to attract tourists with attractive rural tourism programs must be added (Schmidt et al., 2016).

The next main keyword was tourist satisfaction. Tourist satisfaction with rural tourism can be defined as their evaluation of the difference between the expectations they had before visiting and the experiences they had 
while visiting (Truong \& Foster, 2006). Satisfaction after experiencing rural tourism is an important factor to making rural tourism sustainable because it increases customer loyalty to the destination (Ryglová et al., 2018). Tourists' satisfaction, as well as the conservation of nature, the quality of life of the locals, cultural development and economic improvement, are important drivers that make sustainable rural tourism possible (Gurbuz \& Manaros, 2018). The surrounding keywords related to satisfaction were "products", "experience", and "destination image". First, "products" and "experience" in the field of tourism can be considered to be service quality by tourists' evaluation of a standardized service delivery process related to tourism experiences (CampónCerro et al., 2017). Since there can be many factors that make up customer satisfaction, it is very important to check the association between the former and the latter (Kim, Holland, \& Han, 2013). Next, "destination image" can be defined as tourists' involvement level in a specific place, formed through the destination experience (Prayag \& Ryan, 2012). It can be also an important factor influencing customer satisfaction and loyalty to destinations (Kastenholz, Eusébio, \& Carneiro, 2018).

The next main keyword was community. The active involvement of the community, which is the major operator of rural tourism, is an important factor in ensuring the sustainability of rural tourism (Sakata \& Prideaux, 2013). Community is a key body that can protect the natural environment of rural areas, preserve the cultural identity of the region, and help provide economic benefits to residents (Russell, 2000). Community involvement helps to avoid negative socio-cultural changes that may occur due to rural tourism development and maximizes economic benefits by redistributing the benefits obtained from rural tourism (Idziak et al., 2015). Community participation can have an effect on tourists having positive experiences in rural tourism (Moscardo, 2011). Keywords related to community were "attitude", "perceptions", and "ecotourism". The effectiveness and efficiency of sustainable rural tourism development can vary depending on "attitude" and "perceptions" of the community about rural tourism development (Idziak et al., 2015). They are factors that influence the level of community participation in rural tourism development (Simpson, 2008). The keyword "ecotourism" indicates that environmental sustainability should be reflected in the efforts of the community towards achieving sustainable rural tourism (Ristić, Vukoičić, \& Milinčić, 2019). The sustainability of rural tourism destinations should be estimated from the point of view of the balance between the needs of rural tourists and the environment (Zolfani et al., 2015). Assessment of environmental sustainability can derive a sustainable eco-tourism management strategy (Ghorbani et al., 2015).

The final main keyword was indicators. Indicators for measuring sustainability for rural tourism should be able to objectively and accurately assess the status of sustainable development and be scientifically strong and reliable (Ernesto Pérez et al., 2017). In addition, it should be verifiable and easily accessible to decision makers (Reed, Fraser, \& Dougill, 2006). Indicators that measure the status of development can increase the efficiency of management for sustainable rural tourism (Blancas et al, 2010). Keywords related to indicators were "livelihood sustainability", and "quality of life". The keyword "livelihood sustainability" demonstrates that the assessment of economic sustainability should be reflected in indicators of sustainable rural tourism development (Ristić et al., 2019). Rural tourism can be a driving force for economic income and employment opportunities that promote 
livelihood (Su, Aaron, Guan, \& Wang, 2019). Rural tourism can be sustainable when the needs of rural destinations can be exchanged for economic constraints (Timur \& Getz, 2009). In addition, the keyword "quality of life" indicates that social sustainability, such as improving the quality of life of residents and communities, should be reflected in indicators for sustainable rural tourism development (Ernesto Pérez et al., 2017). Rural tourism development has positive or negative impacts on the social life of the community and it also changes the rural environment (Kang et al., 2008). There is a need to prevent departure and increase the social sustainability of the community (D. Hwang, Stewart, \& Ko, 2012). It is also important to maintain and develop local traditional culture that can be damaged by rural tourism, in order to promote social sustainability (Campón-Cerro et al., 2017).

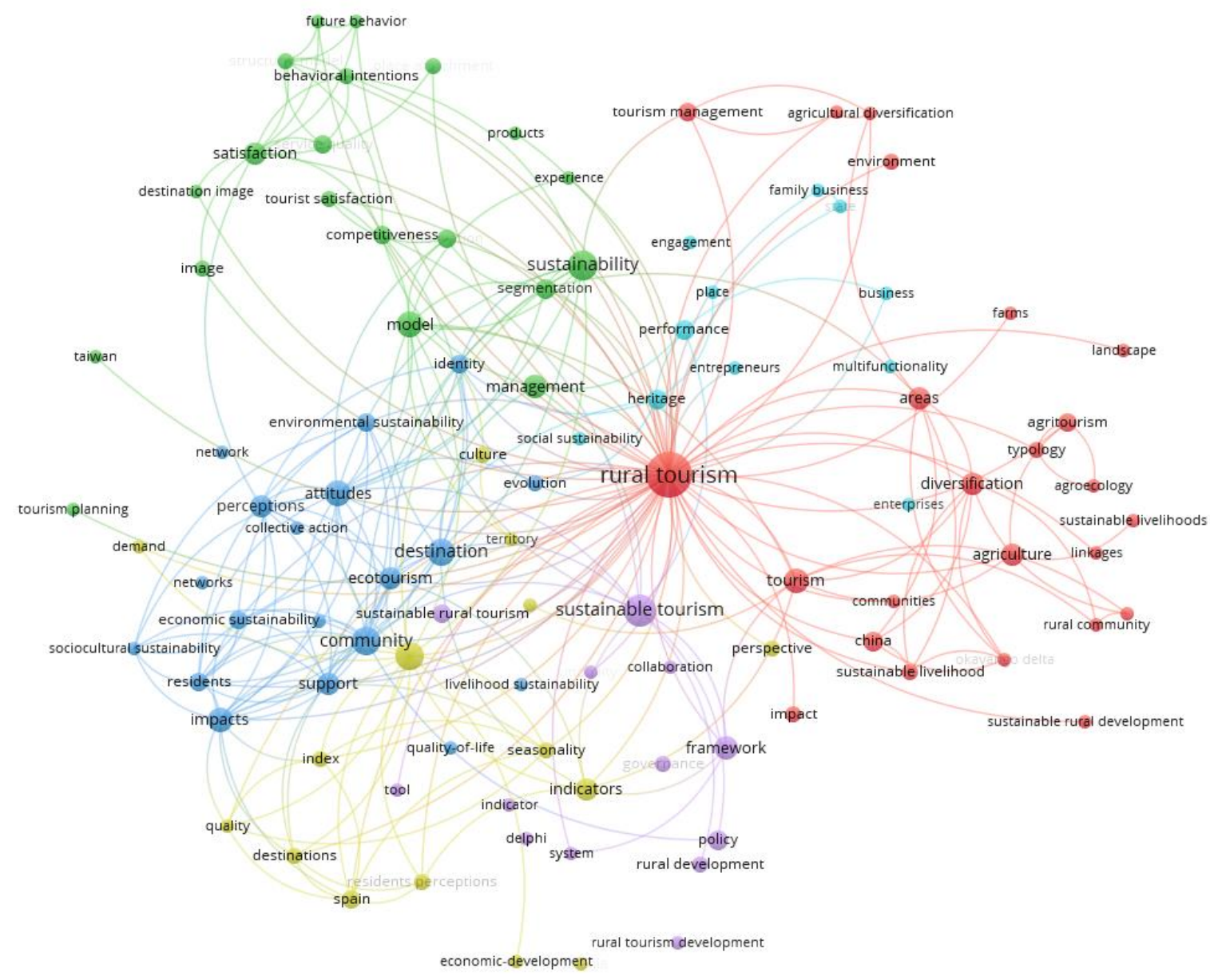

Figure 14. Co-occurrence map for articles related to sustainable rural tourism from 2009 to 2019. 


\subsection{Research topics}

In response to research question 3, the research topics found in the 73 articles were analyzed. The selected articles related to sustainable rural tourism had different types of research topics. The research topics can be divided into five categories: holistic, environmental, social, economic, and customer. Among them, 32 studies (43.8\%) used holistic as the topic, 16 used environmental (21.9\%), 9 used social (12.3\%), 10 used economic (13.7\%), and 6 used customer (8.3\%) (see Figure 15). The proportion of studies dealing with holistic sustainability was significantly higher than that of other topics. It indicates that social and economic aspects as well as the environmental aspects are comprehensively considered in research related to sustainable rural tourism, although in general, the environmental aspect is emphasized when it comes to sustainability. It can be said that the lens of holistic sustainability is actively used to analyze the phenomenon in the rural tourism sector. In view of individual research topics, there was slightly more research on environmental sustainability. Studies on social sustainability, economic sustainability, and customer sustainability were evenly distributed.

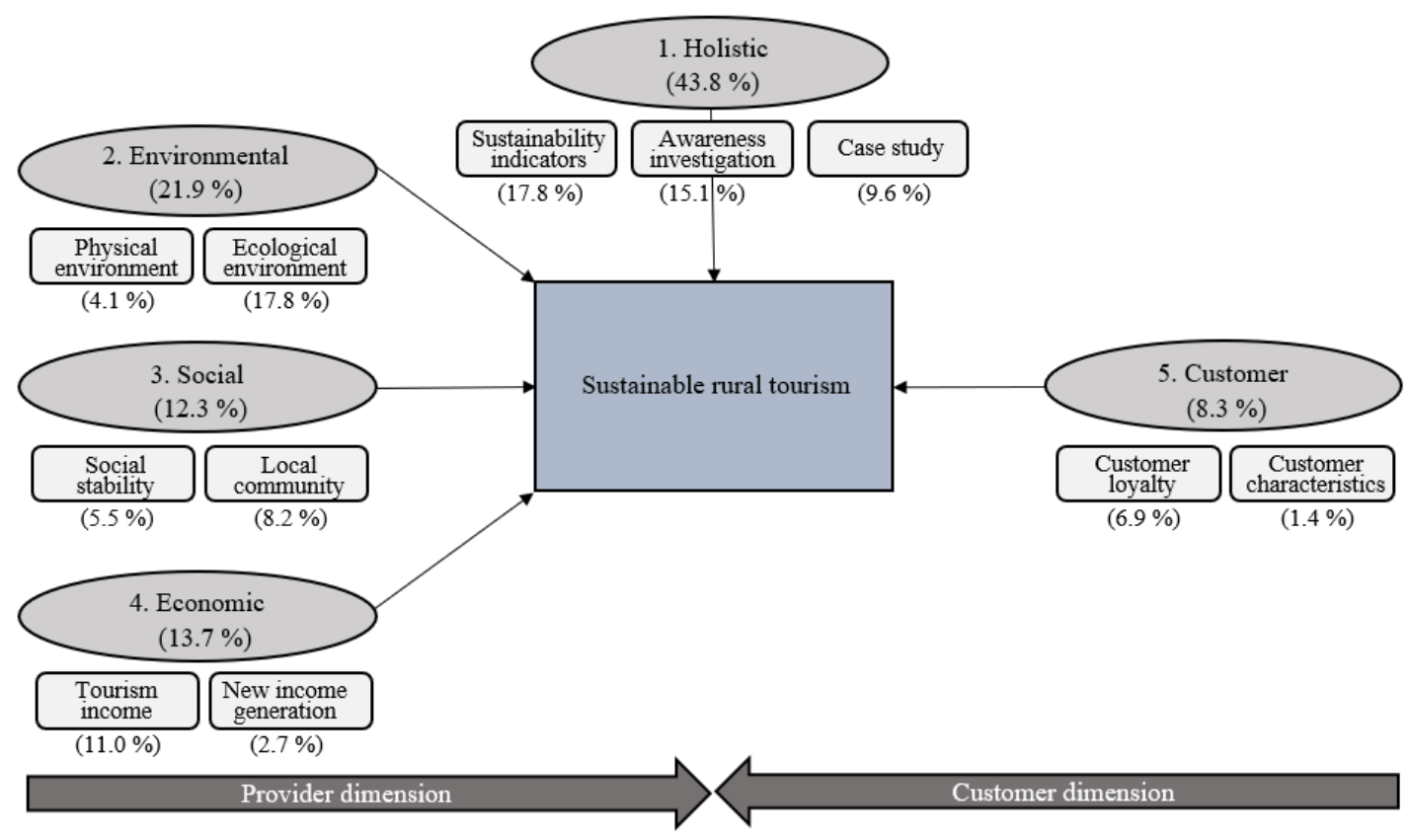

Figure 15. Types of research topics.

\subsubsection{Holistic}

If studies that address the topic of holistic sustainability are classified, they consist of those related to the term "sustainability indicators" for rural tourism (19.2\%), and "awareness investigation" (16.4\%), and "case study" 
(8.2\%) for sustainable rural tourism. First, "sustainability indicators" are the subject of studies that suggest the direction of sustainable rural tourism management by developing and applying indexes to evaluate the sustainability of rural tourism from various perspectives. In order to derive indicators for evaluating the sustainability of rural tourism, surveys were conducted on the following populations: residents (Atun, Nafa, \& Türker, 2019; Hashemi \& Ghaffary, 2017; Lew et al., 2016; Marzo-Navarro, Pedraja-Iglesias, \& Vinzón, 2015; Ristić et al., 2019), experts (Ernesto Pérez et al., 2017; Duk-byeong Park \& Yoon, 2011; Tseng et al., 2019), stakeholders (Lin, 2019; Wanner \& Pröbstl-Haider, 2019), and tourists (Petrović et al., 2018). The indicators were mainly divided into economic, environmental and social aspects of sustainable rural tourism. Next, studies with the subject of "awareness investigation" explored what influences sustainable rural tourism development by examining the attitudes and perceptions of verified stakeholders on sustainable rural tourism development. Several studies have investigated what the drivers of sustainable rural tourism for local residents are (Artal-Tur, BrionesPeñalver, Bernal-Conesa, \& Martínez-Salgado, 2019; De Lucia, Pazienza, Balena, \& Caporale, 2019; Fong, Lo, Songan, \& Nair, 2017; Hernández-Mogollón et al., 2011; Marzo-Navarro, Pedraja-Iglesias, \& Vinzón, 2018; Muresan et al., 2016; Yu, Chancellor, \& Cole, 2011; Zhu, Liu, Wei, Li, \& Wang, 2017). Other studies explored tourists' perceptions and attitudes about rural tourism as a sustainable development strategy (Juma \& KhademiVidra, 2019; Tan et al., 2013). In the holistic dimension, the last research topic is "case study". These studies analyze the success factors of cases that have developed sustainable rural tourism. They present a development model for sustainable rural tourism through case studies (Cucari et al., 2019; Gao et al., 2019; Sanagustín Fons et al., 2011), and also explore the interaction between rural tourism and sustainable rural development. (Kim \& Jamal, 2015; Mcareavey \& Mcdonagh, 2011; Trukhachev, 2015) (see Table 19.).

\subsubsection{Environmental}

Studies on the topic of environmental sustainability can be divided into those that specifically deal with sustainability in terms of "physical environment" (4.1\%) and those that explore sustainability with regard to "ecological environment" (17.8\%). First, studies related to "physical environment" analyze the transportation accessibility and transportation systems that increase the sustainability of rural tourism (Currie \& Falconer, 2014; Tomej \& Liburd, 2019), and cases of rural tourism used as a tool to increase the sustainability of agricultural land (Topcu, 2016). The second sub-topic in terms of environment is "ecological environment". Studies related to "ecological environment" examine the relationship between rural tourism development and environmental protection from a sustainable rural tourism perspective (J. Chen, Guan, (Bill) Xu, \& Clergeau, 2018; Garau, 2015; Lakner et al., 2018; Randelli \& Martellozzo, 2019; Rodrigues, Rodrigues, \& Peroff, 2015; Villanueva-álvaro, Mondéjar-Jiménez, \& Sáez-Martínez, 2017), suggest the direction of development for strengthening the link between rural tourism and agriculture (Addinsall et al., 2017; Leco et al., 2013; Mastronardi et al., 2015; Moore et al., 2018), and also analyze communication strategies to drive rural tourism tourists toward green behavior (Chin, Chin, \& Wong, 2018; Font, Elgammal, \& Lamond, 2017; Wang et al., 2018). 


\subsubsection{Social}

Studies on social sustainability can be distributed in detail between those dealing with "social stability" (4.1\%) and "local community" (8.2\%). First, studies on "social stability" analyze the effect of rural tourism on population influx from a social sustainability perspective. They examine cases that prevented rural residents from leaving rural areas due to the opportunities presented through rural tourism (Dax, Zhang, \& Chen, 2019), research other cases in which social sustainability was increased for the older population in the community through rural tourism (Chen et al., 2018), and analyze cases in which traditional villages were revitalized from social and cultural perspectives (Gao \& Wu, 2017). The second detailed topic of social sustainability is "local community". Studies related to "local community" focus on finding the role of the local community in sustainable rural tourism. They analyze the factors that determine the sustainability of social perspectives for local communities (L. Zhang \& Zhang, 2018), derive a community participation development model for sustainable rural tourism (Duarte Alonso \& Nyanjom, 2017; D. Hwang et al., 2012; Idziak et al., 2015), and seek the way to make rural tourism sustainable through the use of the traditional life culture of the local community (Tani, Hashimoto, \& Ochiai, 2016; Xu \& Sun, 2019).

\subsubsection{Economic}

The detailed topics of the study on economic sustainability consist of "tourism income" (11.0\%) and "new income generation" (2.7\%). First of all, research related to "tourism income" focuses on analyzing the sustainable livelihoods of local people through rural tourism income. They measure the economic effect of rural tourism (Barbieri, 2013; Butnaru \& Haller, 2017; Mbaiwa \& Stronza, 2010), evaluate the economic sustainability of rural households in response to seasonal changes (Guaita Martínez et al., 2019; Martín Martín et al., 2017; Su, Aaron, Guan, \& Wang, 2019), suggest strategies for the sustainability of households based on rural tourism (Su, Wall, Wang, \& Jin, 2019; Xiao, Luo, \& Yin, 2018). The second detailed topic is "new income generation". Studies based on the sub-topic of "new income generation" focus on analyzing cases of creating new sources of income for rural tourism. They examined cases that promoted economic sustainability by grafting the traditional resources of regions such as tea and the application of food heritagization to rural tourism (Guan, Gao, \& Zhang, 2019; Su, Wall, \& Wang, 2019).

\subsubsection{Customer}

The detailed topics of research on sustainability in terms of the topic of customer can be divided into "customer loyalty" (6.8\%) and "customer characteristics" (1.4\%). First, research on "customer loyalty" concentrate on finding tourists' loyalty that enables sustainable rural tourism. They measure how much loyalty a 
customer has toward rural destinations (Campón-Cerro et al., 2017; Ryglová et al., 2018) and tourists' satisfaction by establishing factors affecting the satisfaction experienced from rural tourism (Gurbuz \& Manaros, 2018; Jin \& Park, 2019; Long \& Nguyen, 2018). The second detailed topic of the research related to customer sustainability is "customer characteristics". Research associated with "customer characteristics" center on analyzing sustainable consumer behavior for rural tourism. In this regard, a segmentation study on the rural tourism market based on sustainable customer behavior was conducted (Kastenholz, Eusébio, et al., 2018).

Table 19. Detailed explanations of research topics.

\begin{tabular}{|c|c|c|}
\hline Topic & Explanation & Selected article \\
\hline \multicolumn{3}{|l|}{ Holistic } \\
\hline $\begin{array}{l}\text { Sustainability } \\
\text { indicators }\end{array}$ & $\begin{array}{l}\text { Development and application of an index that } \\
\text { evaluates the sustainability of rural tourism from } \\
\text { various perspectives. Assessment of sustainability } \\
\text { mainly in environmental, social and economic } \\
\text { aspects. }\end{array}$ & $\begin{array}{l}\text { Atun et al. (2019); Blancas et al. (2011); Ernesto } \\
\text { Pérez et al. (2017); Hashemi and Ghaffary (2017); } \\
\text { Lew et al. (2016); Lin (2019); Marzo-Navarro et } \\
\text { al. (2015); Park and Yoon (2011); Petrović et al. } \\
\text { (2018); Pjerotic et al. (2017); Ristić et al. (2019); } \\
\text { Tseng et al. (2019); Wanner and Pröbstl-Haider } \\
\text { (2019) }\end{array}$ \\
\hline $\begin{array}{l}\text { Awareness } \\
\text { investigation }\end{array}$ & $\begin{array}{l}\text { Survey on the perceptions and attitudes of local } \\
\text { residents, farmers, rural entrepreneurs, and tourists } \\
\text { about sustainable rural tourism development. } \\
\text { Derivation of factors influencing sustainable rural } \\
\text { tourism development. }\end{array}$ & $\begin{array}{l}\text { Artal-Tur et al. (2019); De Lucia et al. (2019); } \\
\text { Fong et al. (2017); Hernández-Mogollón et al. } \\
\text { (2011); Juma and Khademi-Vidra (2019); } \\
\text { Kallmuenzer et al. (2018); Marzo-Navarro et al. } \\
\text { (2018); Muresan et al. (2016); Tan et al. (2013); } \\
\text { Yu et al. (2011); Zhu et al. (2017) }\end{array}$ \\
\hline Case study & $\begin{array}{l}\text { Analysis of cases related to sustainable rural } \\
\text { tourism development. Presentation of a sustainable } \\
\text { rural tourism development model. }\end{array}$ & $\begin{array}{l}\text { Cucari et al. (2019); Gao et al. (2019); Kim and } \\
\text { Jamal (2015); Mcareavey and Mcdonagh (2011); } \\
\text { Sanagustín Fons et al. (2011); Schmidt et al. } \\
\text { (2016); Trukhachev (2015) }\end{array}$ \\
\hline \multicolumn{3}{|c|}{ Environmental } \\
\hline $\begin{array}{l}\text { Physical } \\
\text { environment }\end{array}$ & $\begin{array}{l}\text { Analysis of transportation accessibility or } \\
\text { transportation systems that enable sustainable rural } \\
\text { tourism. Examination of rural tourism used as a } \\
\text { tool to increase the sustainability of agricultural } \\
\text { land. }\end{array}$ & $\begin{array}{l}\text { Currie and Falconer (2014); Tomej and Liburd } \\
\text { (2019); Topcu (2016) }\end{array}$ \\
\hline $\begin{array}{l}\text { Ecological } \\
\text { environment }\end{array}$ & $\begin{array}{l}\text { Review of the relationship between tourism } \\
\text { development and environmental protection from a } \\
\text { sustainable rural tourism perspective. Factor }\end{array}$ & $\begin{array}{l}\text { Addinsall et al. (2017); Chen et al. (2018); Chin et } \\
\text { al. (2018); Font et al. (2017); Garau (2015); } \\
\text { Lakner et al. (2018); Leco et al. (2013); }\end{array}$ \\
\hline
\end{tabular}


analysis for rural tourism development without environmental damage.

Social

Social stability

Studies on cases of preventing rural residents from leaving through rural tourism and increasing social sustainability of the older population in the community

Local community

Tourism income

Research on how to promote the economic sustainability of local residents through rural tourism. Analysis of a sustainable livelihood structure through rural tourism.

New income Studies on cases of creating a new rural tourism generation income source beyond accommodation

\section{Customer}

Customer loyalty Survey of tourists' loyalty and satisfaction in order to enable sustainable rural tourism market based on sustainable consumer behavior
Mastronardi et al. (2015); Moore et al. (2018); Randelli and Martellozzo (2019); Rodrigues et al. (2015); Villanueva-álvaro et al. (2017); Wang et al. (2018)

Chen et al. (2018); Dax et al. (2019); Gao and Wu (2017); Ibanescu et al. (2018)

Duarte Alonso \& Nyanjom (2017); Hwang et al. (2012); Idziak et al. (2015); Tani et al. (2016); Xu and Sun (2019); Zhang and Zhang (2018)

Barbieri (2013); Butnaru and Haller (2017); Guaita Martínez et al. (2019); Martín Martín et al (2017); Mbaiwa and Stronza (2010); Su, Wall, Wang, and Jin (2019); Su, Aaron, Guan, and Wang (2019); Xiao et al. (2018)

Guan et al. (2019); Su, Wall, and Wang (2019) Campón-Cerro et al. (2017); Gurbuz and Manaros (2018); Jin and Park (2019); Long and Nguyen (2018); Ryglová et al. (2018)

Kastenholz et al. (2018) 
This study examined various aspects of understanding sustainability in the rural tourism sector, and extensively reviewed the literature by applying the topic of sustainable rural tourism. It analyzed 73 articles from 29 journals published from January 2009 to December 2019 through systematic review and detailed content analysis. The selected papers were divided into 11 detailed topics according to the classification system developed for this study. The results of this systematic review will help researchers and on-site rural tourism providers easily access publications on sustainable rural tourism, thereby contributing to narrowing the knowledge gap in sustainable rural tourism. It can also help them choose an approach for future research in the field of sustainable rural tourism and build a framework.

There are several key points that this study found in the literature related to sustainable rural tourism. First of all, research on sustainable rural tourism has been increasing steadily for about 10 years, as observed from 2009 to 2019. In particular, sustainable rural tourism centered on Europe and Asia has been treated as an important research topic in those regions. This means that sustainable rural tourism has become an increasingly important topic with the passage of time. Second, in general, the concept of sustainability applied to rural tourism is interpreted and implemented differently, depending on the researchers (J. Lu \& Nepal, 2009). In this study, it was revealed that more than $40 \%$ of papers on sustainable rural tourism were carried out from a holistic sustainability perspective. It shows that the sustainability in the rural tourism sector is understood and applied as a holistic concept without being biased to any one of the environmental, economic and social aspects. In the field of rural tourism, it is important to pay attention to interactions in all aspects of the environment, economy, and society, and to analyze them overall. Third, this study confirmed that efforts have been made to understand sustainable rural tourism from the customer perspective. Studies on tourists' loyalty and satisfaction, that enable sustainable rural tourism, reveal these efforts. It means that in order to become a sustainable rural tourism destination, it is indispensable to ultimately gain the tourists' hearts. Fourth, the detailed tendency of research related to sustainable rural tourism was confirmed. In the field of sustainable rural tourism, studies using environmental sustainability as a topic deal with sustainability in the "physical environment" and "ecological environment". Research on the topic of social sustainability, in detail, deals with "social stability", which analyzes the effect of rural tourism on population inflow from the perspective of social sustainability, and the "local community", which seeks the role of the community in sustainable rural tourism. The study on economic sustainability shows a tendency to focus on "tourism income", which analyzes the sustainable livelihood structure of local people through rural tourism income and "new income generation", which analyzes the cases in which new income sources are created. Finally, research on the customer dimension consists of topics related to "customer loyalty" and associated with "customer characteristics".

This study has some limitations despite the aforementioned contributions. First, the data used in this review were collected only from the Web of Science, thus studies on sustainable rural tourism from other journals were not utilized. It limits the opportunity to obtain broader information on sustainable rural tourism. Future studies should make efforts to find a wider range of journals covering sustainable rural tourism. The next limitation is that, although most articles are written in English, this study only reviewed English language written papers 
dealing with sustainable rural tourism. It also means that a more diverse and in-depth analysis of sustainable rural tourism research has not been made. Lastly, since there were several detailed topics within the topic of sustainable rural tourism, it was impossible to analyze 73 studies under a single framework to identify discrepancies in the research results and suggest the causes for them. It is desirable for future research to make efforts to generate a new concept framework and new knowledge by analyzing the consensus and inconsistency of the results of selected studies with more specific systematic review research topics in the sustainable rural tourism field. 
CHAPTER IV. GENERAL DISCUSSION 
94 


\section{IV.1. Main findings}

This thesis conducted a series of studies with the goal of offering a basis upon which to establish the strategic direction, which can strengthen the competitive capacity, to rural tourism providers and the local government, through a deep analysis of the essence of the customer experience in order to enhance customer value in rural tourism as a whole. This thesis drew various conclusions on rural tourism through diverse studies (Table 20).

Table 20. Main findings of the thesis

\begin{tabular}{|c|c|c|}
\hline & & Contents \\
\hline STUDY 1 & Title & $\begin{array}{l}\text { From netnography to segmentation for the description of the rural tourism market } \\
\text { based on tourist experiences in Spain } \\
\text { Journal of Destination Marketing \& Management, } 2021\end{array}$ \\
\hline & Objective & $\begin{array}{l}\text { This study aims to offer a basis for developing appropriate response strategies through } \\
\text { understanding tourists' natural perceptions related to their rural tourism experiences and the } \\
\text { characteristics of the rural tourism market segments. }\end{array}$ \\
\hline & Findings & $\begin{array}{l}\text { Diversified rural tourism experiences are pursued by Spanish tourists, which means that they } \\
\text { enjoy rural tourism with a variety of motivations and in diverse ways. } \\
\text { - It was confirmed that three market segments exist in rural tourism in Spain. } \\
\text { - Three corresponding themes associated with rural tourism experiences were derived from the } \\
\text { analysis. }\end{array}$ \\
\hline STUDY 2 & Title & $\begin{array}{l}\text { Exploring rural tourism experiences through subjective perceptions: A visual Q } \\
\text { approach } \\
\text { Spanish Journal of Agricultural Research, } 2020\end{array}$ \\
\hline & Objective & $\begin{array}{l}\text { The aim of study was to explore rural tourists' views in order to identify different market } \\
\text { segmentation in relation to rural tourism experiences. }\end{array}$ \\
\hline & Findings & $\begin{array}{l}\text { Three factors and consensus images on the experiences in rural tourism through the use of } \\
\text { visual Q were derived. } \\
\text { This paper suggests that rural tourism should offer a range of value propositions, thereby } \\
\text { escaping the existing monotonous ones. }\end{array}$ \\
\hline STUDY 3 & Title & $\begin{array}{l}\text { How can rural tourism be sustainable? A systematic review } \\
\text { Sustainability, } 2020\end{array}$ \\
\hline & Objective & $\begin{array}{l}\text { The objective of Study } 3 \text { is to enable researchers designing new research into sustainable } \\
\text { rural tourism to understand a cutting-edge subject and quickly get used to it. }\end{array}$ \\
\hline & Findings & $\begin{array}{l}\text { In the field of rural tourism, it is essential to pay attention to interactions in all aspects of the } \\
\text { environment, economy, and society, and to analyze them overall. } \\
\text { - Efforts to understand sustainable rural tourism from the customer perspective have been } \\
\text { increased, since customer loyalty is considered important for sustainability. }\end{array}$ \\
\hline
\end{tabular}


The objective of Study 1, which was conducted based on customers' natural perceptions of rural tourism experiences collected through the application of netnography, was to offer a basis for developing appropriate response strategies by understanding customers' natural perceptions related to their rural tourism experiences as well as the characteristics of the rural tourism market segments through the application of the non-artificial survey method, netnography, and providing it to rural tourism providers. The results of this study show that diversified rural tourism experiences are pursued by Spanish tourists. In addition, it was confirmed that three market segments exist in rural tourism in Spain and three corresponding themes were also derived from the results. In this study, three key themes associated with rural tourism experiences were derived from the analysis and rural tourism markets were segmented. Above all, the first theme was named 'comfort-driven visitor' that lays emphasis on staying mainly in rural accommodations of high quality. It included tourist experiences such as maintenance of facilities, cleanliness, well-equipped, and coziness. It is similar to 'inactives' in Portugal (Eusébio et al., 2017) that show a passive attitude and present low literacy levels and with higher familiarity levels with rural areas; 'the relaxers' in Scotland (Frochot, 2005) that prefer cheaper accommodations and do not practice many activities; 'passive tourists' in South Korea (Park \& Yoon, 2009) with low motivation but educated and wealthy; and 'enjoying rural destination's services and facilities' in Spain (Polo Peña et al., 2014) with the pursuit of comfort in rural tourism. According to Hearne and Salinas (2002), being well-equipped is a very important attribute in choosing rural tourism. Also, in terms of functionality, the maintenance of facilities is an important experience pursued by tourists (Polo Peña et al., 2014). This segment contains a high proportion of people who enjoy rural tourism in 'family' or 'friend group' units and seek accommodations at a relatively affordable price. This is presumably because the segment 'comfort-driven visitor' utilizes rural tourism with a focus on rural tourism facilities for gatherings with family or friends. In sequence, the second theme was entitled 'rural ambiance spender', which is characterized by the pursuit of enjoyment and quiet rest around rural tourism accommodations. They pursue experiences in rural tourism such as convenience, customer care, overall atmosphere, rustic landscape, gastronomy, and value for money. It is consistent with the segment 'ruralist' derived from Almeida, Correia, and Pimpão (2014) or the term 'rural explorers' determined by Dong et al., (2013). This group shares an interest in the rural lifestyle from other empirical research such as 'traditional ruralists' in Portugal (Kastenholz et al., 1999), 'the rurals' in Scotland (Frochot, 2005) or 'rural life tourists' in South-Eastern Spain (Molera \& Albaladejo-Pina, 2007). In rural tourism choices, customer care created through the interaction between rural tourism hosts and tourists should also be seen as an important attribute (Choo \& Petrick, 2014). Additionally, previous studies show that a rustic landscape is a key resource of rural tourism (Figueiredo \& Raschi, 2012; Kastenholz et al., 2012). Simultaneously, gastronomy is regarded as an important attractor in maximizing the tourist experiences on a sensory level (Everett, 2008). This segment has a high proportion of 'couple' units and consists of people paying relatively medium prices for rural tourism accommodations. These results are presumed to stem from the fact that the segment 'rural ambience spender' seeks to enjoy the rural atmosphere and is willing to pay more money for this. Finally, the third theme is 'active leisure seeker', which is characterized by pursuing a variety of ways to enjoy active leisure in natural areas. The experiences included are activities, relaxation, privacy, natural environment, and lots of cultural tourism. This group has connections with 'nature lovers' and 'active visitors' 
segments in Portugal (Eusébio et al., 2017; Kastenholz, Davis, \& Paul, 1999), 'the actives' and the gazers in Scotland (Frochot, 2005), and 'heritage \& nature seekers' in Gambia (Rid, Ezeuduji, \& Pröbstl-Haider, 2014). According to Chaminuka et al. (2012), outdoor activity should be considered a key attribute when choosing the rural tourism destination. In addition, the relaxation associated with emotional fullness is the most important experience that tourists seek in rural tourism (Richard Sharpley \& Jepson, 2011). Similar to the findings from previous studies, the natural environment plays an important role in choosing the rural tourism destination (Figueiredo \& Raschi, 2012; Kastenholz et al., 2012). This group enjoys rural tourism in 'couple' or 'family' units. In this segment, the high price level is the most common price range. These results may be because the segment 'active leisure seeker' pursues a variety of activities around nature and rural areas and would gladly pay more for rural tourism accommodations that provide the conditions for such activities. This study also confirmed that different themes related to rural tourism experiences were created according to the characteristics sought by customers, which were primarily based on trip types and price levels. The first theme 'comfort-driven visitor' was mainly composed of 'family' and 'friend group' as the type of rural tourism pursued by tourists. In the second theme 'rural ambiance spender', the proportion of 'couple' was relatively high, and in the third theme 'active leisure seeker', the trip type had a relatively high proportion of 'couple' and 'family'. In terms of price level, the first theme 'comfort-driven visitor' contained a number of tourists seeking low and medium price levels. While the medium price level category was mainly distributed into the second theme 'rural ambiance spender', high price level was the majority in the third theme 'active leisure seeker'.

Study 2 was conducted with the goal of exploring rural tourists' perceptions in order to identify different market segmentation in relation to rural tourism experiences from rural tourism providers, as well as policymakers in local governments, amongst others. In this research, three factors and consensus images on the experiences in rural tourism were derived through the use of visual Q. We are able to describe tourist experiences in rural tourism in Spain with the result of the analysis. First, the common pursuit amongst all segments is 'Pleasant break'. Eating good food, seeing verified cultural heritages and resting well in the rural environments are the fundamental elements that most tourists generally seek in rural tourism. The detailed experiences that are pursued are 'Gastronomy', 'Rest', 'Lots of cultural tourism', and 'Value for money'. In sequence, the first segment is called 'Occasion driven visitor', which seeks special experiences based on the facilities of a rural tourist accommodation. For this tourist type, it is important to experience 'Cleanliness', 'Comfort', 'Maintenance of facilities', and 'Customer care'. Next, there is a second segment called 'Active leisure seeker', which pursues a variety of activities in nature. They pursue experiences such as 'Nature', 'Landscape', 'Mountain·Forest' and 'Excursion'. Finally, there is a third segment called 'Rural immersion pursuer' that seeks a perfect escape and deep relaxation in a rural environment, disconnected from daily life. The experiences pursued by tourists of this segment are 'Nature', 'Disconnection from the world', 'Rustic environment', and 'Observation of fauna and flora'. Combining these conclusions, we have been able to define tourist experiences in rural tourism in Spain. From a theoretical point of view, this study has made some contribution. The present study is meaningful for explaining the types of markets that exist in rural tourism by presenting tourist types based on the experiences that tourists truly pursue in rural tourism. This result helps make it possible to understand the rural tourism markets based on tourist needs. 
Since the results of that study were derived based on experiences limited to a specific rural tourism area, it is difficult to apply it to other rural tourism areas with different characteristics. Nonetheless, the results of our research can be applied to the rural tourism areas in various situations because it was surveyed tourists with varied experiences as well as experts in rural tourism. It can give rural tourism an opportunity to put forward various value propositions, thus escaping the monotonous value propositions that we currently observe.

Study 3 was conducted with the goal of enabling researchers designing new research on sustainable rural tourism to understand this cutting-edge subject and quickly become familiar with it. This study examined various aspects of understanding sustainability in the rural tourism sector, and extensively reviewed the literature by applying the topic of sustainable rural tourism. It analyzed 73 articles from 29 journals published from January 2009 to December 2019 through systematic review and detailed content analysis (Table 21). The selected papers were divided into 11 detailed topics according to the classification system developed for this study (Table 22). The results of this systematic review will help researchers and on-site rural tourism providers easily access publications on sustainable rural tourism, thereby contributing to narrowing the knowledge gap in sustainable rural tourism. It can also help them choose an approach for future research in the field of sustainable rural tourism and build a framework. There are several key points that this study found in the literature related to sustainable rural tourism. First of all, research on sustainable rural tourism has been increasing steadily for about 10 years, as observed from 2009 to 2019. In particular, sustainable rural tourism centered on Europe and Asia has been treated as an important research topic in those regions. This means that sustainable rural tourism has become an increasingly important topic with the passage of time. Second, in general, the concept of sustainability applied to rural tourism is interpreted and implemented differently, depending on the researchers (J. Lu \& Nepal, 2009). In this study, it was revealed that more than $40 \%$ of papers on sustainable rural tourism were carried out from a holistic sustainability perspective. It shows that the sustainability in the rural tourism sector is understood and applied as a holistic concept without being biased to any one of the environmental, economic and social aspects. In the field of rural tourism, it is important to pay attention to interactions in all aspects of the environment, economy, and society, and to analyze them overall. Third, this study confirmed that efforts have been made to understand sustainable rural tourism from the customer perspective. Studies on tourists' loyalty and satisfaction, that enable sustainable rural tourism, reveal these efforts. It means that in order to become a sustainable rural tourism destination, it is indispensable to ultimately gain the tourists' hearts. Fourth, the detailed tendency of research related to sustainable rural tourism was confirmed. In the field of sustainable rural tourism, studies using environmental sustainability as a topic deal with sustainability in the "physical environment" and "ecological environment". Research on the topic of social sustainability, in detail, deals with "social stability", which analyzes the effect of rural tourism on population inflow from the perspective of social sustainability, and the "local community", which seeks the role of the community in sustainable rural tourism. The study on economic sustainability shows a tendency to focus on "tourism income", which analyzes the sustainable livelihood structure of local people through rural tourism income and "new income generation", which analyzes the cases in which new income sources are created. Finally, research on the customer dimension consists of topics related to "customer loyalty" and associated with "customer characteristics". 
Table 21. Articles included in the review.

\begin{tabular}{|c|c|c|c|c|c|c|}
\hline ID & Author/Year & Purpose & Topics & $\begin{array}{l}\text { Detailed } \\
\text { topics }\end{array}$ & Research methods & Data source \\
\hline 1 & $\begin{array}{l}\text { Mbaiwa and } \\
\text { Stronza } \\
\text { (2010) }\end{array}$ & $\begin{array}{l}\text { To analyze the impact of rural tourism development } \\
\text { on the livelihood of rural households }\end{array}$ & Economic & $\begin{array}{l}\text { Tourism } \\
\text { income }\end{array}$ & In-depth interview & Residents \\
\hline 2 & $\begin{array}{l}\text { Yu et al. } \\
\text { (2011) }\end{array}$ & $\begin{array}{l}\text { To Investigate local residents' perceptions and } \\
\text { attitudes toward sustainable rural tourism }\end{array}$ & Holistic & $\begin{array}{l}\text { Awareness } \\
\text { investigation }\end{array}$ & $\begin{array}{l}\text { Questionnaire } \\
\text { survey }\end{array}$ & Residents \\
\hline 3 & $\begin{array}{l}\text { Sanagustín } \\
\text { Fons et al. } \\
\text { (2011) }\end{array}$ & $\begin{array}{l}\text { To conduct a case study on sustainable rural tourism } \\
\text { development }\end{array}$ & Holistic & Case study & In-depth interview & Experts \\
\hline 4 & $\begin{array}{l}\text { Mcareavey } \\
\text { and } \\
\text { Mcdonagh } \\
\text { (2011) }\end{array}$ & $\begin{array}{l}\text { To analyze a case where sustainable rural tourism } \\
\text { contributed positively to rural development }\end{array}$ & Holistic & Case study & $\begin{array}{l}\text { Qualitative } \\
\text { analysis on textual } \\
\text { data }\end{array}$ & $\begin{array}{l}\text { Secondary } \\
\text { data }\end{array}$ \\
\hline 5 & $\begin{array}{l}\text { Park and } \\
\text { Yoon (2011) }\end{array}$ & $\begin{array}{l}\text { To develop an evaluation index for sustainable rural } \\
\text { tourism that can provide the direction of sustainable } \\
\text { rural tourism management }\end{array}$ & Holistic & $\begin{array}{l}\text { Sustainability } \\
\text { indicators }\end{array}$ & Delphi & Experts \\
\hline 6 & $\begin{array}{l}\text { Hernández- } \\
\text { Mogollón et } \\
\text { al. (2011) }\end{array}$ & $\begin{array}{l}\text { To understand farmers' awareness of the } \\
\text { sustainability of agritourism }\end{array}$ & Holistic & $\begin{array}{l}\text { Awareness } \\
\text { investigation }\end{array}$ & $\begin{array}{l}\text { Questionnaire } \\
\text { survey }\end{array}$ & Residents \\
\hline 7 & $\begin{array}{l}\text { Blancas et } \\
\text { al. (2011) }\end{array}$ & $\begin{array}{l}\text { To propose indicators for analyzing sustainability of } \\
\text { rural tourism }\end{array}$ & Holistic & $\begin{array}{l}\text { Sustainability } \\
\text { indicators }\end{array}$ & $\begin{array}{l}\text { Quantitative } \\
\text { analysis on } \\
\text { statistical data }\end{array}$ & $\begin{array}{l}\text { Secondary } \\
\text { data }\end{array}$ \\
\hline 8 & $\begin{array}{l}\text { Hwang et al. } \\
\text { (2012) }\end{array}$ & $\begin{array}{l}\text { To analyze the role of the rural community for } \\
\text { sustainable rural tourism development }\end{array}$ & Social & $\begin{array}{l}\text { Local } \\
\text { community }\end{array}$ & In-depth interview & Residents \\
\hline 9 & $\begin{array}{l}\text { Barbieri } \\
(2013)\end{array}$ & $\begin{array}{l}\text { To assess the sustainability of farms that provide } \\
\text { agritourism in economic terms }\end{array}$ & Economic & $\begin{array}{l}\text { Tourism } \\
\text { income }\end{array}$ & $\begin{array}{l}\text { Quantitative } \\
\text { analysis on } \\
\text { statistical data }\end{array}$ & Residents \\
\hline 10 & $\begin{array}{l}\text { Leco et al. } \\
(2013)\end{array}$ & $\begin{array}{l}\text { To investigate tourists' attitudes and motivations for } \\
\text { agritourism, which is an activity with strong } \\
\text { environmental factors }\end{array}$ & $\begin{array}{l}\text { Environ- } \\
\text { mental }\end{array}$ & $\begin{array}{l}\text { Ecological } \\
\text { environment }\end{array}$ & $\begin{array}{l}\text { Questionnaire } \\
\text { survey }\end{array}$ & Tourists \\
\hline 11 & $\begin{array}{l}\text { Tan et al. } \\
\text { (2013) }\end{array}$ & $\begin{array}{l}\text { To investigate tourists' perceptions of important } \\
\text { factors influencing the development of sustainable } \\
\text { rural tourism }\end{array}$ & Holistic & $\begin{array}{l}\text { Awareness } \\
\text { investigation }\end{array}$ & $\begin{array}{l}\text { Questionnaire } \\
\text { survey }\end{array}$ & Tourists \\
\hline 12 & $\begin{array}{l}\text { Currie and } \\
\text { Falconer } \\
(2014)\end{array}$ & $\begin{array}{l}\text { To survey the perceptions of building a } \\
\text { transportation system to increase sustainable } \\
\text { accessibility to rural tourism }\end{array}$ & $\begin{array}{l}\text { Environ- } \\
\text { mental }\end{array}$ & $\begin{array}{l}\text { Physical } \\
\text { environment }\end{array}$ & In-depth interview & Stakeholders \\
\hline 13 & $\begin{array}{l}\text { Trukhachev } \\
\text { (2015) }\end{array}$ & $\begin{array}{l}\text { To analyze cases where rural tourism positively } \\
\text { affected sustainable rural development and rural } \\
\text { production }\end{array}$ & Holistic & Case study & Delphi & Stakeholders \\
\hline 14 & $\begin{array}{l}\text { Rodrigues et } \\
\text { al. (2015) }\end{array}$ & $\begin{array}{l}\text { To conduct a case study on sustainable rural tourism } \\
\text { development using nature in rural areas }\end{array}$ & $\begin{array}{l}\text { Environ- } \\
\text { mental }\end{array}$ & $\begin{array}{l}\text { Ecological } \\
\text { environment }\end{array}$ & $\begin{array}{l}\text { Quantitative } \\
\text { analysis on } \\
\text { statistical data }\end{array}$ & $\begin{array}{l}\text { Secondary } \\
\text { data }\end{array}$ \\
\hline 15 & $\begin{array}{l}\text { Garau } \\
(2015)\end{array}$ & $\begin{array}{l}\text { To conduct a case study on balanced development } \\
\text { between rural tourism and landscape protection from } \\
\text { a sustainable rural tourism perspective }\end{array}$ & $\begin{array}{l}\text { Environ- } \\
\text { mental }\end{array}$ & $\begin{array}{l}\text { Ecological } \\
\text { environment }\end{array}$ & $\begin{array}{l}\text { Quantitative } \\
\text { analysis on } \\
\text { statistical data }\end{array}$ & $\begin{array}{l}\text { Secondary } \\
\text { data }\end{array}$ \\
\hline
\end{tabular}


Navarro et sustainability for rural tourism

al. (2015)

$17 \quad$ Kim and

To conduct a case study on new forms of rural

Jamal (2015) tourism that can contribute to sustainable rural development

\section{Idziak et al. To develop a rural tourism development model} based on the participation of local communities that enables the creation of sustainable rural tourism experiences

19 Mastronardi To analyze the environmental performance of farms et al. (2015) providing agricultural tourism

20 Muresan et To investigate local residents' perceptions and al. (2016) attitudes toward sustainable rural tourism development

21 Lew et al. To derive indicators of sustainability and resilience (2016) through research on rural tourism communities

22 Topcu (2016)

23 Schmidt et To conduct a case study on agritourism that provides sustainability for land where productivity is lost al. (2016) To survey important factors affecting sustainable rural tourism for rural tourism entrepreneurs

24 Tani et al. To explore ways to improve the sustainability of (2016) rural tourism through the use of traditional living culture in rural areas

25 Zhu et al. To explore local residents' perceptions of sustainable (2017) rural tourism development

26 Addinsall et To develop a model to strengthen the link between al. (2017) agricultural tourism and agriculture

27 Duarte

To seek the role of the local community in

Alonso and sustainable rural tourism

Nyanjom

(2017)

28 Font et al.

To analyze communication activities related to the sustainability of rural tourism companies

29 Pjerotic et al. (2017)

To develop indicators to evaluate sustainable rural tourism

30 Fong et al. To explore the direction of sustainable rural tourism (2017) development from a rural community perspective

31 Hashemi and To develop an index to evaluate rural tourism Ghaffary sustainability (2017)

32 Butnaru and To measure economic effect in terms of the Haller sustainability of rural tourism (2017)

33 Villanueva- To analyze important factors that enable rural álvaro et al. tourism development without environmental damage (2017)

Sustainability Questionnaire indicators survey

Holistic

Case study

In-depth interview

Stakeholders

Social

Local

community

Participant

observation

Environ-

Ecological

Questionnaire

Residents

mental

environment

survey

Holistic

Awareness

Questionnaire

Residents

investigation survey

Holistic

Sustainability

In-depth interview

Residents

indicators

Environ-

Physical

In-depth interview

Residents

mental

environment

Holistic

Case study

In-depth interview

Stakeholders

Social

Local

community

Holistic

Awareness

Questionnaire

Residents

investigation

survey

Environ-

Ecological

Qualitative

mental

environment

analysis on textua

data

Social

Local

community

Focus group

interview

Environ-

Ecological

In-depth interview

Residents

mental

environment

Holistic

Sustainability

Quantitative

indicators

analysis on

Secondary

data

Holistic

Awareness

statistical data

investigation

Questionnaire

Residents

Holistic

Sustainability

indicators

Residents

Economic

Tourism

Quantitative

Secondary

income

analysis on

statistical data

Environ-

Ecological

Questionnaire

environment survey data

Stakeholders 
(2017)

To investigate ways to create tourist loyalty as a

Cerro et al. sustainable competitive advantage

To evaluate seasonality of rural tourism in terms of

Martín et al. economic sustainability

\section{(2017) villages through rural tourism}

38 Moore et al. To research the integration of agricultural ecology (2018) and rural tourism

39 Chin et al. To research green marketing practices for

(2018) sustainable rural tourism

40 Gurbuz and To measure tourist satisfaction for sustainable rural Manaros tourism

(2018)

41 Petrović et To evaluate competitiveness of rural tourism as a al. (2018) means of sustainable rural development

42 Kallmuenzer To explore the drivers of making rural tourism et al. (2018) family enterprises sustainable

43 Ryglová et To investigate customer loyalty that enables al. (2018) sustainable rural tourism

44 Long and To analyze factors affecting customer satisfaction Nguyen and intention to revisit rural tourism destinations (2018)

45 Lakner et al. To conduct a rural tourism case study developed (2018) without harming the sustainability of the environment

46 Chen et al. To analyze the impact of rural tourism on the (2018) sustainability of the older populations in rural areas

47 Wang et al. To investigate the role of the host to induce (2018) sustainable green behavior of rural tourists

48 Xiao et al. To analyze the effect of rural tourism development on farmers household livelihood

49 Ibanescu et To study the impact of rural tourism on the al. (2018) sustainability of rural society

50 Chen et al. To propose a green tourism supply model that can (2018) solve the environmental damage caused by rural tourism development

51 Zhang and To identify the determinants of social sustainability Zhang for small-scale rural tourism enterprises

(2018)

52 MarzoNavarro et To survey local residents' awareness of sustainable al. (2018)

\begin{tabular}{|c|c|c|c|}
\hline Customer & $\begin{array}{l}\text { Customer } \\
\text { loyalty }\end{array}$ & $\begin{array}{l}\text { Questionnaire } \\
\text { survey }\end{array}$ & Tourists \\
\hline Economic & $\begin{array}{l}\text { Tourism } \\
\text { income }\end{array}$ & $\begin{array}{l}\text { Quantitative } \\
\text { analysis on } \\
\text { statistical data }\end{array}$ & $\begin{array}{l}\text { Secondary } \\
\text { data }\end{array}$ \\
\hline Social & $\begin{array}{l}\text { Social } \\
\text { stability }\end{array}$ & $\begin{array}{l}\text { Participant } \\
\text { observation }\end{array}$ & Stakeholders \\
\hline $\begin{array}{l}\text { Environ- } \\
\text { mental }\end{array}$ & $\begin{array}{l}\text { Ecological } \\
\text { environment }\end{array}$ & $\begin{array}{l}\text { Quantitative } \\
\text { analysis on } \\
\text { statistical data }\end{array}$ & $\begin{array}{l}\text { Secondary } \\
\text { data }\end{array}$ \\
\hline $\begin{array}{l}\text { Environ- } \\
\text { mental }\end{array}$ & $\begin{array}{l}\text { Ecological } \\
\text { environment }\end{array}$ & $\begin{array}{l}\text { Questionnaire } \\
\text { survey }\end{array}$ & Tourists \\
\hline Customer & $\begin{array}{l}\text { Customer } \\
\text { loyalty }\end{array}$ & $\begin{array}{l}\text { Questionnaire } \\
\text { survey }\end{array}$ & Tourists \\
\hline Holistic & $\begin{array}{l}\text { Sustainability } \\
\text { indicators }\end{array}$ & $\begin{array}{l}\text { Questionnaire } \\
\text { survey }\end{array}$ & Tourists \\
\hline Holistic & $\begin{array}{l}\text { Awareness } \\
\text { investigation }\end{array}$ & $\begin{array}{l}\text { Questionnaire } \\
\text { survey }\end{array}$ & Stakeholders \\
\hline Customer & $\begin{array}{l}\text { Customer } \\
\text { loyalty }\end{array}$ & $\begin{array}{l}\text { Questionnaire } \\
\text { survey }\end{array}$ & Tourists \\
\hline Customer & $\begin{array}{l}\text { Customer } \\
\text { loyalty }\end{array}$ & $\begin{array}{l}\text { Questionnaire } \\
\text { survey }\end{array}$ & Tourists \\
\hline $\begin{array}{l}\text { Environ- } \\
\text { mental }\end{array}$ & $\begin{array}{l}\text { Ecological } \\
\text { environment }\end{array}$ & $\begin{array}{l}\text { Questionnaire } \\
\text { survey }\end{array}$ & Stakeholders \\
\hline Social & $\begin{array}{l}\text { Social } \\
\text { stability }\end{array}$ & In-depth interview & Residents \\
\hline $\begin{array}{l}\text { Environ- } \\
\text { mental }\end{array}$ & $\begin{array}{l}\text { Ecological } \\
\text { environment }\end{array}$ & $\begin{array}{l}\text { Participant } \\
\text { observation }\end{array}$ & Tourists \\
\hline Economic & $\begin{array}{l}\text { Tourism } \\
\text { income }\end{array}$ & In-depth interview & Residents \\
\hline Holistic & $\begin{array}{l}\text { Social } \\
\text { stability }\end{array}$ & $\begin{array}{l}\text { Quantitative } \\
\text { analysis on } \\
\text { statistical data }\end{array}$ & $\begin{array}{l}\text { Secondary } \\
\text { data }\end{array}$ \\
\hline $\begin{array}{l}\text { Environ- } \\
\text { mental }\end{array}$ & $\begin{array}{l}\text { Ecological } \\
\text { environment }\end{array}$ & In-depth interview & Stakeholders \\
\hline Social & $\begin{array}{l}\text { Local } \\
\text { community }\end{array}$ & $\begin{array}{l}\text { Questionnaire } \\
\text { survey }\end{array}$ & Residents \\
\hline Holistic & $\begin{array}{l}\text { Awareness } \\
\text { investigation }\end{array}$ & $\begin{array}{l}\text { Questionnaire } \\
\text { survey }\end{array}$ & Residents \\
\hline
\end{tabular}


Artal-Tur et To derive competitive advantage elements to

Holistic al. (2019) enhance sustainability for rural tourism

55 Cucari et al. To conduct a case study on sustainable rural tourism

$$
\text { development }
$$
$\mathrm{Su}, \mathrm{Wa}$

To study the sustainable livelihood structure of local

Wang, and people through rural tourism Jin (2019)

57 Tomej and Liburd (2019) sustainability

59 Wanner and To evaluate stakeholders' awareness of the

Pröbstl- sustainability of rural tourism development

Haider

(2019)

60 Guaita Martínez et

To present indicators to measure the intensity of

Economic

Tourism

Quantitative

income

analysis on

Secondary

al. (2019)

61 Randelli and

To analyze the relationship between rural tourism

Martellozzo

and sustainability in rural communities

(2019)

62 Gao et al.

To derive a sustainable rural development model based on rural tourism through case studies

63 Lin (2019)

To develop a sustainability assessment index for rural tourism

$64 \mathrm{Su}$, Wall

To analyze the relationship between regional

and Wang specialty tea and rural tourism in terms of

sustainability

65 Atun et al. To develop indicators for rural tourism sustainability assessment

66 Dax et al. To conduct a case study that prevented the departure of local residents by providing economic incentives through agricultural tourism

67 Tseng et al. To derive important attributes affecting sustainable (2019)

68 De Lucia et $\begin{array}{ll}\text { To Investigate local people's percep } \\ \text { al. (2019) } & \text { tourism in terms of sustainability }\end{array}$ agricultural tourism

69 Juma and To Investigate urban residents' perceptions of rural Khademi- tourism to develop sustainable rural tourism Vidra (2019) development strategies

Holistic

Case study

\section{Qualitative}

analysis on textual

data

Holistic

Sustainability

Questionnaire

indicators

survey

Economic

New income

Questionnaire

generation survey

Holistic

Sustainability

Questionnaire

Residents

indicators survey

Social

Social

Qualitative

Secondary

stability

analysis on textua

data

data

Holistic

Sustainability Delphi

Experts

indicators

Holistic

Awareness

Questionnaire

Residents

investigation survey

Holistic

Awareness

Questionnaire

Tourists

investigation survey

Economic

Tourism

Questionnaire

Residents 


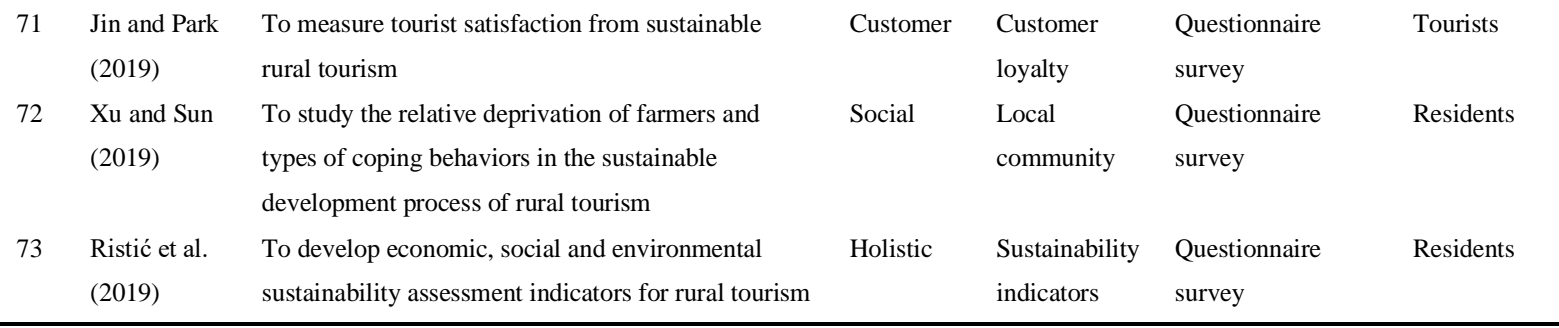

Table 22. Topics and explanations.

Topic Explanation

Holistic

Sustainability Development and application of an index that evaluates the sustainability of rural indicators tourism from various perspectives. Assessment of sustainability mainly in environmental, social and economic aspects.

Awareness Survey on the perceptions and attitudes of local residents, farmers, rural investigation entrepreneurs, and tourists about sustainable rural tourism development. Derivation of factors influencing sustainable rural tourism development.

Case study Analysis of case related to sustainable rural tourism development. Presentation of a sustainable rural tourism development model.

Environmental Physical Analysis of transportation accessibility or transportation systems that enable environment sustainable rural tourism. Examination of rural tourism used as a tool to increase the sustainability of agricultural land.

Ecological Review of the relationship between tourism development and environmental environment protection from a sustainable rural tourism perspective. Factor analysis for rural tourism development without environmental damage.

Social Social stability Studies on cases of preventing rural residents from leaving through rural tourism and increasing social sustainability of the older population in the community
Local Investigation of the role of the local community for sustainable rural tourism.
community Exploration of the sustainability of rural tourism through the use of the local communities' traditional living culture.




\begin{tabular}{|c|c|c|}
\hline \multirow[t]{2}{*}{ Economic } & $\begin{array}{l}\text { Tourism } \\
\text { income }\end{array}$ & $\begin{array}{l}\text { Research on how to promote the economic sustainability of local residents through } \\
\text { rural tourism. Analysis of a sustainable livelihood structure through rural tourism. }\end{array}$ \\
\hline & $\begin{array}{l}\text { New income } \\
\text { generation }\end{array}$ & $\begin{array}{l}\text { Studies on cases of creating a new rural tourism income source beyond } \\
\text { accommodation }\end{array}$ \\
\hline \multirow[t]{2}{*}{ Customer } & $\begin{array}{l}\text { Customer } \\
\text { loyalty }\end{array}$ & $\begin{array}{l}\text { Survey of tourists' loyalty and satisfaction in order to enable sustainable rural } \\
\text { tourism }\end{array}$ \\
\hline & $\begin{array}{l}\text { Customer } \\
\text { characteristics }\end{array}$ & $\begin{array}{l}\text { Study on the segmentation of the rural tourism market based on sustainable } \\
\text { consumer behavior }\end{array}$ \\
\hline
\end{tabular}

\section{IV.2. Theoretical implications}

Study 1 contributes to the existing literature in terms of theory. First, in the theoretical terms, this study was able to derive themes based on rural tourism experiences. The first theme 'comfort-driven visitor' is similar to 'inactives' in Portugal (Eusébio et al., 2017) that show a passive attitude and present low literacy levels and with higher familiarity levels with rural areas; 'the relaxers' in Scotland (Frochot, 2005) that prefer cheaper accommodations and do not practice many activities; 'passive tourists' in South Korea (Park \& Yoon, 2009) with low motivation but educated and wealthy; and 'enjoying rural destination's services and facilities' in Spain (Polo Peña et al., 2014) with the pursuit of comfort in rural tourism. According to Hearne and Salinas (2002), being well-equipped is a very important attribute in choosing rural tourism. Also, in terms of functionality, the maintenance of facilities is an important experience pursued by tourists (Polo Peña et al., 2014). With regard to existing research, the second theme 'rural ambiance spender' is consistent with the segment 'ruralist' derived from Almeida, Correia, and Pimpão (2014) or the term 'rural explorers' determined by Dong et al., (2013). This group shares an interest in the rural lifestyle from other empirical research such as 'traditional ruralists' in Portugal (Kastenholz et al., 1999), 'the rurals' in Scotland (Frochot, 2005) or 'rural life tourists' in South-Eastern Spain (Molera \& Albaladejo-Pina, 2007). In rural tourism choices, customer care created through the interaction between rural tourism hosts and tourists should also be seen as an important attribute (Choo \& Petrick, 2014). Additionally, previous studies show that a rustic landscape is a key resource of rural tourism (Figueiredo \& Raschi, 2012; Kastenholz et al., 2012). Simultaneously, gastronomy is regarded as an important attractor in maximizing the tourist experiences on a sensory level (Everett, 2008). The final theme 'active leisure seeker' has connections with 'nature lovers' and 'active visitors' segments in Portugal (Eusébio et al., 2017; Kastenholz, Davis, \& Paul, 1999), 'the actives' and the gazers in Scotland (Frochot, 2005), and 'heritage \& nature seekers' in Gambia (Rid, Ezeuduji, \& Pröbstl-Haider, 2014). According to Chaminuka et al. (2012), outdoor activity should be considered a key 
attribute when choosing the rural tourism destination. In addition, the relaxation associated with emotional fullness is the most important experience that tourists seek in rural tourism (Richard Sharpley \& Jepson, 2011). Similar to the findings from previous studies, the natural environment plays an important role in choosing the rural tourism destination (Figueiredo \& Raschi, 2012; Kastenholz et al., 2012). This study enables researchers to promote an experiential approach by understanding the experiences pursued by rural tourists. Although there are specific experiences in which each theme has a deeper relationship, this study found that tourists seek comprehensive experiences in terms of the cognition, affection and sensory factors. In the first theme 'comfort-driven visitor', experiences in the cognitive dimension related to facilities were most highly considered in the selection process (Knutson \& Beck, 2008). In the second theme 'rural ambiance spender', sensory experiences based on landscape and gastronomy were most emphasized and affective experiences related to customer care were considered next (Choo \& Petrick, 2014; Kastenholz et al., 2012). In the third theme 'active leisure seeker', affective experiences based on relaxation and sensory experiences derived from nature and culture were primarily considered to be of equal important (Frochot, 2005; Richard Sharpley \& Jepson, 2011).

Study 2 has added some meaning to the existing literature from theoretical perspectives. Fernandes and Cruz (2016) analyzed the factors that affect tourism experiences such as functional benefits, service providers, entertainment, learning, trust and environment. They provided criteria for identifying the kinds of experiences existing within tourism by classifying the types of tourist experiences, whereas the present study is meaningful for explaining the types of markets that exist in rural tourism by presenting tourist types based on the experiences that tourists truly pursue in rural tourism. This result helps make it possible to understand the rural tourism markets based on tourist needs. Also, related to tourist experiences in rural tourism, Sharpley and Jepson (2011) conducted focus group interviews of the tourists who had visited the Lake District and discovered four kinds of experiences in rural tourism: remoteness, the spiritualness of place, solitude/quietness and altitude/the limitless. Since the results of that study were derived based on experiences limited to a specific rural tourism area, it is difficult to apply it to other rural tourism areas with different characteristics. Nonetheless, the results of our research can be applied to the rural tourism areas in various situations because it was surveyed tourists with varied experiences as well as experts in rural tourism. It can give rural tourism an opportunity to put forward various value propositions, thus escaping the monotonous value propositions that we currently observe.

\section{IV.3. Methodological implications}

Study 1, in terms of methodology, is significant in that it has quantitatively analyzed tourist experiences and segmented the market through the qualitative application of netnography based on the tourists' voluntarily provided opinions rather than on artificial consumer surveys (García, 2011). This study started with collecting user-generated online content from netnography. This means that the tourists' voluntarily revealed consciousness 
was observed online. Thus, it was able to deeply reflect the tourists' potential needs and reduce the possibility of errors and limited choice in the response process, due to the characteristics of netnography such as direct access to research participants and higher reflective quality of online opinions (Kozinets, 2015). Also, the characteristics of online-based netnography make it possible to access a wide variety of data. Therefore, it is possible to get a sufficient amount of data in a relatively short time to enable various quantitative analyses (Xun \& Reynolds, 2010). The utility of data collection in terms of cost and time will be an important consideration for the use of netnography in many fields in the future. Finally, in this study, some quantitative analyses such as MCA, and clustering were performed by collecting online data generated from the experiences of 1002 customers. MCA is considered a good alternative segmentation method when respondents must only answer yes, no, or not sure, instead of the traditional factor-cluster segmentation based on Likert-type scales (Greenacre, 2016). Since the associations between respondents who are close to each other as well as other variables can be quantified through MCA, market segmentation becomes possible. It is also important to note that through MCA and clustering, this research was able overcome the limitation of data expression by collecting voluntary customer opinions (Markos et al., 2018). This study is significant in that it began with the qualitative collection from netnography, analyzed with the quantitative segmentation of the market based on tourist experiences, and then finished with qualitative interpretation (Table 23).

Table 23. Themes, detailed experiences, and qualitative observation

\begin{tabular}{|c|c|c|}
\hline Themes & Detailed experiences & Qualitative observation \\
\hline $\begin{array}{l}\text { Comfort-driven } \\
\text { visitor }\end{array}$ & $\begin{array}{l}\text { Well-equipped } \\
\text { Cleanliness } \\
\text { Maintenance of facilities } \\
\text { Coziness }\end{array}$ & $\begin{array}{l}\text { "The house is fully equipped with everything you might need, from the } \\
\text { bathrooms to the kitchen. We had the possibility to enjoy a spa and sauna, } \\
\text { to make barbecues in the patio with garden, as well as to use the children's } \\
\text { playroom and the football table itself." } \\
\text { "The house is clean and mostly tidy. It has everything you need, clean } \\
\text { sheets and towels. Ideal for a weekend..." } \\
\text { "The facilities cannot be of better quality. The sports spaces are also very } \\
\text { well maintained. It is the general comment of all who attend. I will visit } \\
\text { again absolutely." } \\
\text { "The house was in perfect condition with equipment that we felt at home. } \\
\text { It was very comfortable with everything we needed." }\end{array}$ \\
\hline $\begin{array}{l}\text { Rural ambiance } \\
\text { spender }\end{array}$ & Value for money & $\begin{array}{l}\text { "The house has a very large kitchen, a comfortable and cozy living room, } \\
\text { two bathrooms and the water come out hot and with pressure. It has the } \\
\text { more quality and value for the price. The house seemed excellent." } \\
\text { "Regarding the stay, the house has enough rooms, many bathrooms, }\end{array}$ \\
\hline
\end{tabular}




\begin{tabular}{|c|c|c|}
\hline & $\begin{array}{l}\text { Overall atmosphere } \\
\text { Rustic landscape }\end{array}$ & $\begin{array}{l}\text { kitchen amenities, and above all, a fenced exterior where there is } \\
\text { everything." } \\
\text { "The owner is a woman of the most endearing who has gone out of her } \\
\text { way to give us all the necessary explanations to make sure that we take } \\
\text { full advantage of our vacation in her beautiful land. She opened the doors } \\
\text { of her home in a detailed, generous and affectionate way." } \\
\text { "The house is super maintained, decorated in the last detail, and with a } \\
\text { rustic but comfortable touch. It's nice to wake up with the crowing of the } \\
\text { rooster .... what a big difference to the noise of the cars. The environment } \\
\text { is a huge gift." } \\
\text { "The house was clean and comfortable, with a terrace overlooking olive } \\
\text { groves and hillsides. The landscape that surrounds the farmhouse is } \\
\text { wonderful. There is an impossible greener valley in which absolute } \\
\text { tranquility is breathed." }\end{array}$ \\
\hline $\begin{array}{l}\text { Active leisure } \\
\text { seeker }\end{array}$ & $\begin{array}{l}\text { Activities } \\
\text { Relaxation } \\
\text { Privacy } \\
\text { Natural environment }\end{array}$ & $\begin{array}{l}\text { "Perfectly equipped house and the tennis, soccer, and ping-pong court has } \\
\text { been fun for seniors and children. We have enjoyed hiking and horse } \\
\text { riding, too." } \\
\text { "A very quiet place to fully enjoy your free time and disconnect from } \\
\text { noise. Whether you go with friends or with children, you have everything } \\
\text { at hand, zero worries. A beautiful cabin with all possible comforts." } \\
\text { "An ideal place for a family getaway to enjoy nature. We chose here } \\
\text { because we found it a beautiful and well- located natural enclave not only } \\
\text { to make excursions in the countryside with the children but also to know } \\
\text { the nearby villages." } \\
\text { "The even better environment has the Jewish quarter. It is full of natural } \\
\text { charms and Roman, Arab and medieval heritage, you will find routes and } \\
\text { excursions of all kinds." }\end{array}$ \\
\hline
\end{tabular}

From a methodological point of view of Study 2, it contributes to the existing studies in evaluating the visual Q methodology as a better way to extract tourist perceptions of experiences. It has enabled tourist opinions to naturally emerge, without being enforced by a researcher who has his/her own viewpoint drawn from previous hypotheses. Since the visual stimuli of the visual Q methodology led participants to provide a rapid and clear 
response, effective exploration of individual subjectivity was possible. Visual Q made it possible to qualitatively analyze tourist experiences and quantitatively segment the rural tourism market based on tourist experiences. Likewise, the analysis of individual subjectivity allowed for in-depth interpretation of the results. This study is significant in that it began with collecting data from visual Q based on customers' subjective perceptions, analyzed with the quantitative segmentation, and then finished with qualitative interpretation (Table 24).

Table 24. Factors, detailed experiences, and qualitative observation

\begin{tabular}{|c|c|c|}
\hline Factors & Detailed experiences & Qualitative observation \\
\hline $\begin{array}{l}\text { Occasion driven } \\
\text { visitor }\end{array}$ & $\begin{array}{l}\text { Comfort } \\
\text { Maintenance of facilities } \\
\text { Customer care }\end{array}$ & $\begin{array}{l}\text { "I do rural tourism with my family and the families of my three younger } \\
\text { brothers. The only place for four families to gather together seems to be } \\
\text { rural tourism. It seems to be important to have a spacious place where the } \\
\text { four families can stay together and to have the facilities to stay without } \\
\text { inconvenience in choosing rural tourism." } \\
\text { "I normally enjoy rural tourism with my boyfriend. When choosing rural } \\
\text { tourism, the most important thing is whether the accommodation has } \\
\text { facilities for the comfort of the two of us. Above all, I wish the place to be } \\
\text { clean and where privacy can be maintained." } \\
\text { "I often use rural tourism for gatherings with friends. In a word, rural } \\
\text { tourism gives us a good place to gather and party together. Therefore, the } \\
\text { surrounding environment is not important when choosing rural tourism. It } \\
\text { is important to have comfortable facilities." }\end{array}$ \\
\hline $\begin{array}{l}\text { Active leisure } \\
\text { seeker }\end{array}$ & $\begin{array}{l}\text { Nature } \\
\text { Landscape } \\
\text { Mountain·Forest } \\
\text { Excursion }\end{array}$ & $\begin{array}{l}\text { "I like to go trekking and hiking with my family because doing outdoor } \\
\text { activities outside of the city can give us new vitality and relieve our stress } \\
\text { from urban life. When choosing rural tourism, I first consider whether } \\
\text { there are natural surroundings to go walking nearby." } \\
\text { "I like rural tourism because it provides a good environment for me to take } \\
\text { my dog and play with him. When deciding on a rural destination, the most } \\
\text { important consideration is whether I can take my dog and whether there is } \\
\text { space around it for my dog to play." } \\
\text { "As I have children, it is important to have an environment and facilities to } \\
\text { do activities with my family. I carefully consider whether there are well- } \\
\text { equipped facilities for activities such as a swimming pool and table for } \\
\text { table tennis, and the possibility of various outdoor activities such as horse } \\
\text { riding and fishing." }\end{array}$ \\
\hline Rural & Nature & "I am a person who is too busy and has a lot to care about. Since rural \\
\hline
\end{tabular}




\begin{tabular}{|c|c|c|}
\hline $\begin{array}{l}\text { immersion } \\
\text { pursuer }\end{array}$ & $\begin{array}{l}\text { Disconnection from the } \\
\text { world } \\
\text { Rustic environment } \\
\text { Observation of fauna } \\
\text { and flora' }\end{array}$ & $\begin{array}{l}\text { tourism is a great way to get out of the environment around me very easily, } \\
\text { I sometimes enjoy it. If I rest well without doing anything special, it will } \\
\text { be my best experience in rural tourism." } \\
\text { "I like rural tourism because it seems to make me feel refreshed when I } \\
\text { look at the landscape in a place with great natural scenery. I consider not } \\
\text { only whether there are nature and scenery, but also whether I can fully feel } \\
\text { the atmosphere of rural areas." } \\
\text { "I often do rural tourism to give my children growing up in the city the } \\
\text { chance to experience something new. If they can directly touch the soil, } \\
\text { plants, animals, etc., and if they can do stargazing, I think it will be the } \\
\text { best rural tourism for my family." }\end{array}$ \\
\hline $\begin{array}{l}\text { A pleasant } \\
\text { break }\end{array}$ & $\begin{array}{l}\text { Gastronomy } \\
\text { Rest } \\
\text { Lots of cultural tourism } \\
\text { Value for money' }\end{array}$ & $\begin{array}{l}\text { "The element that I consider important in rural tourism seems to be } \\
\text { gastronomy. Eating something delicious with my family while doing rural } \\
\text { tourism makes me feel pretty satisfied. It's important whether rural } \\
\text { tourism accommodation is well-equipped with barbecue and cooking } \\
\text { facilities, and whether there are famous restaurants nearby." } \\
\text { "I only do rural tourism for the purpose of accommodation during my trip. } \\
\text { This is because rural tourism accommodation is cheaper and of higher } \\
\text { quality. For me, rural tourism is just a place for sleeping like a hotel. } \\
\text { Therefore, the quality of a room for the price charged for it is the most } \\
\text { important factor for me." } \\
\text { "Since my hometown is rural, I am already so used to the rural } \\
\text { environment. I don't have much interest if rural tourism means just resting } \\
\text { in a rural atmosphere. There must be something to do around the } \\
\text { countryside and a lot of cultural heritage. I consider this a lot before going } \\
\text { to do rural tourism." }\end{array}$ \\
\hline
\end{tabular}

\section{IV.4. Practical implications}

Since tourist experiences based on the theme of each segment were identified, it's possible to know specifically which experiences to offer in order to implement each theme and attract the appropriate customer base. It allows for the establishment and implementation of effective marketing strategies for the targeted tourist groups. The results of this investigation can be applied to the tourism field. The results of this study offer many strategic implications to both local governments and rural tourism providers. First, at a local government level, it 
was found that tourists are pursuing various experiences in rural tourism in Spain and there are multiple markets implicated in this research. This means that the motivations for rural tourism are diverse and many ways of reaching rural tourism consumption exist. Local governments should employ the approach of localizing the region. They should not push for general and broad strategies to support all existing segments, but rather develop specific strategies to meet the needs of market subdivisions, concentrating on a specific segment with relevance to their region. Based on these strategies, they must invest in marketing their regions as a distinctive rural tourism destination through creating rural tourism products that respond to the needs of a specific segment. They must expand communication activities such as online communication, PR and marketing campaigns to inform also potential tourists of the differentiated region. These measures should be also taken into account for the supporting rural tourism providers. Second, at a rural tourism provider level, each rural tourism provider should evaluate the derived segment and select a market on which they should concentrate. They should decide their core target audience, carefully contemplating whether they have the ability to provide the appropriate experiences for the core target, while considering their surrounding environment. In addition, it is necessary to establish a positioning strategy that can meet the needs of rural tourism tourists, considering the characteristics of the core target. Positioning strategies should be able to differentiate themselves from competitors in the same market and capture the strengths that they have, as well as meet the market demands. Positioning strategies should also express the fundamental reasons why the product and service should exist in the market or their service philosophy. These positioning strategies should be used as criteria for developing all services and communicating with tourists. With this criteria, rural tourism providers can not only offer differentiated rural tourism experiences for the tourists by developing services that are relevant to the positioning strategies, but also communicate with tourists to inform them of the corresponding rural tourism in a consistent manner at all touch points.

In this thesis, each theme includes relevant tourist experiences in three dimensions: cognitive, affective, and sensory. Therefore, it is possible to derive information on which destination identity should be pursued on the cognitive level, which memorable experiences should be provided on the affective level, and which sense should be stimulated for tourists on the sensory level, depending on the tourist attraction. The results of this investigation can be applied to the tourism field. Rural tourism providers should choose one or two segments that are relevant to their own resources and environment and that are considered to be marketable in terms of segment size. They have to set up the primary target and secondary target to focus on. The need to derive a target-oriented positional strategy has emerged. Above all, if the first segment, 'comfort-driven visitor', is targeted, the core value to be offered to the customer is comfort. A positioning strategy should be centered on this core value, thus for example, 'like home' could be a positioning statement. The appealing point is that customers can enjoy special moments with the people who accompany them in a cozy atmosphere with sincere service. In order to implement this positioning strategy, improvements to the infrastructures, accommodation services and well-equipped facilities should be made. Next, if the second segment, 'rural ambience spender', is set up as a core target, the core value to be provided to the customer is pleasure in rural environments. A positioning strategy should be developed around this core value, thus for example, 'unusual delight' can be a positioning statement. The appealing point of this positioning strategy is that a specific rural tourism experience can offer pleasure beyond customer 
expectations. In order to employ this positioning strategy, it is necessary to secure and improve the surrounding or complementary facilities that can be utilized and enjoyed. In addition, it is necessary to offer an atmosphere where tourists can feel an easygoing environment and friendly, warm hosts appeal to them. Finally, if the third segment, 'active leisure seeker', is targeted, the core value is activity. A positioning strategy should be developed around this core value, thus for example, 'revitalization' can be a positioning statement. The appealing point of this positioning strategy is that a specific rural tourism experience adds creative inspiration and vitality to the customers' lives. Based on this idea, it is necessary to be able to discover something to experience by utilizing the surrounding cultural tourism as well as various activities to be able to be enjoyed in the natural environment. Based on this positioning strategy, it is necessary to develop the appropriate experiences that can be provided for the target, and to consistently communicate the positioning statement through the customer contact points of nonmass media communications such as the web site, social network services (SNS) and word-of-mouth. When evaluating management performance, the indicators appropriate for the characteristics of a selected segment should be developed and utilized in the evaluation process.

\section{IV.5. Future study lines and limitations}

In Study 1, netnography based on user-generated online content can have a wide range of applications in tourism research. First, segmentation by MCA after the collection of user-generated online content through netnography can be applied to diverse tourism research such as wine tourism, ecotourism, cruise tourism, and hospitality, as well as rural tourism. It would be possible to subdivide each unique tourism market into segments based on customer perspective by quantifying the associations between the respondents and variables of each market. In addition, through using the attributes derived from this netnography study, various research methodologies such as visual Q approach, choice experiments, and best-worst scaling, which are able to better define the market, can also be applied to these tourism studies. However, a limitation exists because it was impossible to collect and verify the sociodemographic features (age, income, occupation, place of residence, etc.) of the customers since the study only analyzed opinions that the customers had already voluntarily left in online communities. These aforementioned aspects are especially interesting because they are considered sociodemographic variables and may have some influence on the customer's choices. Furthermore, this study is limited by a lack of information on customers' lifestyles and motivations for rural tourism, which can be obtained through the customers' direct responses. This shortage of information made it difficult to analyze the data more stereoscopically. For the future, supplementation through further offline quantitative research is needed. It would be necessary to combine online data from netnography with offline data such as personal interviews and focus group interviews to generalize them.

Regarding the use of visual Q in Study 2, there were also limitations. With only 50 respondents collected, it is difficult to obtain representativeness in terms of sociodemographic features (age, occupation, place of residence, trip type, price level, etc.). This is due to the fact that Visual $\mathrm{Q}$ is a semi-qualitative methodology whose 
ultimate goal is a qualitative assessment of the individual through a quantitative statistical analysis. It is possible to grasp the characteristics of the rural tourism market by quantitatively examining individual perceptions, which have a qualitative aspect, but it is impossible to generalize the demographic characteristics of the individuals through such a small sample. Thus, it is difficult to identify the more detailed characteristics of each segment through the current study. According to Zabala (2014), the results of the Q methodology can be used as a point of departure for other quantitative methodologies and be applied conjointly with qualitative methodologies. Since this study basically served to confirm existing markets, it is still necessary to quantify the characteristics of each rural tourism market by carrying out additional quantitative research focusing on demographics. It will be possible to develop corresponding policies by determining the rural tourism market size and collecting detailed characteristics of the market. Also, based on the results of this visual Q study, we can thoroughly analyze the question of the optimal combination of tourist experiences that rural tourism can provide. In addition, Visual Q based on personal subjectivity can be widely applied to diverse tourism research in the future: hospitality, cruise tourism, ecotourism and wine tourism.

Related to the systematic review in Study 3, some limitations also existed, despite the aforementioned contributions. First, the data used in this review were collected only from the Web of Science, thus studies on sustainable rural tourism from other journals were not utilized. It limits the opportunity to obtain broader information on sustainable rural tourism. Future studies should make efforts to find a wider range of journals covering sustainable rural tourism. The next limitation is that, although most articles are written in English, this study only reviewed English language written papers dealing with sustainable rural tourism. It also means that a more diverse and in-depth analysis of sustainable rural tourism research has not been made. Lastly, since there were several detailed topics within the topic of sustainable rural tourism, it was impossible to analyze 73 studies under a single framework to identify discrepancies in the research results and suggest the causes for them. It is desirable for future research to make efforts to generate a new concept framework and new knowledge by analyzing the consensus and inconsistency of the results of selected studies with more specific systematic review research topics in the sustainable rural tourism field.

\section{IV.6. Conclusions}

1. In Study 1, the netnography methodology, which was based on user-generated online qualitative data combined with quantitative tools, was used to describe the rural tourism market in Spain. Rural tourism experiences are shown to be composed of a component of cognitive, affective, and sensory parts. The combination of MCA and cluster analysis was used to describe the market. In this study, three primary segments in the rural tourism market in Spain were defined: comfort-driven visitor, rural ambiance spender, and active leisure seeker. Three significant experiential themes were also discovered through segmentation. These three themes differ in terms of trip types, price levels and region of origin. The results of this investigation can be applied to the tourism field. Rural tourism 
providers should choose one or two segments that are relevant to their own resources and environment and that are considered to be marketable in terms of segment size. They have to set up the primary target and secondary target to focus on. If the first segment, 'comfort-driven visitor', is targeted, the core value to be offered to the customer is comfort. The appealing point is that customers can enjoy special moments with the people who accompany them in a cozy atmosphere with sincere service. Improvements to the infrastructures, accommodation services and well-equipped facilities should be made. Next, if the second segment, 'rural ambience spender', is set up as a core target, the core value to be provided to the customer is pleasure in rural environments. The appealing point of this positioning strategy is that a specific rural tourism experience can offer pleasure beyond customer expectations. It is necessary to secure and improve the surrounding or complementary facilities that can be utilized and enjoyed. In addition, it is necessary to offer an atmosphere where tourists can feel an easygoing environment and friendly, warm hosts appeal to them. Finally, if the third segment, 'active leisure seeker', is targeted, the core value is activity. The appealing point of this positioning strategy is that a specific rural tourism experience adds creative inspiration and vitality to the customers' lives. Based on this idea, it is necessary to be able to discover something to experience by utilizing the surrounding cultural tourism as well as various activities to be able to be enjoyed in the natural environment. This study is significant in that it began with the qualitative collection of user-generated online content from netnography and finished with the quantitative segmentation of the market based on tourist experiences.

2. In Study 2, visual Q, a methodology used to intuitively explore individual subjectivity, was applied to the elicitation of rural tourism marketing strategy with the purpose of exploring rural tourists' views in order to identify different market segmentation in relation to rural tourism experiences. The first of three factors derived from analyzing customer experiences in rural tourism in Spain, is called 'nature leisure seeker', which pursues experiences such as 'nature', 'landscape', 'mountain - forest' and 'rustic environment'. The second factor is named 'occasion driven visitor', which seeks experiences such as 'cleanliness', 'comfort', 'tranquility of the establishment', and 'customer care'. The third factor is named 'pleasure spender', which pursues experiences such as 'lots of cultural tourism', 'winery', 'promotion' and 'rustic environment'. Each factor has a different pursuit of experiences from the others, but the common pursuit without reference to segments is 'Complete break', which seeks experiences such as 'rest', 'gastronomy', 'disconnection from the world' and 'value for money'. This study is significant in that it began with the collection of data from visual Q based on customers' subjective perceptions, analyzed with the quantitative segmentation, and then finished with qualitative interpretation

3. Study 3 reviewed relevant studies related to sustainable rural tourism in high-level journals belonging to SSCI (Social Sciences Citation Index) and SCIE (Science Citation Index Expanded), which were searched using Web 
of Science during the period of 2009-2019. The findings indicate that many papers on sustainable rural tourism were written from a holistic sustainability perspective without being biased towards any one of the environmental, economic, and social aspects. More than $40 \%$ of papers on sustainable rural tourism were carried out from a holistic sustainability perspective. It shows that the sustainability in the rural tourism sector is understood and applied as a holistic concept without being biased to any one of the environmental, economic and social aspects. In the field of rural tourism, it is essential to pay attention to interactions in all aspects of the environment, economy, and society, and to analyze them overall. In addition, this study confirmed that efforts to understand sustainable rural tourism from the customer perspective have been increased since customer loyalty is considered important for sustainability. Studies on tourists' loyalty and satisfaction, that enable sustainable rural tourism, reveal these efforts. It means that in order to become a sustainable rural tourism destination, it is indispensable to ultimately gain the tourists' hearts. This study is significant in that since it evaluated the knowledge status for the first time through systematic review and applied content analysis to academic literature related to sustainability in the sector of rural tourism, it can expand and deepen knowledge and the understanding of related topics and raise awareness of a new research direction. 
115 
CHAPTER V. REFERENCES 
Addinsall, C., Scherrer, P., Weiler, B., \& Glencross, K. (2017). An ecologically and socially inclusive model of agritourism to support smallholder livelihoods in the South Pacific. Asia Pacific Journal of Tourism Research, 22(3), 301-315. https://doi.org/10.1080/10941665.2016.1250793

Agapito, D., Mendes, J., \& Valle, P. (2013). Exploring the conceptualization of the sensory dimension of tourist experiences. Journal of Destination Marketing and Management, 2(2), 62-73. https://doi.org/10.1016/j.jdmm.2013.03.001

Agapito, D., Valle, P., \& Mendes, J. (2014). The sensory dimension of tourist experiences: Capturing meaningful sensory-informed themes in Southwest Portugal. Tourism Management, 42, 224-237. https://doi.org/10.1016/j.tourman.2013.11.011

Albaladejo-Pina, I. P., \& Díaz-Delfa, M. T. (2005). Rural tourism demand by type of accommodation. Tourism Management, 26(6), 951-959. https://doi.org/10.1016/j.tourman.2004.06.013

Albaladejo-Pina, I. P., \& Díaz-Delfa, M. T. (2009). Tourist preferences for rural house stays: Evidence from discrete choice modelling in Spain. Tourism Management, 30(6), 805-811. https://doi.org/10.1016/j.tourman.2009.01.001

Almeida-García, F., Peláez-Fernández, M. Á., Balbuena-Vázquez, A., \& Cortés-Macias, R. (2016). Residents' perceptions of tourism development in Benalmádena (Spain). Tourism Management, 54, 259-274. https://doi.org/10.1016/j.tourman.2015.11.007

Amedeo, D., Pitt, D. G., \& Zube, E. H. (1989). Landscape feature classification as a determinant of perceived scenic value. Landscape Journal, 8(1), 36-50. https://doi.org/10.3368/lj.8.1.36

Andereck, K. L., \& Nyaupane, G. P. (2011). Exploring the nature of tourism and quality of life perceptions among residents. Journal of Travel Research, 50(3), 248-260. https://doi.org/10.1177/0047287510362918

Anderson, J. F., Hair, W. C., Black, B. J., \& Babin, R. E. (2009). Multivariate data analysis (P. Hall, ed.).

Arimond, G., \& Elfessi, A. (2001). A clustering method for categorical data in tourism market segmentation research. Journal of Travel Research. https://doi.org/10.1177/004728750103900405

Artal-Tur, A., Briones-Peñalver, A. J., Bernal-Conesa, J. A., \& Martínez-Salgado, O. (2019). Rural community tourism and sustainable advantages in Nicaragua. International Journal of Contemporary Hospitality Management, 31(6), 2232-2252. https://doi.org/10.1108/IJCHM-05-2018-0429

Atun, R. A., Nafa, H., \& Türker, Ö. O. (2019). Envisaging sustainable rural development through 'contextdependent tourism': case of northern Cyprus. Environment, Development and Sustainability, 21(4), 17151744. https://doi.org/10.1007/s10668-018-0100-8

Azizian, A., Watson, T. D., Parvaz, M. A., \& Squires, N. K. (2006). Time course of processes underlying picture and word evaluation: an event-related potential approach. Brain Topography, 18(3), 213-222. 
https://doi.org/10.1007/s10548-006-0270-9

Bacher, K., Gordoa, A., \& Mikkelsen, E. (2014). Stakeholders' perceptions of marine fish farming in Catalonia (Spain): A Q-methodology approach. Aquaculture, 424-425, 78-85. https://doi.org/10.1016/j.aquaculture.2013.12.028

Baloglu, S., \& McCleary, K. W. (1999). A model of destination image formation. Annals of Tourism Research, 26(4), 868-897. https://doi.org/10.1016/S0160-7383(99)00030-4

Barbieri, C. (2013). Assessing the sustainability of agritourism in the US: A comparison between agritourism and other farm entrepreneurial ventures. Journal of Sustainable Tourism, 21(2), 252-270. https://doi.org/10.1080/09669582.2012.685174

Barczak, G. (2017). From the editor: Writing a review article. Journal of Product Innovation Management, 34(2), 120-121.

Bengry-Howell, A., Wiles, R., Nind, M., \& Crow, G. (2011). A review of the academic impact of three methodological innovations: Netnography, child-led research and creative research methods. ESRC National Centre for Research Methods, (July), 35. Retrieved from http://eprints.soton.ac.uk/194895/1/Report_on_uptake_of_innovation_final_1.8.11.doc

Besteiro, B. (2006). El turismo rural en Galicia. Análisis de su evolución en la última década. Cuadernos de Turismo, 17, 25-49.

Bigné Alcañiz, E., Sánchez García, I., \& Sanz Blas, S. (2009). The functional-psychological continuum in the cognitive image of a destination: A confirmatory analysis. Tourism Management, 30(5), 715-723. https://doi.org/10.1016/j.tourman.2008.10.020

Bigné, J. E., Mattila, A. S., \& Andreu, L. (2008). The impact of experiential consumption cognitions and emotions on behavioral intentions. Journal of Services Marketing, 22(4), 303-315. https://doi.org/10.1108/08876040810881704

Blancas, F. J., Lozano-Oyola, M., González, M., Guerrero, F. M., \& Caballero, R. (2011). How to use sustainability indicators for tourism planning: The case of rural tourism in Andalusia (Spain). Science of the Total Environment, 412-413, 28-45. https://doi.org/10.1016/j.scitotenv.2011.09.066

Blancas, Francisco J., Caballero, R., González, M., Lozano-Oyola, M., \& Pérez, F. (2010). Goal programming synthetic indicators: An application for sustainable tourism in Andalusian coastal counties. Ecological Economics, 69(11), 2158-2172. https://doi.org/10.1016/j.ecolecon.2010.06.016

Blanco, F. (1996). Fundamentos de la política comunitaria y española en materia de turismo rural. Estudios Turísticos, 131, 25-49. Retrieved from http://scholar.google.es/scholar?q=fundamentos+de+la+politica+comunitaria+y+española+en+materia+de 
+turismo+rural\&btnG=\&hl=es\&as_sdt=0,5\#0

Borg, I., \& Groenen, P. J. F. (2005). Modern multidimensional scaling: Theory and applications. Springer Science \& Business Media.

Botschen, G., Thelen, E. M., \& Pieters, R. (1999). Using means-end structures for benefit segmentation: An application to services. European Journal of Marketing, 33(1/2), 38-58. https://doi.org/Permanent link tdx.doi.org/10.1108/EUM0000000004491

Bramwell, B., \& Lane, B. (1993). Sustainable tourism: An evolving global approach. Journal of Sustainable Tourism, 1(1), 1-5. https://doi.org/10.1080/09669589309514792

Brown, L., \& Osman, H. (2017). The female tourist experience in Egypt as an Islamic destination. Annals of Tourism Research, 63, 12-22. https://doi.org/10.1016/j.annals.2016.12.005

Buhalis, D. (2000). Marketing the competitive destination of the future. Tourism Management, 21(1), 97-116. https://doi.org/10.1016/S0261-5177(99)00095-3

Burton, I. (1987). Report on reports: Our common future. Environment: Science and Policy for Sustainable Development, 29(5), 25-29. https://doi.org/10.1080/00139157.1987.9928891

Butnaru, G. I., \& Haller, A. P. (2017). Perspective of sustainable rural tourism in the United Kingdom of Great Britain and Northern Ireland (UK): Comparative study of $\beta$ and $\sigma$ convergence in the economic development regions. Sustainability, 9(4). https://doi.org/10.3390/su9040525

Caffyn, A. (2000). Developing sustainable tourism in the Trossachs, Scotland in Richards. In Tourism and Sustainable Community Development (pp. 83-100). Routledge.

Cairns, R., Sallu, S. M., \& Goodman, S. (2014). Questioning calls to consensus in conservation: a Q study of conservation discourses on Galápagos. Environmental Conservation, 41(1), 13-26. https://doi.org/10.1017/S0376892913000131

Callan, R. J., \& Bowman, L. (2000). Selecting a hotel and determining salient quality attributes a preliminary study of mature British travellers. International Journal of Tourism Research, 2, 97-118.

Campón-Cerro, A. M., Hernández-Mogollón, J. M., \& Alves, H. (2017). Sustainable improvement of competitiveness in rural tourism destinations: The quest for tourist loyalty in Spain. Journal of Destination Marketing and Management, 6(3), 252-266. https://doi.org/10.1016/j.jdmm.2016.04.005

Cánoves, G., Villarino, M., Priestley, G. K., \& Blanco, A. (2004). Rural tourism in Spain: An analysis of recent evolution. Geoforum, 35(6 SPEC.ISS.), 755-769. https://doi.org/10.1016/j.geoforum.2004.03.005

Carroll, J. D., Green, P. E., \& Schaffer, C. M. (1986). Interpoint distance comparisons in correspondence analysis. Journal of Marketing Research, 23(3), 271-280. https://doi.org/10.2307/3151485 
Carroll, J. D., Green, P. E., \& Schaffer, C. M. (1987). Comparing interpoint distances in correspondence analysis: a clarification. Journal of Marketing Research, 24(4), 445-450.

Chaminuka, P., Groeneveld, R. A., Selomane, A. O., \& van Ierland, E. C. (2012). Tourist preferences for ecotourism in rural communities adjacent to Kruger National Park: A choice experiment approach. Tourism Management, 33(1), 168-176. https://doi.org/10.1016/j.tourman.2011.02.016

Chen, B., Qiu, Z., Usio, N., \& Nakamura, K. (2018). Tourism's impacts on rural livelihood in the sustainability of an aging community in Japan. Sustainability, 10(8). https://doi.org/10.3390/su10082896

Chen, J., Guan, J., (Bill) Xu, J., \& Clergeau, C. (2018). Constructing the green supply chain for rural tourism in China: Perspective of front-back stage decoupling. Sustainability, 10(11). https://doi.org/10.3390/su10114276

Chen, L. C., Lin, S. P., \& Kuo, C. M. (2013). Rural tourism: Marketing strategies for the bed and breakfast industry in Taiwan. International Journal of Hospitality Management, 32(1), 278-286. https://doi.org/10.1016/j.ijhm.2012.07.005

Chin, C. H., Chin, C. L., \& Wong, W. P. M. (2018). The implementation of green marketing tools in rural tourism: The readiness of tourists? Journal of Hospitality Marketing and Management, 27(3), 261-280. https://doi.org/10.1080/19368623.2017.1359723

Choo, H., \& Petrick, J. F. (2014). Social interactions and intentions to revisit for agritourism service encounters. Tourism Management, 40, 372-381. https://doi.org/10.1016/j.tourman.2013.07.011

Clemente-Ricolfe, J. S., \& Escribá-Pérez, C. (2014). Aplicando netnografía a la obtención del mapa de posicionamiento para empresas de distribución alimentaria. Cuadernos de Gestion, 14(1), 57-74. https://doi.org/10.5295/cdg.110322jc

Cohen, J. B., Pham, M. T., \& Andrade, E. B. (2008). The nature and role of affect in consumer behavior. Handbook of Consumer Psychology.

Coogan, J., \& Herrington, N. (2011). Q methodology: an overview. Research in Secondary Teacher Education, $1(2), 24-28$.

Correia, A., \& Oliveira, C. (2016). Perfil del consumidor del estudio internacional sobre turismo rural en España. Retrieved from http://www.toprural.com/info/files/live/sites/tr/files/Landing-pages/estudioturismo-rural-internacional/medias/perfildelconsumidordelestudiointernacional.pdf

Correia Loureiro, S. M., \& Miranda González, F. J. (2006). Calidad, satisfacción y fidelidad en el turismo rural: un análisis hispano-portugués. Papers de Turisme, 0(40), 49-66.

Cucari, N., Wankowicz, E., \& Esposito De Falco, S. (2019). Rural tourism and Albergo Diffuso: A case study for sustainable land-use planning. Land Use Policy, 82(November 2018), 105-119. 
https://doi.org/10.1016/j.landusepol.2018.11.050

Currie, C., \& Falconer, P. (2014). Maintaining sustainable island destinations in Scotland: The role of the transport-tourism relationship. Journal of Destination Marketing and Management, 3(3), 162-172. https://doi.org/10.1016/j.jdmm.2013.10.005

Daniel, T. C. (2001). Whither scenic beauty? Visual landscape quality assessment in the 21 st century. Landscape and Urban Planning, 54(1-4), 267-281. https://doi.org/10.1016/S0169-2046(01)00141-4

Davis, C. H., \& Michelle, C. (2011). Q methodology in audience research: bridging the qualitative/quantitative 'divide'? Journal of Audience \& Reception Studies, 8(2), 559-593.

Dax, T., Zhang, D., \& Chen, Y. (2019). Agritourism initiatives in the context of continuous out-migration: Comparative perspectives for the Alps and Chinese mountain regions. Sustainability, 11(16). https://doi.org/10.3390/su11164418

De Luca, A. I., Iofrida, N., Leskinen, P., Stillitano, T., Falcone, G., Strano, A., \& Gulisano, G. (2017). Life cycle tools combined with multi-criteria and participatory methods for agricultural sustainability: Insights from a systematic and critical review. Science of the Total Environment, 595, 352-370. https://doi.org/10.1016/j.scitotenv.2017.03.284

De Lucia, C., Pazienza, P., Balena, P., \& Caporale, D. (2019). Exploring local knowledge and socio-economic factors for touristic attractiveness and sustainability. International Journal of Tourism Research, 22(1), 81-99. https://doi.org/10.1002/jtr.2320

Devi Juwaheer, T. (2004). Exploring international tourists' perceptions of hotel operations by using a modified SERVQUAL approach - a case study of Mauritius. Managing Service Quality: An International Journal, 14(5), 350-364. https://doi.org/10.1108/09604520410557967

Dillette, A. K., Douglas, A. C., \& Andrzejewski, C. (2016). An exploratory examination of the wellness tourist experience using netnography. Travel and Tourism Research Associaion. https://doi.org/10.1258/ijsa.2011.010359

Do Valle, P. O., Mendes, J., \& Guerreiro, M. (2012). Residents' participation in events, events image, and destination image: A correspondence analysis. Journal of Travel and Tourism Marketing, 29(7), 647-664. https://doi.org/10.1080/10548408.2012.720151

Dong, E., Wang, Y., Morais, D., \& Brooks, D. (2013). Segmenting the rural tourism market: The case of Potter County, Pennsylvania, USA. Journal of Vacation Marketing, 19(2), 181-193. https://doi.org/10.1177/1356766712471231

Du Pisani, J. A. (2006). Sustainable development - historical roots of the concept. Environmental Sciences, 3(2), 83-96. https://doi.org/10.1080/15693430600688831 
Duarte Alonso, A., \& Nyanjom, J. (2017). Local stakeholders, role and tourism development. Current Issues in Tourism, 20(5), 480-496. https://doi.org/10.1080/13683500.2015.1078782

Echebarria, C., Barrutia, J. M., Eletxigerra, A., Hartmann, P., \& Apaolaza, V. (2018). Local sustainability processes worldwide: a systematic review of the literature and research agenda. Journal of Environmental Planning and Management, 61(8), 1289-1317. https://doi.org/10.1080/09640568.2017.1342611

Elkington, J. (1997). Cannibals with forks - Triple bottom line of 21st century business. New Society Publishers.

Ellis, G. D., \& Rossman, J. R. (2008). Creating value for participants through experience staging: parks, recreation, and tourism in the experience industry. Journal of Park and Recreation Administration, 26(4), 1-20. Retrieved from http://search.ebscohost.com/login.aspx?direct=true \&db=s3h\&AN=35765314\&site=ehost-live

Ernesto Pérez, V., HernandezSantoyo, A., Guerrero, F., Amparo León, M., Luiz da Silva, C., \& Caballero, R. (2017). Measuring the sustainability of Cuban tourism destinations considering stakeholders' perceptions. International Journal of Tourism Research, 19(3), 318-328. https://doi.org/10.1002/jtr.2114

Eusébio, C., Carneiro, M. J., Kastenholz, E., Figueiredo, E., \& Soares da Silva, D. (2017). Who is consuming the countryside? An activity-based segmentation analysis of the domestic rural tourism market in Portugal. Journal of Hospitality and Tourism Management, 31, 197-210. https://doi.org/10.1016/j.jhtm.2016.12.006

Everett, S. (2008). Beyond the visual gaze? The pursuit of an embodied experience through food tourism. Tourist Studies, 8(3), 337-358. https://doi.org/10.1177/1468797608100594

Fairweather, J. R., \& R. Swaffield, S. (2001). Visitor experiences of Kaikoura, New Zealand: an interpretative study using photographs of landscapes and Q method. Tourism Management, 22(3), 219-228. https://doi.org/10.1016/S0261-5177(00)00061-3

Fernandes, T., \& Cruz, M. (2016). Dimensions and outcomes of experience quality in tourism: the case of Port wine cellars. Journal of Retailing and Consumer Services, 31, 371-379. https://doi.org/10.1016/j.jretconser.2016.05.002

Figueiredo, E., \& Raschi, A. (2012). Immersed in green? Reconfiguring the Italian countryside through rural tourism promotional materials. Advances in Culture, Tourism and Hospitality Research, 6, 17-44. https://doi.org/10.1108/S1871-3173(2012)0000006005

Fiore, A. M., \& Kim, J. (2007). An integrative framework capturing experiential and utilitarian shopping experience. International Journal of Retail \& Distribution Management, 35(6), 421-442. https://doi.org/10.1108/09590550710750313 
Fong, S. F., Lo, M. C., Songan, P., \& Nair, V. (2017). Self-efficacy and sustainable rural tourism development: local communities' perspectives from Kuching, Sarawak. Asia Pacific Journal of Tourism Research, 22(2), 147-159. https://doi.org/10.1080/10941665.2016.1208668

Font, X., Elgammal, I., \& Lamond, I. (2017). Greenhushing: the deliberate under communicating of sustainability practices by tourism businesses. Journal of Sustainable Tourism, 25(7), 1007-1023. https://doi.org/10.1080/09669582.2016.1158829

Fox, N., \& Roberts, C. (1999). GPs in cyberspace: the sociology of a "virtual community." Sociological Review, 47(4). https://doi.org/10.1111/1467-954X.00190

Frochot, I. (2005). A benefit segmentation of tourists in rural areas: a Schottish perspective. Tourism Management, 26, 335-346. https://doi.org/10.1016/j.tourman.2003.11.016

Gao, C., Cheng, L., Iqbal, J., \& Cheng, D. (2019). An integrated rural development mode based on a tourismoriented approach: Exploring the beautiful village project in China. Sustainability, 11(14). https://doi.org/10.3390/su11143890

Gao, J., \& Wu, B. (2017). Revitalizing traditional villages through rural tourism: A case study of Yuanjia Village, Shaanxi Province, China. Tourism Management, 63, 223-233. https://doi.org/10.1016/j.tourman.2017.04.003

Garau, C. (2015). Perspectives on cultural and sustainable rural tourism in a smart region: The case study of Marmilla in Sardinia (Italy). Sustainability, 7(6), 6412-6434. https://doi.org/10.3390/su7066412

García, J. L. (1996). El turismo rural como factor diversificador de rentas en la tradicional economía agraria. Estudios Turísticos, 132, 45-60.

García, M. del F. (2011). Netnografía: Investigación, análisis e intervención social online (Edición: 1; S. L. Editorial UOC, ed.).

Garrod, B., Wornell, R., \& Youell, R. (2006). Re-conceptualising rural resources as countryside capital: The case of rural tourism. Journal of Rural Studies, 22(1), 117-128. https://doi.org/10.1016/j.jrurstud.2005.08.001

Gentile, C., Spiller, N., \& Noci, G. (2007). How to sustain the customer experience:. An overview of experience components that co-create value with the customer. European Management Journal, 25(5), 395-410. https://doi.org/10.1016/j.emj.2007.08.005

Ghorbani, A., Raufirad, V., Rafiaani, P., \& Azadi, H. (2015). Ecotourism sustainable development strategies using SWOT and QSPM model: A case study of Kaji Namakzar Wetland, South Khorasan Province, Iran. Tourism Management Perspectives, 16, 290-297. https://doi.org/10.1016/j.tmp.2015.09.005

Gifi, A. (1990). Nonlinear multivariate analysis (J. W. \& Sons, ed.). 
Glavič, P., \& Lukman, R. (2007). Review of sustainability terms and their definitions. Journal of Cleaner Production, 15(18), 1875-1885. https://doi.org/10.1016/j.jclepro.2006.12.006

Gnoth, J. (2003). Consumer activated services networks: Towards a dynamic model for tourism destinations. The 32nd EMAC.

Grande, J., \& Maynar, M. (2010). Hacia un nuevo modelo de turismo rural.

Grande, Julio, \& Maynar, M. (2010). Hacia un nuevo modelo de turismo rural. Fundación Espacios XXI.

Greenacre, M. (2016). Correspondence analysis in practice (3rd ed.). Chapman and Hall/CRC.

Guaita Martínez, J. M., Martín Martín, J. M., Salinas Fernández, J. A., \& Mogorrón-Guerrero, H. (2019). An analysis of the stability of rural tourism as a desired condition for sustainable tourism. Journal of Business Research, 100(March), 165-174. https://doi.org/10.1016/j.jbusres.2019.03.033

Guan, J., Gao, J., \& Zhang, C. (2019). Food heritagization and sustainable rural tourism destination: The case of China’s Yuanjia Village. Sustainability, 11(10). https://doi.org/10.3390/su11102858

Guo, Y., Jiang, J., \& Li, S. (2019). A sustainable tourism policy research review. Sustainability, 11(11), 1-16. https://doi.org/10.3390/su11113187

Gurbuz, I. B., \& Manaros, M. (2018). Local sustainability: Evaluating visitors' level of satisfaction in Cumalikizik, Turkey. Fresenius Environmental Bulletin, 27(5), 3433-3438. Retrieved from http://www.redibw.de/db/ebsco.php/search.ebscohost.com/login.aspx\%3Fdirect\%3Dtrue\%26db\%3D8gh\%26AN\%3D129 $530409 \% 26$ site\%3Dehost-live

Hall, C. M. (2008). Tourism Planning: Policies, Processes and Relationships. Pearson/Prentice Hall.

Hardy, A., \& Pearson, L. J. (2018). Examining stakeholder group specificity: An innovative sustainable tourism approach. Journal of Destination Marketing and Management, 8(April 2016), 247-258. https://doi.org/10.1016/j.jdmm.2017.05.001

Hashemi, N., \& Ghaffary, G. (2017). A Proposed Sustainable Rural Development Index (SRDI): Lessons from Hajij village, Iran. Tourism Management, 59, 130-138. https://doi.org/10.1016/j.tourman.2016.07.021

Hearne, R. R., \& Salinas, Z. M. (2002). The use of choice experiments in the analysis of tourist preferences for ecotourism development in Costa Rica. Journal of Environmental Management, 65(2), 153-163. https://doi.org/10.1006/jema.2001.0541

Hernández-Mogollón, J. M., Campón-Cerro, A. M., Leco-Berrocal, F., \& Pérez-Díaz, A. (2011). Agricultural diversification and the sustainability of agricultural systems: Possibilities for the development of agrotourism. Environmental Engineering and Management Journal, 10(12), 1911-1921. 
https://doi.org/10.30638/eemj.2011.255

Hoffmann, D. L., \& Franke, G. R. (1986). Correspondence analysis : Graphical of categorical data in marketing research. Journal of Marketing Research, 23(3), 213-227.

Houston, M. B. (2019). Four facets of rigor. Journal of the Academy of Marketing Science, 47(4), 570-573. https://doi.org/10.1007/s11747-019-00665-7

Hulland, J., \& Houston, M. B. (2020). Why systematic review papers and meta-analyses matter: an introduction to the special issue on generalizations in marketing. Journal of the Academy of Marketing Science, 48(3), 351-359. https://doi.org/10.1007/s11747-020-00721-7

Hwang, D., Stewart, W. P., \& Ko, D. wan. (2012). Community behavior and sustainable rural tourism development. Journal of Travel Research, 51(3), 328-341. https://doi.org/10.1177/0047287511410350

Hwang, H., Dillon, W. R., \& Takane, Y. (2006). An extension of multiple correspondence analysis for identifying heterogeneous subgroups of respondents. Psychometrika, 71(1), 161-171. https://doi.org/10.1007/s11336-004-1173-x

Ibanescu, B. C., Stoleriu, O. M., Munteanu, A., \& Iaţu, C. (2018). The impact of tourism on sustainable development of rural areas: Evidence from Romania. Sustainability, 10(10), 1-19. https://doi.org/10.3390/su10103529

Idziak, W., Majewski, J., \& Zmyślony, P. (2015). Community participation in sustainable rural tourism experience creation: a long-term appraisal and lessons from a thematic villages project in Poland. Journal of Sustainable Tourism, 23(8-9), 1341-1362. https://doi.org/10.1080/09669582.2015.1019513

INE (Instituto Nacional de Estadística). (2017). Yearly number of tourists staying in rural accommodations in Spain between 2006 and 2016.

INE (Instituto Nacional de Estadística). (2018). Encuesta de ocupación en alojamientos turísticos.

Ji, M., Li, M., \& Hsu, C. H. C. (2016). Emotional encounters of chinese tourists to Japan. Journal of Travel and Tourism Marketing, 33(5), 645-657. https://doi.org/10.1080/10548408.2016.1167353

Jin, Y., \& Park, Y. (2019). An integrated approach to determining rural tourist satisfaction factors using the IPA and conjoint analysis. International Journal of Environmental Research and Public Health, 16(20). https://doi.org/10.3390/ijerph16203848

Juma, L. O., \& Khademi-Vidra, A. (2019). Community-based tourism and sustainable development of rural regions in Kenya; Perceptions of the citizenry. Sustainability, 11(17). https://doi.org/10.3390/su11174733

Kallmuenzer, A., Nikolakis, W., Peters, M., \& Zanon, J. (2018). Trade-offs between dimensions of sustainability: exploratory evidence from family firms in rural tourism regions. Journal of Sustainable 
Tourism, 26(7), 1204-1221. https://doi.org/10.1080/09669582.2017.1374962

Kang, S. K., Lee, C. K., Yoon, Y., \& Long, P. T. (2008). Resident perception of the impact of limited-stakes community-based casino gaming in mature gaming communities. Tourism Management, 29(4), 681-694. https://doi.org/10.1016/j.tourman.2007.07.011

Kastenholz, E., Carneiro, M. J., Marques, C. P., \& Lima, J. (2012). Understanding and managing the rural tourism experience - The case of a historical village in Portugal. Tourism Management Perspectives, 4 , 207-214. https://doi.org/10.1016/j.tmp.2012.08.009

Kastenholz, E., Davis, D., \& Paul, G. (1999). Segmenting tourism in rural areas: The case of north and central Portugal. Journal of Travel Research, 37(4), 353-363. https://doi.org/10.1177/004728759903700405

Kastenholz, E., Eusébio, C., \& Carneiro, M. J. (2018). Segmenting the rural tourist market by sustainable travel behaviour: Insights from village visitors in Portugal. Journal of Destination Marketing and Management, 10(November 2017), 132-142. https://doi.org/10.1016/j.jdmm.2018.09.001

Kastenholz, E., João Carneiro, M., \& Eusébio, C. (2015). Diverse socializing patterns in rural tourist experiences-a segmentation analysis. Current Issues in Tourism, 21(4), 401-421. https://doi.org/10.1080/13683500.2015.1087477

Kastenholz, E., João Carneiro, M., Peixeira Marques, C., \& Correia Loureiro, S. M. (2018). The dimensions of rural tourism experience: impacts on arousal, memory, and satisfaction. Journal of Travel and Tourism Marketing, 35(2), 189-201. https://doi.org/10.1080/10548408.2017.1350617

Kheiri, J., \& Nasihatkon, B. (2016). The effects of rural tourism on sustainable livelihoods (Case study: Lavij Rural, Iran). Modern Applied Science, 10(10), 10. https://doi.org/10.5539/mas.v10n10p10

Kiefer, M., \& Pulvermüller, F. (2012). Conceptual representations in mind and brain: theoretical developments, current evidence and future directions. Cortex, 48(7), 805-825. https://doi.org/10.1016/j.cortex.2011.04.006

Kim, S.-H., Holland, S., \& Han, H.-S. (2013). A structural model for examining how destination image, perceived value, and service quality affect destination loyalty: A case study of Orlando. International Journal of Tourism, 15(4), 313-328. https://doi.org/https://doi.org/10.1002/jtr.1877

Kim, S., \& Jamal, T. (2015). The co-evolution of rural tourism and sustainable rural development in Hongdong, Korea: complexity, conflict and local response. Journal of Sustainable Tourism, 23(8-9), 1363-1385. https://doi.org/10.1080/09669582.2015.1022181

Kline, C. S., Greenwood, J. B., Swanson, J., \& Cárdenas, D. (2014). Paddler market segments: Expanding experience use history segmentation. Journal of Destination Marketing and Management, 2(4), 228-240. https://doi.org/10.1016/j.jdmm.2013.10.004 
Knutson, B. J., \& Beck, J. A. (2008). Identifying the dimensions of the experience construct. Journal of Quality Assurance in Hospitality ..., 4(3-4), 23-35. https://doi.org/10.1300/J162v04n03

Kozinets, R. V. (2002). The field behind the screen: using netnography for marketing research in online communities. Journal of Marketing Research, 39(1), 61-72. https://doi.org/10.1509/jmkr.39.1.61.18935

Kozinets, R. V. (2015). Netnography: Redefined. In London: Sage. https://doi.org/10.1002/9781118290743.wbiedcs067

Kristjánsdóttir, K. R., Ólafsdóttir, R., \& Ragnarsdóttir, K. V. (2018). Reviewing integrated sustainability indicators for tourism. Journal of Sustainable Tourism, 26(4), 583-599.

https://doi.org/10.1080/09669582.2017.1364741

Ladhari, R. (2009). Service quality, emotional satisfaction, and behavioural intentions: A study in the hotel industry. Managing Service Quality, 19(3), 308-331. https://doi.org/10.1108/09604520910955320

Lakner, Z., Kiss, A., Merlet, I., Oláh, J., Máté, D., Grabara, J., \& Popp, J. (2018). Building coalitions for a diversified and sustainable tourism: Two case studies from Hungary. Sustainability, 10(4), 1-23. https://doi.org/10.3390/su10041090

Lane, B. (1994). Sustainable rural tourism strategies: A tool for development and conservation. Journal of Sustainable Tourism, 2(1-2), 102-111. https://doi.org/10.1080/09669589409510687

Lane, B. (2009). Rural tourism: an overview. SAGE publications.

Lane, B., \& Kastenholz, E. (2015). Rural tourism: the evolution of practice and research approaches - towards a new generation concept? Journal of Sustainable Tourism, 23(8-9), 1133-1156.

https://doi.org/10.1080/09669582.2015.1083997

Law, R., Leung, D., \& Cheung, C. (2012). A systematic review, analysis, and evaluation of research articles in the Cornell Hospitality Quarterly. Cornell Hospitality Quarterly, 53(4), 365-381. https://doi.org/10.1177/1938965512457458

Leco, F., Pérez, A., Hernández, J. M., \& Campón, A. M. (2013). Rural tourists and their attitudes and motivations towards the practice of environmental activities such as agrotourism. International Journal of Environmental Research, 7(1), 255-264. https://doi.org/10.22059/ijer.2012.604

Lew, A. A., Ng, P. T., Ni, C. cheng (Nickel), \& Wu, T. chiung (Emily). (2016). Community sustainability and resilience: similarities, differences and indicators. Tourism Geographies, 18(1), 18-27. https://doi.org/10.1080/14616688.2015.1122664

Lin, C.-L. (2019). Establishing environment sustentation strategies for urban and rural/town tourism based on a hybrid MCDM approach. Current Issues in Tourism, O(0), 1-36. https://doi.org/10.1080/13683500.2019.1642308 
Liu, C. H., Tzeng, G. H., Lee, M. H., \& Lee, P. Y. (2013). Improving metro-airport connection service for tourism development: Using hybrid MCDM models. Tourism Management Perspectives, 6, 95-107. https://doi.org/10.1016/j.tmp.2012.09.004

Long, N. T., \& Nguyen, T. L. (2018). Sustainable development of rural tourism in an Giang Province, Vietnam. Sustainability, 10(4), 1-20. https://doi.org/10.3390/su10040953

Lu, J., \& Nepal, S. K. (2009). Sustainable tourism research: An analysis of papers published in the Journal of Sustainable Tourism. Journal of Sustainable Tourism, 17(1), 5-16. https://doi.org/10.1080/09669580802582480

Lu, W., \& Stepchenkova, S. (2015). User-generated content as a research mode in tourism and hospitality applications: Topics, methods, and software. Journal of Hospitality Marketing and Management, 24(2), 119-154. https://doi.org/10.1080/19368623.2014.907758

MaríaYagüe, R. (2002). Rural tourism in Spain. Annals of Tourism Research, 29(4), 1101-1110. https://doi.org/10.1016/S0160-7383(02)00025-7

Markos, A., D’Enza, A. I., \& Velden, M. van de. (2018). Beyond tandem analysis : Joint dimension reduction and clustering in R. Journal of Statistical Software, in press(May). Retrieved from https://www.researchgate.net/publication/317225498\%0ABeyond

Martin, D., O’Neill, M., Hubbard, S., \& Palmer, A. (2008). The role of emotion in explaining consumer satisfaction and future behavioural intention. Journal of Services Marketing, 22(3), 224-236. https://doi.org/10.1108/08876040810871183

Martín, J. M., \& del Campo, V. L. (2019). Los Raids de Aventura como motor dinamizador de entornos naturales en Extremadura. Journal of Sport and Social Sciences, 2.

Martín Martín, J. M., Salinas Fernández, J. A., Rodríguez Martín, J. A., \& Jiménez Aguilera, J. de D. (2017). Assessment of the tourism's potential as a sustainable development instrument in terms of annual stability: Application to Spanish rural destinations in process of consolidation. Sustainability, 9(10). https://doi.org/10.3390/su9101692

Martins-Almeida, A. M., Correia, A., \& Pimpão, A. (2014). Segmentation by benefits sought: the case of rural tourism in Madeira. Current Issues in Tourism, 17(9), 813-831. https://doi.org/10.1080/13683500.2013.768605

Marujo, N., \& Santos, N. (2012). Tourism, tourists and landscape. Investigaciones Turísticas, 35-48.

Marzo-Navarro, M., Pedraja-Iglesias, M., \& Vinzón, L. (2018). Perception of residents on the development of the micer region Tierra of Palmares from the integrated rural tourism perspectivel. Revista de La Facultad de Ciencias Agrarias, 50(2), 253-278. 
Marzo-Navarro, Mercedes, Pedraja-Iglesias, M., \& Vinzón, L. (2015). Sustainability indicators of rural tourism from the perspective of the residents. Tourism Geographies, 17(4), 586-602. https://doi.org/10.1080/14616688.2015.1062909

Mascarenhas, O. A., Kesavan, R., \& Bernacchi, M. (2006). Lasting customer loyalty: A total customer experience approach. Journal of Consumer Marketing, 23(7), 397-405. https://doi.org/10.1108/07363760610712939

Mastronardi, L., Giaccio, V., Giannelli, A., \& Scardera, A. (2015). Is agritourism eco-friendly? A comparison between agritourisms and other farms in italy using farm accountancy data network dataset. SpringerPlus, 4(1), 1-12. https://doi.org/10.1186/s40064-015-1353-4

Matzler, K., Pechlaner, H., \& Hattenberger, G. (2004). Lifestyle-typologies and market segmentation : the case of Alpine skiing tourism Titelangaben. EUR.AC research, European Academy: Bozen.

Mbaiwa, J. E., \& Stronza, A. L. (2010). The effects of tourism development on rural livelihoods in the Okavango Delta, Botswana. Journal of Sustainable Tourism, 18(5), 635-656. https://doi.org/10.1080/09669581003653500

Mcareavey, R., \& Mcdonagh, J. (2011). Sustainable Rural Tourism: Lessons for Rural Development. Sociologia Ruralis, 51(2), 175-194. https://doi.org/10.1111/j.1467-9523.2010.00529.x

McKeown, B. (1998). Circles: Q methodology and hermeneutical science. Operant. Subjectivity, 21, $112-138$.

McKeown, B., \& Thomas, D. B. (2013). Q Methodology (Second edi). SAGE Publications.

Meyer, C., \& Schwager, A. (2007). Understanding customer experience. Harvard Business Review.

Middleton, V. T. C., Fyall, A., \& Morgan, M. (2009). Marketing in travel and tourism. ButtenworthHeinemann.

Millán-Vazquez de la Torre, M. G., Arjona-Fuentes, J. M., \& Amador-Hidalgo, L. (2017). Olive oil tourism: Promoting rural development in Andalusia (Spain). Tourism Management Perspectives, 21, 100-108. https://doi.org/10.1016/j.tmp.2016.12.003

Mkono, M. (2012). A netnographic examination of constructive authenticity in Victoria Falls tourist (restaurant) experiences. International Journal of Hospitality Management, 31(2), 387-394. https://doi.org/10.1016/j.ijhm.2011.06.013

Mkono, M., \& Markwell, K. (2014). The application of netnography in tourism studies. Annals of Tourism Research, 48, 289-291. https://doi.org/10.1016/j.annals.2014.07.005

Mok, C., \& Iverson, T. J. (2000). Expenditure-based segmentation: Taiwanese tourists to Guam. Tourism Management, 21(3), 299-305. https://doi.org/10.1016/S0261-5177(99)00060-6 
Molera, L., \& Albaladejo-Pina, I. P. (2007). Profiling segments of tourists in rural areas of South-Eastern Spain. Tourism Management, 28(3), 757-767. https://doi.org/10.1016/j.tourman.2006.05.006

Molina, A., Gómez, M., González-Díaz, B., \& Esteban, Á. (2015). Market segmentation in wine tourism: strategies for wineries and destinations in Spain. Journal of Wine Research, 26(3), 192-224. https://doi.org/10.1080/09571264.2015.1051218

Moore, A., Johnson, M., Gbolagun, J., Miller, A., Rombouts, A., van der Ven, L., ... Hall, G. B. (2018). Integrating agroecology and sustainable tourism: applying geodesign to farm management in Aotearoa New Zealand. Journal of Sustainable Tourism, 26(9), 1543-1561. https://doi.org/10.1080/09669582.2018.1484751

Moscardo, G. (2011). Exploring social representations of tourism planning: Issues for governance. Journal of Sustainable Tourism, 19(4-5), 423-436. https://doi.org/10.1080/09669582.2011.558625

Mossberg, L. (2007). A marketing approach to the tourist experience. Scandinavian Journal of Hospitality and Tourism, 7(1), 59-74. https://doi.org/http://dx.doi.org/10.1080/15022250701231915

Mulet-Forteza, C., Genovart-Balaguer, J., Mauleon-Mendez, E., \& Merigó, J. M. (2019). A bibliometric research in the tourism, leisure and hospitality fields. Journal of Business Research, 101(December), 819827. https://doi.org/10.1016/j.jbusres.2018.12.002

Munar, A. M., Gyimóthy, S., \& Cai, L. (2013). Tourism social media: Transformations in identity, community, and culture. Emerald group.

Muresan, I. C., Oroian, C. F., Harun, R., Arion, F. H., Porutiu, A., Chiciudean, G. O., ... Lile, R. (2016). Local residents' attitude toward sustainable rural tourism development. Sustainability, 8(1), 1-14. https://doi.org/10.3390/su8010100

Naspetti, S., Mandolesi, S., \& Zanoli, R. (2016). Using visual Q sorting to determine the impact of photovoltaic applications on the landscape. Land Use Policy, 57(September), 564-573. https://doi.org/10.1016/j.landusepol.2016.06.021

Naspetti, Simona, Mandolesi, S., \& Zanoli, R. (2014). Innovation acceptability in dairy supply chain: a Q methodology analysis. Economia Agro-Alimentare, 2, 79-95. https://doi.org/10.3280/ECAG2014-002005

Nenadic, O., \& Greenacre, M. (2007). Correspondence analysis in R, with two- and three-dimensional graphics: The ca package. Journal of Statistical Software, 20(3), 1-13. https://doi.org/10.1359/JBMR.0301229

Neuhofer, B. (2016). An exploration of the technology enhanced tourist experience. European Journal of Tourism Research, 220-223.

Nickerson, N. P., Jorgenson, J., \& Boley, B. B. (2016). Are sustainable tourists a higher spending market? Tourism Management, 54, 170-177. https://doi.org/10.1016/j.tourman.2015.11.009 
Niñerola, A., Sánchez-Rebull, M. V., \& Hernández-Lara, A. B. (2019). Tourism research on sustainability: A bibliometric analysis. Sustainability, 11(5), 1-17. https://doi.org/10.3390/su11051377

Otto, J. E., \& Ritchie, J. R. B. (1996). The service experience in tourism. Tourism Management, 17(3), $165-174$. https://doi.org/10.1016/0261-5177(96)00003-9

Palmatier, R. W., Houston, M. B., \& Hulland, J. (2018). Review articles: purpose, process, and structure. Journal of the Academy of Marketing Science, 46(1). https://doi.org/10.1007/s11747-017-0563-4

Pan, S., \& Ryan, C. (2009). Tourism sense-making: The role of the senses and travel journalism. Journal of Travel and Tourism Marketing, 26(7), 625-639. https://doi.org/10.1080/10548400903276897

Park, D. B., \& Yoon, Y. S. (2009). Segmentation by motivation in rural tourism: A Korean case study. Tourism Management, 30(1), 99-108. https://doi.org/10.1016/j.tourman.2008.03.011

Park, Duk-byeong, \& Yoon, Y. (2011). Developing sustainable rural tourism evaluation indicators. International Journal of Tourism Research, 13, 401-415. https://doi.org/10.1002/jtr.804

Park, DukByeong, Lee, H., \& Yoon, Y. (2014). Understanding the benefit sought by rural tourists and accommodation preferences: A South Korea case. IInternational Journal of Tourism Research, 16, 291302. https://doi.org/10.1002/jtr.1929 Understanding

Pearce, P. L., \& Wu, M. Y. (2018). Entertaining international tourists: An empirical study of an iconic site in China. Journal of Hospitality and Tourism Research, 42(5), 772-792. https://doi.org/10.1177/1096348015598202

Pelegrín, J., González-Menorca, C., \& Meraz, L. (2019). The influence of the emotions produced by the wine offer, winery visits, and wine news on wine purchase intent in tourists. Spanish Journal of Agricultural Research, 17(1), 1-14. https://doi.org/10.5424/sjar/2019171-13524

Pereira, M. A., Fairweather, J. R., Woodford, K. B., \& Nuthall, P. L. (2016). Assessing the diversity of values and goals amongst Brazilian commercial-scale progressive beef farmers using Q-methodology. Agricultural Systems, 144, 1-8. https://doi.org/10.1016/j.agsy.2016.01.004

Pesonen, J. A., \& Tuohino, A. (2015). Activity-based market segmentation of rural well-being tourists: Comparing online information search. Journal of Vacation Marketing, 23(2), 145-158. https://doi.org/10.1177/1356766715610163

Petrović, M. D., Vujko, A., Gajić, T., Vuković, D. B., Radovanović, M., Jovanović, J. M., \& Vuković, N. (2018). Tourism as an approach to sustainable rural development in post-socialist countries: A comparative study of Serbia and Slovenia. Sustainability, 10(1), 1-14. https://doi.org/10.3390/su10010054

Pjerotic, L., Delibasic, M., Joksiene, I., Griesiene, I., \& Georgeta, C. P. (2017). Sustainable tourism development in the rural areas. Transformations in Business \& Economics, 16(3), 21-30. 
Polo Peña, A. I., Frías Jamilena, D. M., Rodríguez Molina, M. Á., \& Rey Pino, J. M. (2014). Online marketing strategy and market segmentation in the Spanish rural accommodation sector. Journal of Travel Research, 55(3), 362-379. https://doi.org/10.1177/0047287514546224

Prayag, G., \& Ryan, C. (2012). Antecedents of tourists' loyalty to mauritius: The role and influence of destination image, place attachment, personal involvement, and satisfaction. Journal of Travel Research, 51(3), 342-356. https://doi.org/10.1177/0047287511410321

Prebensen, N. K., \& Foss, L. (2011). Coping and co-creating in tourist experiences. International Journal of Tourism Research, 13(1), 54-67. https://doi.org/10.1002/jtr.799

Previte, J., Pini, B., \& Haslam-mckenzie, F. (2007). Q methodology and rural research. Sociologia Ruralis, 47(2), 135-147. https://doi.org/10.1111/j.1467-9523.2007.00433.x

Quinlan Cutler, S., Doherty, S., \& Carmichael, B. (2018). The experience sampling method: examining its use and potential in tourist experience research. Current Issues in Tourism, 21(9), 1052-1074. https://doi.org/10.1080/13683500.2015.1131670

Rageh, A., Melewar, T. C., \& Woodside, A. (2013). Using netnography research method to reveal the underlying dimensions of the customer/tourist experience. Qualitative Market Research: An International Journal, 16(2), 126-149. https://doi.org/10.1108/13522751311317558

Ramlo, S. E., \& Newman, I. (2011). Q methodology and its position in the mixed-methods continuum. Operant Subjectivity, 34(3), 172-191.

Randelli, F., \& Martellozzo, F. (2019). Is rural tourism-induced built-up growth a threat for the sustainability of rural areas? The case study of Tuscany. Land Use Policy, 86(December 2018), 387-398. https://doi.org/10.1016/j.landusepol.2019.05.018

Reed, M. S., Fraser, E. D. G., \& Dougill, A. J. (2006). An adaptive learning process for developing and applying sustainability indicators with local communities. Ecological Economics, 59(4), 406-418. https://doi.org/10.1016/j.ecolecon.2005.11.008

Ribeiro, M. A., Valle, P. O. do, \& Silva, J. A. (2013). Residents' attitudes towards tourism development in Cape Verde Islands. Tourism Geographies, 15(4), 654-679. https://doi.org/10.1080/14616688.2013.769022

Rid, W., Ezeuduji, I. O., \& Pröbstl-Haider, U. (2014). Segmentation by motivation for rural tourism activities in The Gambia. Tourism Management, 40, 102-116. https://doi.org/10.1016/j.tourman.2013.05.006

Ristić, D., Vukoičić, D., \& Milinčić, M. (2019). Tourism and sustainable development of rural settlements in protected areas - Example NP Kopaonik (Serbia). Land Use Policy, 89(July), 104231. https://doi.org/10.1016/j.landusepol.2019.104231

Ritchie, J. R. B., \& Hudson, S. (2009). Understanding and meeting the challenges of consumer/tourist 
experience research. International Journal of Tourism Research, 126, 111-126.

https://doi.org/10.1002/jtr.v11:2

Rodrigues, A. L. O., Rodrigues, A., \& Peroff, D. M. (2015). The sky and sustainable tourism development: A case study of a dark sky reserve implementation in Alqueva. International Journal of Tourism Research, 17(3), 292-302. https://doi.org/https://doi.org/10.1002/jtr.1987

Russell, P. (2000). Community-based tourism. Travel \& Tourism Analyst, 5, 89-116.

Ryglová, K., Rašovská, I., Šácha, J., \& Maráková, V. (2018). Building customer loyalty in rural destinations as a pre-condition of sustainable competitiveness. Sustainability, 10(4). https://doi.org/10.3390/su10040957

Saarinen, J. (2006). Traditions of sustainability in tourism studies. Annals of Tourism Research, 33(4), 11211140. https://doi.org/10.1016/j.annals.2006.06.007

Sakata, H., \& Prideaux, B. (2013). An alternative approach to community-based ecotourism: A bottom-up locally initiated non-monetised project in Papua New Guinea. Journal of Sustainable Tourism, 21(6), 880-899. https://doi.org/10.1080/09669582.2012.756493

Sanagustín Fons, M. V., Fierro, J. A. M., \& Patiño, M. G. y. (2011). Rural tourism: A sustainable alternative. Applied Energy, 88(2), 551-557. https://doi.org/10.1016/j.apenergy.2010.08.031

Schlochtermeier, L. H., Kuchinke, L., Pehrs, C., Urton, K., Kappelhoff, H., \& Jacobs, A. M. (2013). Emotional picture and word processing: an fMRI study on effects of stimulus complexity. PLoS ONE, 8(2). https://doi.org/10.1371/journal.pone.0055619

Schmidt, C. M., Cielo, I. D., Wenningkamp, K. R., \& Tomio, M. (2016). Collective actions in sustainable rural tourism: A case study of the western region of Paraná. Systems Research and Behavioral Science, 33(2), 249-258. https://doi.org/10.1002/sres.2380

Schmitt, B. (1999). Experiential Marketing. Journal of Marketing Management, 15(1-3), 53-67. https://doi.org/10.1362/026725799784870496

Sharpley, R. (2003). Rural tourism and sustainability - A Critique. In New directions in rural tourism (pp. 3853). Ashgate Publishing Limited.

Sharpley, Richard, \& Jepson, D. (2011). Rural tourism: A spiritual experience? Annals of Tourism Research, 38(1), 52-71. https://doi.org/10.1016/j.annals.2010.05.002

Shaw, C. (2005). Revolutionize your customer experience. Springer.

Simpson, M. C. (2008). Community Benefit Tourism Initiatives-A conceptual oxymoron? Tourism Management, 29(1), 1-18. https://doi.org/10.1016/j.tourman.2007.06.005

Sims, R. (2009). Food, place and authenticity: Local food and the sustainable tourism experience. Journal of 
Sustainable Tourism, 17(3), 321-336. https://doi.org/10.1080/09669580802359293

Son, A., \& Pearce, P. (2005). Multi-faceted image assessment. International Students' Views of Australia as a Tourist Destination, 18(4). https://doi.org/10.1300/J073v18n04

Stamboulis, Y., \& Skayannis, P. (2003). Innovation strategies and technology for experience-based tourism. Tourism Management, 24(1), 35-43. https://doi.org/10.1016/S0261-5177(02)00047-X

Stepchenkova, S., \& Mills, J. E. (2010). Destination image: A meta-analysis of 2000-2007 research. Journal of Hospitality Marketing and Management, 19(6), 575-609. https://doi.org/10.1080/19368623.2010.493071

Stockinger, H. (2015). Open innovation research: emerging methods of the digital era. ULM University.

Su, M. M., Wall, G., \& Wang, Y. (2019). Integrating tea and tourism: a sustainable livelihoods approach. Journal of Sustainable Tourism, 27(10), 1591-1608. https://doi.org/10.1080/09669582.2019.1648482

Su, M. M., Wall, G., Wang, Y., \& Jin, M. (2019). Livelihood sustainability in a rural tourism destination - Hetu Town, Anhui Province, China. Tourism Management, 71(October 2018), 272-281. https://doi.org/10.1016/j.tourman.2018.10.019

Su, Z., Aaron, J. R., Guan, Y., \& Wang, H. (2019). Sustainable livelihood capital and strategy in rural tourism households: A seasonality perspective. Sustainability, 11(18). https://doi.org/10.3390/su11184833

Swaffield, S. R., \& Fairweather, J. R. (1996). Investigation of attitudes towards the effects of land use change using image editing and Q sort method. Landscape and Urban Planning, 35(4), 213-230. https://doi.org/10.1016/S0169-2046(96)00320-9

Tan, W. K., Liu, W. C., \& Hu, Y. N. (2013). Finding the crucial factors for sustainable development of ruralbased tourist destinations: Using Nanzhuang, Taiwan as a case study. Service Business, 7(4), 623-640. https://doi.org/10.1007/s11628-012-0178-2

Tani, Y., Hashimoto, S., \& Ochiai, M. (2016). What makes rural, traditional, cultures more sustainable? Implications from conservation efforts in mountainous rural communities of Japan. Landscape Research, 41(8), 892-905. https://doi.org/10.1080/01426397.2016.1184631

Timur, S., \& Getz, D. (2009). Sustainable tourism development: How do destination stakeholders perceive sustainable urban tourism? Sustainable Development, 17(4), 220-232. https://doi.org/10.1002/sd.384

Tomej, K., \& Liburd, J. J. (2019). Sustainable accessibility in rural destinations: a public transport network approach. Journal of Sustainable Tourism, 28(2), 129-146. https://doi.org/10.1080/09669582.2019.1607359

Topcu, E. D. (2016). Agri-tourism: a rural planning instrument for sustainability of agricultural lands. Journal of Environmental Protection and Ecology, 17(2), 813-821. 
Trukhachev, A. (2015). Methodology for evaluating the rural tourism potentials: A tool to ensure sustainable development of rural settlements. Sustainability, 7(3), 3052-3070. https://doi.org/10.3390/su7033052

Truong, T. H., \& Foster, D. (2006). Using HOLSAT to evaluate tourist satisfaction at destinations: The case of Australian holidaymakers in Vietnam. Tourism Management, 27(5), 842-855. https://doi.org/10.1016/j.tourman.2005.05.008

Tseng, M. L., Chang, C. H., Wu, K. J., Lin, C. W. R., Kalnaovkul, B., \& Tan, R. R. (2019). Sustainable agritourism in Thailand: Modeling business performance and environmental sustainability under uncertainty. Sustainability, 11(15). https://doi.org/10.3390/su11154087

Turpo Gebera, O. W. (2008). La netnografía: un método de investigación en Internet. Educar, 42, 81-93.

Uriely, N. (2005). The tourist experience: Conceptual developments. Annals of Tourism Research, 32(1), 199216. https://doi.org/10.1016/j.annals.2004.07.008

van Eck, N. J., \& Waltman, L. (2010). Software survey: VOSviewer, a computer program for bibliometric mapping. Scientometrics, 84(2), 523-538. https://doi.org/10.1007/s11192-009-0146-3

Van Exel, J., \& De Graaf, G. (2005). Q methodology: a sneak preview. Social Sciences, 2(June), 1-30. Retrieved from http://qmethod.org/articles/vanExel.pdf

Vichi, M., \& Kiers, H. A. L. (2001). Factorial k-means analysis for two-way data. Computational Statistics and Data Analysis, 37(1), 49-64. https://doi.org/10.1016/S0167-9473(00)00064-5

Villanueva-álvaro, J. J., Mondéjar-Jiménez, J., \& Sáez-Martínez, F. J. (2017). Rural tourism: Development, management and sustainability in rural establishments. Sustainability, 9(5), 1-8. https://doi.org/10.3390/su9050818

Walls, A. R., Okumus, F., Wang, Y. R., \& Kwun, D. J. W. (2011). An epistemological view of consumer experiences. International Journal of Hospitality Management, 30(1), 10-21. https://doi.org/10.1016/j.ijhm.2010.03.008

Wang, W., Wu, J., Wu, M. Y., \& Pearce, P. L. (2018). Shaping tourists' green behavior: The hosts' efforts at rural Chinese B\&Bs. Journal of Destination Marketing and Management, 9(January), 194-203. https://doi.org/10.1016/j.jdmm.2018.01.006

Wanner, A., \& Pröbstl-Haider, U. (2019). Barriers to stakeholder involvement in sustainable rural tourism development-experiences from southeast Europe. Sustainability, 11(12). https://doi.org/10.3390/su10023372

Watts, S., \& Stenner, P. (2012). Doing Q methodological research: theory, method \& interpretation. SAGE publications. 
Wijesinghe, S. N. R., Mura, P., \& Bouchon, F. (2017). Tourism knowledge and neocolonialism-a systematic critical review of the literature. Current Issues in Tourism, 22(11), 1263-1279. https://doi.org/10.1080/13683500.2017.1402871

Woods, M. (2003). Conflicting environmental visions of the rural: Windfarm development in mid Wales. Sociologia Ruralis, 43(3), 271-288. https://doi.org/10.1111/1467-9523.00245

WTO. (1993). Tourism report year 2000 and beyond qualitative aspects.

Xia, J. (Cecilia), Evans, F. H., Spilsbury, K., Ciesielski, V., Arrowsmith, C., \& Wright, G. (2010). Market segments based on the dominant movement patterns of tourists. Tourism Management, 31(4), 464-469. https://doi.org/10.1016/j.tourman.2009.04.013

Xiao, Y., Luo, D., \& Yin, K. (2018). Change of Farmers' Household Livelihood Strategies Based on the Coastal Rural Tourism Background. Journal of Coastal Research, 83(10083), 225-228.

Xu, Z., \& Sun, B. (2019). Influential mechanism of farmers' sense of relative deprivation in the sustainable development of rural tourism. Journal of Sustainable Tourism, 28(1), 110-128. https://doi.org/10.1080/09669582.2019.1675675

Xun, J., \& Reynolds, J. (2010). Applying netnography to market research: The case of the online forum. Journal of Targeting, Measurement and Analysis for Marketing, 18(1), 17-31. https://doi.org/10.1057/jt.2009.29

Yoon, Y., Gursoy, D., \& Chen, J. S. (1999). An investigation of the relationship between tourism impacts and host communities' characteristics. Anatolia: An International Journal of Tourism and Hospitality Research, 10(1), 29-44. https://doi.org/10.1080/13032917.1999.9686970

Yoopetch, C., \& Nimsai, S. (2019). Science mapping the knowledge base on sustainable tourism development, 1990-2018. Sustainability, 11(13). https://doi.org/10.3390/su11133631

Yu, C. P., Chancellor, H. C., \& Cole, S. T. (2011). Measuring residents' attitudes toward sustainable tourism: A reexamination of the sustainable tourism attitude scale. Journal of Travel Research, 50(1), 57-63. https://doi.org/10.1177/0047287509353189

Zabala, A. (2014). Q method: a package to explore human perspectives using Q methodology. The R Journal, $6(2), 163-173$.

Zabala, A., \& Pascual, U. (2016). Bootstrapping Q methodology to improve the understanding of human perspectives. PLoS ONE, 11(2), 1-19. https://doi.org/10.1371/journal.pone.0148087

Zehrer, A. (2009). Service experience and service design: concepts and application in tourism SMEs. Managing Service Quality, 19(3), 332-349. https://doi.org/10.1108/09604520910955339

Zhang, L., \& Zhang, J. (2018). Perception of small tourism enterprises in Lao PDR regarding social 
sustainability under the influence of social network. Tourism Management, 69(July 2017), 109-120.

https://doi.org/10.1016/j.tourman.2018.05.012

Zhang, Y., \& Hitchcock, M. J. (2017). The Chinese female tourist gaze: a netnography of young women's blogs on Macao. Current Issues in Tourism, 20(3), 315-330. https://doi.org/10.1080/13683500.2014.904845

Zhu, H., Liu, J., Wei, Z., Li, W., \& Wang, L. (2017). Residents' attitudes towards sustainable tourism development in a historical-cultural village: Influence of perceived impacts, sense of place and tourism development potential. Sustainability, 9(1). https://doi.org/10.3390/su9010061

Zolfani, S. H., Sedaghat, M., Maknoon, R., \& Zavadskas, E. K. (2015). Sustainable tourism: A comprehensive literature review on frameworks and applications. Economic Research-Ekonomska Istrazivanja , 28(1), 130. https://doi.org/10.1080/1331677X.2014.995895

Zube, E. H., \& Pitt, D. G. (1981). Gross-cultural perceptions of scenic and heritage. Landscape Planning, 8, 6987.

Zube, E. H., Pitt, D. G., \& Anderson, T. W. (1975). Perception and prediction of scenic resource values of the Northeast: values, perceptions and resources (P. and R. n E. H. Zube, R. O. Brush, \& J. F. Fabos (Eds.), Landscape Assessment: Values, Ed.). Dowden, Hutchinson and Ross. 